NBER WORKING PAPER SERIES

\title{
TOURISM AND ECONOMIC DEVELOPMENT: EVIDENCE FROM MEXICO'S COASTLINE
}

\author{
Benjamin Faber \\ Cecile Gaubert \\ Working Paper 22300 \\ http://www.nber.org/papers/w22300 \\ NATIONAL BUREAU OF ECONOMIC RESEARCH \\ 1050 Massachusetts Avenue \\ Cambridge, MA 02138 \\ June 2016, Revised January 2018
}

We are grateful to Treb Allen, Costas Arkolakis, David Atkin, Lorenzo Caliendo, Arnaud Costinot, Klaus Desmet, Dave Donaldson, Pablo Fajgelbaum, Penny Goldberg, Gordon Hanson, Pete Klenow, Marc Muendler, Natalia Ramondo, Stephen Redding, Andrés Rodríguez-Clare and participants at multiple conferences and seminars for helpful comments. Nicholas Li and Jose Vasquez-Carvajal provided excellent research assistance. The views expressed herein are those of the authors and do not necessarily reflect the views of the National Bureau of Economic Research.

NBER working papers are circulated for discussion and comment purposes. They have not been peerreviewed or been subject to the review by the NBER Board of Directors that accompanies official NBER publications.

(C) 2016 by Benjamin Faber and Cecile Gaubert. All rights reserved. Short sections of text, not to exceed two paragraphs, may be quoted without explicit permission provided that full credit, including $\odot$ notice, is given to the source. 
Tourism and Economic Development: Evidence from Mexico's Coastline Benjamin Faber and Cecile Gaubert

NBER Working Paper No. 22300

June 2016, Revised January 2018

JEL No. F15,F63,O24

\begin{abstract}
$\underline{\text { ABSTRACT }}$
Tourism is a fast-growing services sector in developing countries. This paper combines a rich collection of Mexican microdata with a quantitative spatial equilibrium model and a new empirical strategy to study the long-term economic consequences of tourism both locally and in the aggregate. We find that tourism causes large and significant local economic gains relative to less touristic regions that are in part driven by significant positive spillovers on manufacturing. In the aggregate, however, these local spillovers are largely offset by reductions in agglomeration economies among less touristic regions, so that the national gains from trade in tourism are mainly driven by a classical market integration effect.
\end{abstract}

\author{
Benjamin Faber \\ Department of Economics \\ University of California, Berkeley \\ 697A Evans Hall \\ Berkeley, CA 94720 \\ and NBER \\ benfaber@econ.berkeley.edu \\ Cecile Gaubert \\ Department of Economics \\ University of California, Berkeley \\ 687 Evans Hall \\ Berkeley, CA 94720 \\ and NBER \\ cecile.gaubert@berkeley.edu
}




\section{Introduction}

A conventional view in the literature on economic growth and development is that the production of traded goods is subject to dynamic productivity improvements, whereas the services sector is perceived to be more stagnant. ${ }^{1}$ In line with this view, the locus of agglomeration economies is generally assumed to be the manufacturing sector, rather than services. This asymmetry has important implications for the growth strategies of developing countries, and whether they should prioritize the development of traded goods producing sectors. At the same time, there is relatively little empirical evidence on the economic consequences of the development of the services sector in developing countries, and whether the reallocation of factors of production into services can give rise to adverse long-term effects both locally and in the aggregate. ${ }^{2}$

This paper sets out to study the economic consequences of tourism, a fast-growing services sector in developing countries. Tourism involves the export of otherwise non-traded local services by temporarily moving consumers across space, rather than shipping goods. This form of trade has become an important channel of globalization. Tourism exports of developing countries have grown at an average annual rate of 11 percent over the period 1982-2012. In the past decade, they exceeded manufacturing exports for 40 percent of developing countries, and agricultural exports for half of them. Unsurprisingly in this context, tourism has attracted widespread policy attention. ${ }^{3}$

Our study is based on the empirical context of Mexico, a country where tourism has grown to become an important economic force starting in the 1950s and 60s. Since the development of tourism in Mexico has been driven by both international and domestic tourism flows, we set out to study the consequences of both cross-border and inter-regional tourism integration, and decompose the gains from tourism into an international and domestic component. Given the historical context, our theoretical framework incorporates tax-financed government investments that facilitate the development of tourism. It also explicitly captures the possibility that the development of the services sector due to tourism may have adverse long-run consequences by introducing different sources of local production externalities. By altering the scale of production across sectors, both locally and in the aggregate, tourism can have different implications for productivity. If, following the standard assumption, agglomeration economies mainly operate within the manufacturing sector, the aggregate gains from tourism can be diminished or over-turned compared to the neoclassical gains from tourism trade. On the other hand, if spillovers also operate at the cross-sector level, that is from the development of services to traded goods, then the gains from tourism can be reinforced. Building on the tools developed in single-sector frameworks, we develop a model and methodology to investigate these cross-sectoral interactions, and quantify their implications both at the local level and in the aggregate.

\footnotetext{
${ }^{1}$ This view is in the tradition of Baumol (1967). See e.g. Herrendorf et al. (2014) for a review of the recent literature, and McMillan \& Rodrik (2011) for an analysis in the context of developing countries.

2See for example Copeland (1991) for an early theoretical discussion of tourism as a potential "Dutch disease".

${ }^{3}$ Figures are based on UNCTAD statistics (http://unctad.org/en/pages/Statistics.aspx). See e.g. Hummels (2007) for estimates of air transport costs over time, and Hawkins \& Mann (2007) for a a review of tourism policies.
} 
In answering these questions, the paper contributes to the growing empirical literature that exploits within-country variation to credibly identify the effects of economic shocks on relative regional economic outcomes (e.g. Autor et al. (2013), Mian \& Sufi (2009), Topalova (2010)). While certainly of interest in its own right, this approach generally does not allow to shed light on the corresponding aggregate implications, as those are being soaked up by the constant term or by time fixed effects. This shortcoming is particularly acute when the objective is to estimate longrun effects, as workers over time are mobile to arbitrage away regional variation in real incomes. ${ }^{4}$ To make progress on this trade-off, we combine an empirical analysis that exploits within-country variation with a quantitative spatial equilibrium model. This allows us to explore the aggregate implications that are consistent with the observed local effects, and to quantify the underlying channels.

At the center of the analysis lies the construction of a rich collection of microdata. We assemble a database containing: i) municipality-level hotel revenues, employment, population, wages and output by sector from the Mexican Censos Economicos in 1998 and 2008 and the Mexican population censuses in 2000 and 2010; ii) a long time series of population census data for consistent spatial units going back to 1921; iii) a GIS database including remote sensing satellite data at a resolution of 30x30 meter pixels covering roughly 9,500 km of Mexican coastline during the 1980s and 90s; iv) local public finance data on investments in tourism development at the municipalitylevel; and v) panel data on bilateral tourism exports and relative prices covering 115 countries over the period 1990-2011.

Armed with this database, the analysis proceeds in two parts. In the first part, we provide empirical evidence on the local effects of tourism activity on current-day municipality-level population, employment, local GDP by sector of activity and Mincerized wages. Tourism in Mexico has had more than half a century to materialize into today's observed distribution of regional economic outcomes. In this context, our empirical strategy aims to exploit cross-sectional variation to capture the long-term effects of tourism exposure on relative regional economic outcomes. To do so convincingly, we exploit geological, oceanographic and archaeological variation in local tourism attractiveness across the Mexican coastline. We take inspiration from the tourism management literature arguing that variation in tourism activity is to a large extent determined by the presence and quality of a specific set of local natural and cultural characteristics (Weaver et al. (2000), Leatherman (1997)). We identify a set of beach quality criteria from that literature, such as the presence of a nearby offshore island or the fraction of onshore coastline covered by picturesque white sand, that we can capture using the GIS and satellite data to construct instrumental variables (IVs) for tourism attractiveness along the Mexican coastline. In addition, we collect data on the presence of pre-Hispanic archaeological ruins across Mexican municipalities that we use to construct an additional instrument.

The identifying assumption is that the presence of islands, the fraction of coastline covered by white sand or the presence of archaeological ruins do not affect local economic outcomes relative

\footnotetext{
${ }^{4}$ This limitation and the need for a more structured approach to get at general equilibrium effects has been highlighted by, for example, Kline \& Moretti (2014), Donaldson \& Hornbeck (2015) and Caliendo et al. (2015a).
} 
to other coastal locations except through their effect on tourism activity. We assess the validity of this assumption in several ways. We report how point estimates are affected by the inclusion of pre-determined municipality controls, and assess whether the different IVs, that are based on distinct sources of data and variation, yield similar estimates. We also estimate a placebo falsification test of the IVs' effect on municipality populations in periods before beach tourism had become a discernible force in Mexico, verify the extent to which the IVs are correlated with current-day estimates of residential amenities, and corroborate the cross-sectional results with shorter-term panel variation exploiting a shift-share IV strategy.

Using this design, we find that variation in local tourism activity has strong and significant positive effects on municipality total employment, population, local GDP and wages relative to less touristic regions. According to our preferred specification, a 10 percent increase in local tourism revenues leads to a 2.5 percent increase in municipality total employment, and a 4 percent increase in nominal municipality GDP in today's cross-section of Mexican municipalities. These effects are in part driven by sizable local multiplier effects on manufacturing. We find that a 10 percent increase in local tourism revenues leads to a 3.9 percent increase in local manufacturing GDP. This effect holds for manufacturing sectors that are not intensively used as inputs in the production of tourism-related services.

When interpreting these local effects, we document the role of public investments in local tourism infrastructure that respond to differences in ex ante attractiveness for tourism captured by our IVs. We also note that the observed positive effect of tourism on local manufacturing production does not by itself provide prima facie evidence for positive productivity spillovers from tourism development onto manufacturing. In a world with trade costs, labor mobility and input-output linkages, the net effect of tourism development on local manufacturing is a priori ambiguous and could be positive through neoclassical demand linkages alone. Furthermore, improvements in transport infrastructure could have increased local market access for manufacturing producers regardless of local tourism activity. To investigate these channels and shed light on their aggregate implications, we then turn to studying both the local and aggregate implications of tourism development through the lens of a quantitative spatial equilibrium model. We build on the theoretical framework developed by Allen \& Arkolakis (2014), Ahlfeldt et al. (2015) and Redding (2016), and extend it in several dimensions to capture the economic forces that are relevant in our context. In addition to trade in goods and migration across regions, the model features trade in tourism-related services via traveling consumers across regions and countries, input-output linkages between tourism, manufacturing and non-traded services, public tax-financed capital investments as inputs to tourism development, and local production externalities.

We allow for manufacturing production to be subject to both within and cross-sector spillovers. The within-sector spillover is the standard source of agglomeration economies in economic geography models, and captures the extent to which a larger scale in local manufacturing production is beneficial for manufacturing productivity. In its presence, reducing the scale of manufacturing as the economy re-allocates factors towards services leads to adverse productivity effects in the aggregate. This adverse effect works in the opposite direction of the neoclassical gains from 
falling frictions to tourism trade. On the other hand, the cross-sector spillover captures the extent to which a larger scale of the local services sector affects traded sector productivity. By increasing local services production, the development of tourism may generate long-run positive spillovers on traded goods production by, for example, improving access to business services for local firms, such as finance, accounting or consulting, by loosening local credit constraints directly (through tourism revenues), or by facilitating contacts and business networks. ${ }^{5}$ In the presence of such cross-sectoral agglomeration economies, tourism can give rise to gains in manufacturing productivity that would not have occurred otherwise.

To quantify these forces, we estimate the model parameters, and calibrate the model to currentday Mexico as a reference equilibrium. In particular, we estimate the intensity of the within and cross-sector spillovers using an approach that combines model-based indirect inference with the exclusion restrictions of our IVs. We find that both within and cross-sector agglomeration economies are necessary to rationalize the observed local effects of tourism on Mexican regions, while accounting for a host of neoclassical GE linkages between tourism and manufacturing that the model captures. In addition to the conventional within-manufacturing agglomeration economies, we find that tourism -through its effect on the development of the local services sector- leads to positive spillovers on local traded goods production.

Armed with the model parameters and number of observed moments in our data, we proceed to explore general equilibrium counterfactuals. We find that tourism causes significant gains to the average Mexican household that are in the order of 4.8 percent of household consumption after taking into account the cost of tax-financed investments in Mexican tourism development over the past decades. About 40 percent of these gains are driven by international tourism, and the remainder by domestic tourism across Mexican regions. Turning to the underlying channels, we find that about 60 percent of the observed effect on local GDP can be explained by neoclassical forces, including the direct effect due to local tourism expenditures and indirect effects on other sectors through migration and input-output linkages. The remainder of the local effect on GDP is driven by gains in local manufacturing activity due to both cross and within-sector agglomeration forces. In the aggregate, however, we find that these spillover effects contribute relatively little (about $1 / 10$ th) to the estimated welfare gains. That is, while the presence of within and crosssector spillovers reinforce one another leading to the large observed re-allocations of economic activity towards touristic regions, we find that they largely offset one another at the aggregate level, so that the aggregate gains from trade in tourism are mainly driven by a classical market integration effect.

Finally, an interesting difference emerges when we focus on the gains from international-only tourism. In this case, we find that the gains from tourism integration are somewhat dampened compared to what they would have been in the absence of agglomeration forces. In regions relatively more affected by international tourism, the reduction in the within-manufacturing scale effect outweighs the gains from the local expansion in services. In a framework featuring both

\footnotetext{
${ }^{5}$ See Francois \& Hoekman (2010) for a review of the link between services trade and economic performance in other sectors.
} 
within and cross-sector agglomeration forces, we find that this result is driven by differences in the initial sectoral composition of the regions most affected by international tourism compared to domestic tourism. As a result, the gains from opening up to international tourism in the absence of agglomeration economies would be slightly larger (2.4 percent) compared to the gains that we estimate (1.8 percent).

This paper relates and contributes to the recent literature on trade and development (e.g. Topalova (2010), Donaldson (in press), Atkin et al. (2015)). Relative to the existing literature, we focus on tourism, an important and fast-growing but so far understudied facet of globalization in developing countries. There is a small existing empirical literature that has analyzed crosscountry data to shed light on the determinants and consequences of tourism. ${ }^{6}$ In contrast, this paper leverages within-country variation to estimate the long-run effects of tourism on both local and aggregate economic outcomes. The paper also relates to the literature that studies possible "Dutch disease" effects associated with natural resource booms by comparing regional outcomes within countries (e.g. Caselli \& Michaels (2009), Allcott \& Keniston (2014)). Both the methodology we propose and the focus on tourism as a special kind of natural resource boom differ from the existing literature, but the economic questions are closely related.

Methodologically, the paper follows a recent but growing literature that uses quantitative spatial equilibrium models to analyze the welfare consequences of aggregate or local shocks, taking into account the frictions to trade and mobility between regions within countries (e.g. Redding (2016), Caliendo et al. (2014), Monte et al. (2015), Bryan \& Morten (2015), Caliendo et al. (2015b), Fajgelbaum et al. (2015), Adao et al. (2017) and Galle et al. (2014)). ${ }^{7}$ We build on the framework developed by Allen \& Arkolakis (2014) and Redding (2016) and extend the model and methodology in several dimensions to study the role of within and cross-sector agglomeration externalities, a novel dimension in this class of quantitative frameworks. We combine the structure of the model with observed empirical moments to identify the strength of the agglomeration forces, close to the approach followed in a one sector model in Ahlfeldt et al. (2015). Finally, our approach combines empirical estimates of the local effects with a more structured approach to get at general equilibrium effects, following recent work by Kline \& Moretti (2014) and Donaldson \& Hornbeck (2015).

The remainder of the paper proceeds as follows. Section 2 describes the background of tourism in Mexico and the data. Section 3 presents the empirical evidence. Section 4 presents the theoretical framework that guides the welfare analysis. Section 5 presents the model calibration and the counterfactual analysis. Section 6 concludes.

\footnotetext{
${ }^{6}$ Eilat \& Einav (2004) use panel data on bilateral tourism flows over time to estimate the effect of factors such as political risk or exchange rates on bilateral tourism demand. Sequeira \& Macas Nunes (2008) use country-level panel data to estimate the effect of tourism specialization on country growth. Arezki et al. (2009) regress average country-level growth rates over the period 1980-2002 on a measure of tourism specialization in a cross-section of 127 countries, and use the list of UN World Heritage sites as an instrumental variable for tourism specialization. More recently, McGregor \& Wills (2017) use variation in surfing conditions to estimate positive local effects on night-time lights.

${ }^{7}$ Work by Ahlfeldt et al. (2015) and Allen \& Arkolakis (2016) also follow closely related approaches, but focus on spatial equilibria within cities rather than within countries.
} 


\section{Background and Data}

\subsection{Tourism in Mexico}

According to Mexico's national accounts, tourism activity in Mexico has grown to account for about 10 percent of total GDP in recent years. The bulk of this activity is driven by coastal tourism: as reported in Table 1, two thirds of total hotel revenues in Mexico are located in the 150 coastal municipalities (accounting for 14 percent of Mexico's population). Beach tourism started to emerge in Mexico during the 1950s and 60s, about three decades after a devastating civil war had ended in the 1920s. By that time, the first generation of Mexican tourist destinations, such as the colonial port city of Acapulco on the Pacific coast and the border city of Tijuana in the North, started to emerge and to become popular in Hollywood and among the international jet set. The next generation of Mexican destinations for beach tourism appeared during the 1970s and 80s, that witnessed the emergence of the Yucatan peninsula (e.g. Cancun) and other popular contemporary destinations such as Los Cabos, Ixtapa or Huatulco. As we further discuss below in Section 3.3, tourism development in Mexico, as in many other countries, was facilitated by significant public investments in local tourism infrastructure.

By 2014, Mexico received 29 million foreign visitors. According to the Mexican Secretariat for Tourism (SECTUR), this number was close to zero before the 1960s. US Americans account for the largest share of foreign tourists in Mexico (57\%), followed by Canadians (14\%) and Britons $(3 \%)$. As is the case for most countries in the world, the majority of tourism activity in Mexico today is driven by domestic inter-regional visitors rather than international ones, with a share of roughly 80 to 20 percent in terms of revenues over recent decades according to the Mexican tourism satellite account. In this empirical context, our analysis sets out to quantify the gains from both domestic tourism integration across regions within Mexico and international tourism integration across borders, and to decompose the overall effect into its domestic and international components. Finally, tourism revenues in Mexico can be divided into different types of expenditure. According to the tourism satellite account, 13 percent are spent on artisanals and other goods, and the rest of tourist expenditure goes to local services, with accommodation (hotels and other temporary accommodation), restaurants and transportation as the three main categories.

\subsection{Data}

This subsection provides a brief overview of the main datasets used in the analysis. Appendix Table A.1 provides descriptive statistics and Figure 1 depicts the satellite and GIS data. Appendix 2 provides a more detailed description of the data and construction of variables.

We use municipality-level data from the Censos Economicos Comerciales y de Servicios to obtain local sales of hotels and other temporary accommodation (e.g. hostels) for two cross-sections in 1998 and 2008. We combine this information with data from the Censos Economicos for the same years on total municipality GDP, total municipality wage bill, and GDP broken up by sector of activity. In the analysis, we interpret differences in log hotel sales across municipalities as effectively capturing proportional differences in total local tourism expenditures. The reason is that 
the available data for other tourist expenditures, such as restaurants, do not distinguish between sales to local residents vs visiting non-residents. The underlying assumption is that hotel sales are a constant share of tourist expenditure. As we discuss in Section 3, we also examine this assumption using available data over time and across destinations (see appendix Tables A.2 and A.10).

We use IPUMS microdata from the Mexican Population Census in 2000 and 2010 to construct municipality-level total population and employment, as well as individual-level wages including information on gender, education, age and ethnicity. The IPUMS microdata provide us with 10 percent random census samples in addition to population weights that are linked to each observation. In addition to the two most recent census rounds, we use historical Mexican population census data for the years 1921, 1930, 1940 and 1950 in order to estimate a set of placebo falsification tests. To that end, we use INEGI's database Archivo Historico de Localidades to construct spatial units for the year 2010 that we can trace back consistently to 1921. The historical census database provides us with municipality populations, but not employment.

The analysis also uses several GIS and satellite datasets. We use the earliest high-resolution satellite data from the Global Land Survey (GLS) 1990 dataset. The data is a consolidation of the best-quality LandSat imagery that were taken during the period of 1987-1997 over the coast of Mexico, at a resolution of 30x30 meter pixels and covering six different wavelength bands. When restricted to a $2 \mathrm{~km}$ buffer around the Mexican shoreline, these satellite data provide us with six raster data layers that each have approximately 52 million 30x30 meter pixels (left panel of Figure 1). We combine these satellite data with a number of additional GIS data layers that we obtain from the geo-statistics division of INEGI. These data include the administrative shape file of municipality boundaries for the 2010 population census, the position of the Mexican coastline, the Mexican terrestrial transportation network for the year 2009, the location of pre-Hispanic archaeological ruins, and the coordinates for each island feature within the Mexican maritime territory from the Mexican census of maritime land territory. The right panel of Figure 1 depicts the position of islands within $5 \mathrm{~km}$ of the Mexican coast and the location of pre-Hispanic ruins.

We obtain information on public investments in local tourism development at the municipality level from INEGI's department for public finances (Estadística de Finanzas Públicas Estatales y Municipales (EFIPEM)). This database is the most detailed available account of municipalitylevel public investments for federal, state and local spending covering the period 1989-2010. For earlier years, we complement this database with historical records that we obtain from Mexico's Fondo Nacional de Fomento al Turismo (FONATUR) that provide us with information on public investments in tourism going back to the beginning of the 1960s. To estimate the tourism trade elasticity, we use data on bilateral tourism exports from the World Bank WITS database on trade in services. We link these data to information from the IMF on PPP rates for final consumption goods across countries in order to empirically capture the relative price of local consumption for origin-destination country pairs over time. The database spans the years 1990-2011 and includes 115 origin and destination countries. Appendix 2 provides further details about the database and construction of variables. 


\section{Empirical Evidence}

This section uses the database described above to estimate the effects of tourism on municipalitylevel employment, population, wages and local GDP by sector of activity in today's cross-section of Mexican municipalities. As well as being of interest in their own right, these moments inform the calibration of the model and the quantification of tourism's welfare implications and underlying channels in Sections 4 and 5.

\subsection{Empirical Strategy}

Tourism in Mexico has had more than half a century to materialize into today's observed regional economic outcomes. In this context, our aim is to exploit cross-sectional variation to capture tourism's long-term economic consequences on local economic outcomes across Mexican municipalities. $^{8}$ To estimate the effect of differences in local tourism revenues on relative outcomes in today's cross-section of Mexican municipalities, we estimate the following baseline specification:

$$
\log \left(y_{n t}\right)=\alpha_{c t}+\beta \log \left(\text { Hotel Sales }_{n c t}\right)+\alpha^{\prime} X_{n t}+\epsilon_{n c t}
$$

where $n$ indexes municipalities, $c$ indexes coastal versus non-coastal municipalities and $t$ indexes census years. In our baseline specification, we regress the two most recent cross-sections of municipality-level outcomes, $y_{n t}$, in 2000 and 2010 for outcomes computed using the population censuses, and in 1998 and 2008 for outcomes computed using the Censos Economicos, on the log of municipality hotel sales in 1998 and 2008, a vector of pre-determined municipality controls, $X_{n t}$, and coast-by-period fixed effects. ${ }^{9}$ To address concerns about auto-correlated error terms for the same municipality over time, we cluster standard errors at the municipality level. ${ }^{10}$

As discussed above, we address the lack of data for total local tourism expenditure by making the assumption that accommodation constitutes a roughly constant share of tourist expenditures. Though we cannot directly verify this assumption in the cross-section of municipalities, we can use available Mexican time series data to assess it. Appendix Table A.2 documents that accommodation expenses accounted for on average 13 percent of total Mexican tourist expenditure over the period 2003-2013, with very little variation over time. A related concern is that hotel revenues relate differently to total local tourism expenditure in a way that is correlated with our IVs that we discuss below. We return to this question in the robustness analysis below.

The coefficient $\beta$ captures the total derivative of tourism's local effect on the outcome $y_{n t}$. This

\footnotetext{
${ }^{8}$ To see this more clearly, consider a specification of long differences: $\log \left(y_{n}^{2010}\right)-\log \left(y_{n}^{1950}\right)=$ $\alpha_{c}+\beta\left(\log \left(\right.\right.$ HotelSales $\left._{n}^{2010}\right)-\log \left(\right.$ HotelSales $\left.\left._{n}^{1950}\right)\right)+\epsilon_{n}$. Without discernible variation in tourism pre-1960 (setting HotelSales $_{n}^{1950}$ to a constant close to zero), this can be re-written as in (1): $\log \left(y_{n}^{2010}\right)=\alpha_{c}^{\prime}+\beta \log \left(\right.$ HotelSales $\left._{n}^{2010}\right)+$ $\epsilon_{n c}+\log \left(y_{n}^{1950}\right)$, with the identifying assumption that our IVs are unrelated to economic outcomes before tourism emerges. As discussed in detail below, we further assess this exclusion restriction in several ways.

${ }^{9}$ We use the inverse hyperbolic sine (IHS) transformation, $\log \left(\right.$ HotelSales $\left._{n c t}+\left(\text { HotelSales }_{n c t}^{2}+1\right)^{1 / 2}\right)$, in order not to throw away variation from municipalities in places with zero hotel sales. In practice, this does not affect the estimates since the identifying variation in our IV estimation stems from coastal municipalities that except for three instances in the two cross-sections have no reported zeroes for hotel sales. As discussed below, we also report results without this transformation, or after assigning the log of 1 to values of zero.

${ }^{10}$ Clustering instead at the state-level or the state-by-year level leads to slightly smaller standard errors.
} 
includes both the direct effect of variation in local tourism sales (holding all else constant), as well as the indirect effects through, for example, increased demand for inputs from other sectors, immigration or changes in local productivity due to spillovers. ${ }^{11}$ The empirical analysis below and the quantitative model then allow us to shed light on, and decompose the channels underlying the estimated total derivatives $\widehat{\beta}$. The main concern for causal identification of this total effect in (1) is that municipalities with higher hotel sales are also subject to other local unobserved factors that affect both tourism activity as well as economic outcomes. For example, economically vibrant municipalities could report higher tourism sales because of business travel, better transport links or skilled labor with foreign language skills. Conversely, tourism could locate in remote locations with cheaper land prices for building hotel resorts. In contrast, it could also be that tourist resorts follow a specific set of natural and cultural amenities that are largely unrelated to economic outcomes, except through tourism activity.

To investigate which of these scenarios is the case in our empirical setting, we propose the following empirical strategy that proceeds in several steps. In the first step, we include an additional set of pre-determined municipality controls and report how this affects the OLS estimates of $\beta$. In the baseline specification, $X_{n c t}$ includes the log distance to Mexico City, the log distance to the closest stretch of the US border and the log municipality area. These geographical controls are aimed to address concerns that larger municipalities that are located close to the main domestic or foreign economic centers have both higher tourism sales as well as more economic activity on the left hand side of specification 1. We then report how the estimate of $\beta$ is affected after additionally including dummies for state capitals, historical cities $^{12}$, colonial ports, and the logarithm of the average annual temperature and the average annual precipitation. Reporting point estimates before and after adding these controls helps us document the extent to which variation in local tourism activity within a given coast-by-year cell may be correlated with a number of observable pre-determined confounding factors that also affect local economic outcomes.

In the second step, we construct a number of instrumental variables for log $\left(\right.$ HotelSales $\left._{n c t}\right)$. We take inspiration from the tourism management literature (e.g. Weaver et al. (2000), Leatherman (1997)) arguing that tourism activity is to a large extent determined by the quality of a set of very specific local natural and cultural amenities. We identify two criteria for touristic beach quality that we can empirically capture along the roughly $9500 \mathrm{~km}$ of Mexican coastline using our GIS database: i) the presence of a nearby offshore island; and ii) the fraction of coastline covered by white sand beaches. In addition, we collect data on the presence of pre-Hispanic archaeological ruins across Mexican municipalities to construct a third instrumental variable.

The first instrumental variable that we construct is whether or not a coastal municipality has access to an offshore island within $5 \mathrm{~km}$ of its coastline. ${ }^{13}$ This measure is aimed at capturing both

${ }^{11}$ The estimated total derivative is $\widehat{\beta}=\frac{d \log \left(y_{n t}\right)}{d \log \left(\text { HotelSales }_{n t}\right)}=\frac{\partial \log \left(y_{n t}\right)}{\partial \log (\text { HotelSales } n t)}+\sum_{j}^{J}\left(\frac{\partial \log \left(y_{n t}\right)}{\partial \log \left(X_{n t}^{j}\right)} \times \frac{d \log \left(X_{n t}^{j}\right)}{\operatorname{dlog}^{\prime}\left(\text { HotelSales }_{n t}\right)}\right)$.

The first term is the direct effect of local tourism, holding all other J determinants unchanged. The $X_{n t}^{j}$ are J other determinants of the local outcome $y_{n t}$ that are affected by tourism, such as e.g. local manufacturing production.

${ }^{12}$ Following INEGI's definition of cities with a population above 20k in 1930.

${ }^{13}$ Our island and beach IVs have no variation across non-coastal municipalities (we set them to a constant of zero for 
scenic beauty, as well as the availability of popular beach activities, such as snorkeling around the island or taking a boat trip to the offshore beaches. To measure offshore islands, we use the Mexican census of maritime land territory conducted by the INEGI. To assess the sensitivity of the $5 \mathrm{~km}$ cutoff, we alternatively report results using islands within $10 \mathrm{~km}$ of the shoreline.

The second instrumental variable is aimed at capturing the presence of picturesque white sand beaches along the Mexican coastline. Because an explicit specification of what constitutes an attractive stretch of beach in Mexico has not been formulated in the remote sensing literature, we proceed by binding our hands to the best existing ranking of Mexican beaches that we could find. That ranking refers to the "Eight Best Beaches of Mexico" published by the ranking analytics company U.S. News and World Report. ${ }^{14}$ We take these top-ranked beaches and construct a municipality-level beach quality measure using the historical satellite data. For each of the eight beaches, we start by computing the wavelength ranges for each of the six different LandSat sensors computed across the $30 \mathrm{~m}$ pixels covering the beach. We then classify all $30 \mathrm{~m}$ pixels within $100 \mathrm{~m}$ of the Mexican shoreline into zeroes and ones depending on whether they fall within these reference wavelength ranges. Using this information, we construct the fraction of pixels that is covered by either of these eight types of high quality beaches. To assess the sensitivity to the 100 $\mathrm{m}$ range, we also report results using a $200 \mathrm{~m}$ distance from the shoreline.

For the third IV, the geo-statistics division at INEGI provided us with the location of preHispanic archaeological ruins in Mexico that we depict in Figure 1. Using this information, we construct a municipality-level indicator whether an archaeological site is present. The identifying assumption is that the presence of nearby offshore islands, a higher fraction of coastline covered by white sand beaches or the presence of pre-Hispanic ruins affect municipality-level economic outcomes relative to other coastal locations only through their effect on local tourism activity. To assess this assumption, we report the IV point estimates both before and after including additional pre-determined municipality controls, and test whether the island IV, the beach IV and the archaeological ruins IV -which rely on distinct datasets and sources of variation along the Mexican coastline (Figure 1) - yield similar point estimates of the effect of tourism on local economic outcomes. As we discuss in detail below, we also report a number of additional robustness checks.

\subsection{Estimation Results}

Municipality Employment and Population We begin by estimating the effect of differences in local tourism activity on municipality-level total employment and population. We report the results of specification (1) above in OLS, the reduced form (outcomes on IVs) and the second-stage IV point estimates of $\widehat{\beta}$. Viewed through the lens of a spatial equilibrium with labor mobility,

inland regions). Given specification (1) features coast-by-period fixed effects, it follows that the identifying variation is purely within the coastal municipality group. For these two IVs, including the full sample of Mexican municipalities increases power when estimating additional municipality controls in $X_{n c t}$. As a robustness check in Table A.14, we also allow the controls to have heterogeneous effects among coastal and non-coastal regions as discussed below.

${ }^{14}$ In their description (http://travel.usnews.com/Rankings/Best_Mexico_Beaches/), they write: "To help you find the ideal Mexican destination for sunbathing on the sand and splashing in the waves, U.S. News considered factors like scenery, water clarity, crowd congestion, and nearby amenities. Expert insight and user votes were also taken into account when creating this list of the country's best beaches." The 8 beaches are Playa del Carmen, Tulum, Cozumel, Cancun, Acapulco, Mazatlan, Puerto Vallarta and Los Cabos. 
these are two of the most informative long-term local economic outcomes: over time, workers respond to changes in local economic outcomes by moving to places with better prospects. By a revealed preference argument, location choices are thus directly informative about differences in the underlying attractiveness of regions. ${ }^{15}$ We estimate specification (1) with log employment or $\log$ population on the left-hand side that we construct from the Mexican census microdata for 2000 and 2010. Table 2 presents the OLS, reduced-form and IV estimation results both separately for each of the three IVs and using them jointly.

The OLS point estimate of the effect of tourism on municipality employment is statistically significant at the 1 percent level and changes little before and after including the full set of municipality controls. Given that the vast majority of Mexican tourism is beach-oriented and located along the coastline, and the fact that our baseline specification includes coast-by-period fixed effects, one interpretation of the OLS results is that tourism in Mexico is to a large extent determined by a specific set of natural and cultural amenities, such as beaches or archaeological sites, that appear not be strongly correlated with some of the obvious observable and pre-determined control variables that also affect local economic outcomes.

To further assess these results, columns 3-10 present the reduced form and IV estimates. As for the OLS, the IV estimates of the effect of tourism on municipality total employment change little before and after including the full set of controls for each of the three IVs as well as when using them jointly. The IV point estimates are slightly larger compared to the OLS in the full specifications, and the three IVs yield similar point estimates as documented by the p-value of the over-identification test in columns 9 and 10. The likeliest explanation for why the IV point estimates are slightly higher than the OLS estimates is the concern of measurement error in our measure of local tourism activity, which relies on reported establishment revenues in the survey questionnaires of the Censos Economicos for 1998 and 2008.

The results suggest that local tourism activity has a strong and significant positive effect on total municipality employment relative to other coastal regions. The elasticity is estimated to be 0.25 in the full specification with all three instruments in column 10, suggesting that a 10 percent increase in local tourism activity in 1998 and 2008 on average leads to an increase in total municipality employment of on average 2.5 percent in 2000 and 2010 respectively. Columns 11 and 12 of Table 2 report the estimation results of the IV specification using the instruments jointly on $\log$ municipality total population instead of total employment. The point estimate is about 0.045 below the point estimate for employment, suggesting that a 10 percent increase in local tourism expenditure leads to an increase of 2 percent in total population. ${ }^{16}$

Municipality Wage Bill, GDP by Sector and Wages To further investigate the channels underlying the positive effects on local employment and population, we explore tourism's impact on local production. Table 3 reports the OLS, reduced-form and IV estimation results of the effect

\footnotetext{
${ }^{15}$ More formally, see equation (12) in the spatial equilibrium model of Section 4.

${ }^{16}$ The small difference in tourism's effect on population relative to total employment can be due to demographics (e.g. differences in the age profile and family size of the workforce), labor force participation as well as commuting. In our model, we abstract from these adjustment margins and use information on total local employment to capture the regional effects on the workforce and economic activity.
} 
on the municipality-level total wage bill (labor income), GDP, GDP by sector of economic activity and Mincerized wages. Tourism has a strong and significant positive effect on local aggregate labor income and GDP. According to the IV point estimates in the full specification with three instruments, a 10 percent increase in local tourism revenues leads to 4.8 percent increase in the local wage bill, and a 4 percent increase in local GDP. Given tourism only accounts for on average roughly 10 percent of total GDP in Mexico (and about 20 percent among coastal municipalities), ${ }^{17}$ these results suggest strong multiplier effects on the local economy. Using the 20 percent figure, tourism would have a direct effect on local GDP that is about half of the observed effect (2 percent for a 10 percent increase in tourism). ${ }^{18}$

In support of a multiplier effect, we find significant positive effects of tourism on local manufacturing GDP. A 10 percent increase in local hotel revenues leads to an increase in local manufacturing GDP of 3.9 percent. We return to the decomposition of the estimated total effect on local GDP in Section 5.2, after taking into account input-output linkages and spillovers. The point estimate on local agriculture is also positive, but smaller and not significant at conventional levels in the IV estimation. The last two columns of Table 3 report OLS and IV estimates of the effect of local tourism expenditure on average municipality Mincerized wages, after flexibly controlling for observable differences in local workforce composition (age, education, gender and ethnicity using the microdata of the Mexican population censuses). We find that a 10 percent increase in local tourism revenues leads to an increase of 0.45 percent in local nominal wages.

Robustness We address two potentially remaining concerns. First, maybe the previous robustness checks missed omitted variables that are both correlated with the instruments conditional on controls, and affect local economic outcomes. Second, islands, whiter beaches or archaeological sites could affect the local economy not just through their effect on local tourism, but also by directly influencing the residential choice of Mexicans relative to other coastal locations. Even though we sought to be careful in constructing our IVs to capture a very particular set of features of the local environment that are arguably specific to tourism, it could be the case that the IVs have a significant direct amenity effect on local employment and populations relative to other coastal locations.

In Table 4 and appendix Tables A.4-A.10, we further assess these concerns in six different ways. ${ }^{19}$ First, appendix Table A.4 reports additional robustness tests against omitted variable

\footnotetext{
${ }^{17}$ As discussed in Section 2, local tourism shares are not directly observable in the data and based on the assumption that hotel expenditures account for on average roughly 15 percent of total tourism expenditure.

${ }^{18}$ See Footnote 11 . In the case of $\log$ total GDP as the outcome, the direct effect is approximately equal to the share of tourism in local GDP since tourism output is part of the sum of local GDP (i.e. $\left.\frac{\partial \log \left(G D P_{n t}\right)}{\left.\partial \log (\operatorname{TourismGDP})_{n t}\right)} \approx \frac{\operatorname{TourismGDP}_{n t}}{G D P_{n t}}\right)$.

${ }^{19}$ We also report additional checks in appendix Tables A.11-A.15. Table A.11 confirms that the estimation results are not sensitive to using the IHS transformation, since the identifying variation stems from differences across coastal municipalities, that except for three instances report non-zero hotel revenues. Table A.12 reports results after replacing hotel revenues with number of tourists. Table A.13 uses additional information from the 100 percent census samples to confirm that the 10 percent samples do not give rise to sparseness concerns at the municipality level. Table A.14 first confirms that the identifying variation for the island and beach IVs is purely driven by coastal municipalities, and then reports close to identical point estimates after allowing all municipality controls to be interacted with the coastal region dummy. Table A.15 addresses the concern that the first stage F-statistic drops from 17.56 to 15.3 when including the full set of controls in the joint IV specification in columns 10 and 12 in Table 2. To this end, we compare 2SLS estimates
} 
bias. In columns 2-4, we find little support for the concern that our IV estimates may be driven by correlations with sea accessibility (flat terrain vs coastal cliffs) or local fishery potential (measured by primary ocean productivity). In column 5 , we find little sensitivity to excluding the origin municipalities of the top-ranked beaches. In the final two columns, we find that doubling the cutoff values for island proximity or coastline ranges does not affect the point estimates.

Second, we run a placebo falsification test on the identical sample of municipalities during a period before beach tourism had become a discernible force in Mexico. This involves the construction of a long time series of population census data for consistent spatial units for the years 1921, 1930, 1940 and 1950, in addition to the two most recent rounds of population census data 2000 and 2010 that we use in our baseline regressions. As discussed in the data section, the historical census database provides us with municipality populations, but not employment. Table 4 reports the results of these specifications. ${ }^{20}$ We report the results across two panels, that deal in different ways with the fact that not all municipalities reported non-zero populations for all census rounds between 1921-2010. The first panel is based on the same strategy as for log hotel sales above, and uses the IHS transformation on the left-hand side in order to not ignore zero populations. The second panel replaces zero population values with the $\log$ of 1 , instead. We report results both before and after controlling for access to road infrastructure in 1940, as a way to check robustness to controlling for pre-existing differences in remoteness.

For all three IVs, we find slightly negative but insignificant point estimates of the effect on municipality populations before 1960, and a significant positive effect afterward. The estimates on the geographical municipality controls, and controls for pre-existing access to infrastructure are estimated with similar precision in both periods, giving some reassurance against the concern that the historical census population data could simply be more noisy than the more recent data. These results suggest that the oceanographic, geological and archaeological variation that we use to construct instruments for tourism attractiveness are unlikely to capture locational fundamentals that directly enter Mexican location choices along the coastline in a discernible way.

Third, we address the potentially remaining concern that while Mexicans may not have cared about white sand beaches, islands or ruins when deciding where to live and work in the 1950s, their tastes may have evolved over time so that by 2000 these IVs pick up significant direct amenity effects relative to other coastal locations. To this end, we verify in today's cross-section of municipalities to what extent our model-based estimates of local amenities that we discuss in Section 5.1 -essentially local population residuals left unexplained by spatial variation in real incomes- are significantly related to the presence of islands, the fraction of white sand coverage or the presence of pre-Hispanic ruins. Appendix Table A.5 reports the estimation results. Consistent with the findings of the placebo falsification test above, we find that current-day estimates of local amenities are

using both IVs to limited information maximum likelihood (LIML) estimates. As the LIML estimator has been found to be more robust to weak instrument bias, the fact that the reported LIML point estimates are slightly higher provides reassurance against this concern.

${ }^{20}$ One potential caveat for the ruins IV is that it is possible that not all archaeological sites had been discovered pre-1960s. We include the basic set of geographical controls used in the previous tables rather than the complete set, as some of the controls were arguably not pre-determined in the early census periods. 
not significantly correlated with the instruments. ${ }^{21}$ Related to this, we also check the sensitivity of the IV estimates to the inclusion of a comprehensive list of controls for differences in the local crime and security environment. This exercise is useful to judge the extent to which the observed positive effect of tourism on total employment and population could be mediated by an improvement of local security due to tourism, which is a specific type of local amenity. Reassuringly, as reported in appendix Table A.7, we find that the point estimates remain close to unchanged, while several of the crime controls (e.g. homicides, assaults, extorsions per capita) enter significantly and with the expected negative sign.

Fourth, we verify whether the positive effect of our IVs on local populations in today's crosssection of regions is driven by economically active Mexicans rather than pensioners, as another way to differentiate between economic incentives due to tourism versus a correlation between the IVs and local attractiveness for residents. As reported in appendix Table A.8, we find that the positive effect of the instruments on the number of municipality immigrants who are economically active is significantly less positive and close to zero among retired migrants.

Fifth, the results up to this point have been based on cross-sectional variation with the aim to capture the long-run effects of tourism exposure (since the 1950s) on regional economic outcomes in Mexico. In our final set of results, we corroborate the causal interpretation of our IV strategy using shorter-term variation that is based on panel data. To this end, we exploit the long time series of municipality population data 1921-2010 described in Section 2 to estimate the differential effect of decadal changes in tourist arrivals to Mexico across coastal municipalities with or without nearby islands, higher or lower fractions of white sand coverage, and with or without pre-Hispanic ruins. To do so convincingly, we propose a shift-share IV strategy. In OLS, we interact the cross-sectional IVs with the number of tourist arrivals to Mexico after including municipality and coast-by-period fixed effects. In the IV regressions, we then instrument for the number of tourist arrivals to Mexico with the log average air fare paid by US airline passengers (in constant US dollars). As reported in appendix Table A.9, we find that inflows of tourists to Mexico have a significantly more positive effect on local populations for municipalities with higher (instrumented) tourism potential relative to other coastal municipalities. ${ }^{22}$ This result holds for all three IVs, and is robust to flexibly controlling for differences in trends after interacting the full set of municipality controls discussed above with census year fixed effects. These findings provide additional corroborating evidence in support of our IV identification strategy.

Finally, we also investigate to what extent measurement error in the relationship between hotel sales and total tourist expenditures could be systematically related to the instruments. In particular, we would over-estimate (under-estimate) the true causal effect of tourism on local economic outcomes if accommodation constituted a smaller (larger) fraction of tourist expenditure in places

\footnotetext{
${ }^{21}$ The point estimates are -.0238 (.323) for the island IV, .0997 (2.958) for the beach IV and .183 (.365) for the ruins IV. We also verify that the model-based measures of local amenities are correlated with direct measures, such as weather, greenness, crime, car congestion and access to inland bodies of water or the ocean, as reported in appendix Table A.6.

${ }^{22}$ In particular, we find that a 10 percent increase in the arrival of tourists to Mexico leads to $1.7,0.3$ and 0.7 percentage point higher population growth for, respectively, municipalities with a nearby island, a 1 sd higher fraction of white sand coverage, and the presence of pre-Hispanic ruins relative to other beach locations.
} 
with islands, nicer beaches or archaeological sites, since the IVs would be positively (negatively) correlated with measurement error in the residual term. Related to this, it would be natural to assume that the share of professional travelers in local hotel revenues is lower among attractive beach destinations. To the extent that local expenditures of professional travelers should not be counted as tourism expenditure on the right-hand side of (1), this could lead to under-estimating the true causal effect of tourist expenses on local economic outcomes. Since our analysis is mainly based on comparing beach destinations along the coastline, rather than comparing e.g. Mexico City to Cancun, the latter concern would seem somewhat less likely.

To further assess these questions, we use available data on the composition of tourist expenses and the share of hotel nights booked for professional vs leisure travel across different destinations that we obtain from EuroStat. Related to the first question, we find in appendix Table A.10 that the accommodation share of tourist expenditures does not systematically differ across destinations with higher or lower fractions of coastal tourism (positive point estimate close to zero). Related to the second question, we find that destinations with higher shares of coastal tourism have significantly lower shares of professional travel, as expected. We also confirm that this relationship becomes insignificant with a point estimate close to zero after we include a dummy for predominantly coastal destinations (defined as destinations with three quarters of coastal tourism or more ( $40 \%$ of sample)). Taken together, these results suggest that the use of hotel sales as a measure of local tourism activity is unlikely to give rise to measurement error that is also systematically related to the three types of IVs we exploit.

In summary, the additional results discussed above provide some further reassurance that our IV strategy captures a specific set of shifters to local tourism attractiveness that do not appear to have discernible direct effects on local populations, or to be correlated with other omitted variables affecting local economic outcomes or measurement error in tourism sales. In addition to the analysis presented here, we also quantitatively assess the sensitivity of the estimated gains from tourism to potentially remaining concerns about the exclusion restriction as part of the counterfactual analysis in Section 5.1.4.

\subsection{Discussion}

The previous subsection presents evidence that tourism activity has led to significant increases in local total employment and population relative to less touristic regions in Mexico. Underlying these results, we find significant positive effects on local GDP and wages, as well as sizable positive multiplier effects on manufacturing production. We now provide additional evidence to narrow down the interpretation of these local effects, and to inform the structure of the model in the following section.

Role of Public Investments and Infrastructure As in many countries, Mexico's tourism sector has developed with the help of significant public investments in tourism infrastructure both at the federal and local levels of government since the 1960s. At the federal level, Mexico's FONATUR has invested in the creation of seven planned tourism centers between the 1960s and 2010: Can- 
cun, Los Cabos, Ixtapa, Huatulco, Loreto and more recently Nayarit and Cozumel. ${ }^{23}$ Federal $^{2}$ investments in planned centers through FONATUR and its predecessors account for slightly more than 90 percent of the current stock of public investment in tourism in Mexico. ${ }^{24}$ The first wave of these investments were targeted to raise foreign reserves for the Mexican central bank in the 1960s and 70s, and the objective was to create tourism centers in coastal destinations with the most promising natural and cultural potential for tourism development. ${ }^{25}$ In addition to federal investments through FONATUR, both state and municipality governments have made additional investments in the development and promotion of local tourism, accounting for the remainder of public spending targeted at the tourism sector.

These public investments have mainly taken two forms. The first are investments in local public capital and infrastructure that are specific to the tourism sector, such as building museums and monuments, tourist information centers, restoring historical buildings and structures, developing the marina, and spending on tourism promotion and advertising campaigns. The second are investments in transport infrastructure, such as roads and airports, that were mainly targeted at government-planned tourism centers through FONATUR starting from the 1960s.

Against this background, we can investigate the extent to which ex ante differences in tourism attractiveness, captured by our IVs, have been followed by and endogenous policy response of public investments targeted at the development of the tourism sector. These results serve to document the role of government policy in facilitating the development of tourism in Mexico. In turn, they help inform the model that we develop in the next section to interpret the observed local effects and quantify the gains from tourism.

To this end, we use the historical database on Mexican federal and local government investments, and construct a measure of the installed public capital stock of investments in tourism development across municipalities in the 1998 and 2008 cross-sections. We also use geo-referenced information on government-planned tourism centers, airports and the Mexican terrestrial transportation network (all roads and railways) that we obtain from INEGI's geo-statistics division. As reported in Table 5, we find that the stock of public investment in tourism is positively affected by our IVs for tourism attractiveness. In line with this, higher tourism attractiveness also leads to closer distances to planned tourism centers, better access to transport infrastructure, and reduced transport travel times on the full Mexican road and railway network to other municipalities in Mexico and border crossings to the US.

These findings inform the model that we develop in the next section in two ways. First, we model tax-financed public investments as inputs to the development of the tourism sector. This allows us to take into account the role of the government, and to quantify the gains from tourism net of costly tax-financed public investments. Second, it could also be the case that public in-

\footnotetext{
${ }^{23}$ FONATUR was created in 1974 by merging two previous agencies INFRATUR and FOGATUR. After the end of our sample period in 2010, FONATUR more recently invested in two additional planned projects: Marinas Turisticas and Playa Espiritu.

${ }^{24}$ Appendix 2 provides a more detailed description.

${ }^{25}$ For some interesting background on this, the New York Times published an article on 05 March in 1972 titled: "Why the Computer Chose Cancun".
} 
vestments in tourism affect economic outcomes not just through their effect on increased local tourism activity, but also directly by improving access to infrastructure and reducing trade costs for the local manufacturing sector. To provide a first empirical check on such direct effects, we report in appendix Table A.16 the extent to which the IV point estimates of the local effects of tourism change after either excluding or controlling for distance to government-planned tourism centers, that were the target of transport investments and account for more than 90 percent of overall public spending on tourism development in the data. The fact that the point estimates are not noticeably reduced after excluding the bulk of public investments suggests that the local effects of higher ex ante tourism attractiveness operate mainly through increased local tourism activity, rather than additional direct effects due to the endogenous increase in public investments in tourism. ${ }^{26}$ To further investigate and re-visit this channel in the quantification, we will also allow for tourism development to lead to an endogenous reduction in trade costs that we quantify in the data following Table 5, and test the extent to which this additional channel affects the estimation of the gains from tourism and local agglomeration forces, as we discuss below.

Tourism Input Demand The second question is to what extent the positive multiplier effect on traded sector production may be driven by a subset of manufacturing sectors that are used intensively as local inputs for tourism-related services. As reported in appendix Table A.17, we break up the 21 three-digit manufacturing sectors into above and below-median intensity of touristic input use among traded industries. In particular, we construct two different measures. The first is based on the three-digit level total requirement coefficients from the 2007 Mexican input output tables. We use the total (direct and indirect) input requirement coefficients for the hotel sector across the 21 manufacturing sectors, and divide these sectors into above and below the median. ${ }^{27}$ Alternatively, to better capture sectors that tourists demand directly -rather than solely relying on what the hotel sector uses as inputs in the Mexican IO tables-, we also construct a second measure of tourism's input intensity: the Mexican tourism satellite account splits up total tourist tradable consumption into five 3-digit sectors. These are (in decreasing order of importance): the food industry, artisanal products (part of other manufacturing), pharmaceuticals (part of chemical industry), clothing industry, and printed media (part of printing industry). We use these five sectors as our second binary measure of traded sectors which may be used intensively by the tourism sector.

As reported in appendix Table A.17, we find that, as expected, sectors more intensively used in tourism are slightly more strongly affected by variation in local tourism activity. At the same time,

\footnotetext{
${ }^{26}$ Formally, the total derivative of the first stage is: $\frac{d \log \left(\text { HotelSales }_{n t}\right)}{d \text { Attractiveness }_{n t}}=\frac{\partial \log \left(\text { HotelSales }_{n t}\right)}{\partial \text { Attractiveness }_{n t}}+\frac{\partial \log \left(\text { HotelSales }_{n t}\right)}{\partial \log \left(\text { PublicInvestment }_{n t}\right)} \times$ $\frac{d \log \left(\text { PublicInvestment }_{n t}\right)}{d \text { Attractiveness }_{n t}}$, while the total derivative of the second-stage is: $\frac{d \log \left(y_{n t}\right)}{\operatorname{dlog}\left(\text { HotelSales }_{n t}\right)}=\frac{\partial \log \left(y_{n t}\right)}{\partial \log \left(\text { HotelSales }_{n t}\right)}+$ $\frac{\partial \log \left(y_{n t}\right)}{\partial \log \left(\text { PublicInvestment }_{n t}\right)} \times \frac{d \log \left(\text { PublicInvestment }_{n t}\right)}{d \partial \log \left(\text { HotelSales }_{n t}\right)}$. The fact that the IV point estimates $\left(\frac{d \log \left(y_{n t}\right)}{\text { dlog }\left(\text { HotelSales }_{n t}\right)}\right)$ remain unchanged after excluding the bulk of public spending in Table A.16 suggests that while public investments respond as a function of higher ex ante tourism attractiveness, their effect on local outcomes operates mainly through the increase in tourism activity they were intended to bring about. In line with this, in earlier versions of this paper we also confirmed that the IV point estimates remain stable after including a comprehensive set of measures for access to infrastructure as controls on the right-hand side. The advantage of the approach above is that it provides a simple and transparent empirical check that does not run into concerns about adding several endogenous ("bad") control variables.

${ }^{27}$ The two most intensively used input sectors are chemical products and petroleum/carbon-based products (both used in building hotels and resorts), and the two least used input sectors are leather products and the food industry.
} 
the positive multiplier effects remain sizable and statistically significant in sectors with belowmedian tourism input intensity. These results suggest that part of the positive effect of tourism on local traded goods production may be driven in part by better market access for local input suppliers to tourism. To reflect this finding in our quantification, we allow for input-output linkages between tourism related services and all other sectors of the local economy in the theoretical framework that follows.

\section{Theoretical Framework}

With these empirical results in hand, we now lay out a spatial equilibrium framework, whose main objectives are twofold. First, the estimation of the model allows us to shed light on the aggregate implications of tourism that are consistent with the local effects that we estimate in the previous section. Since we exploit within-country variation, our empirical estimates are by construction based on relative effects and cannot directly speak to aggregate effects of tourism. This limitation is particularly acute because tourism has had more than five decades to affect regional economic outcomes in the Mexican context: as we report above, local populations and employment strongly respond to differences in tourism activity, suggesting that the regional welfare differentials brought about by tourism activity have been smoothed over time.

Second, the model allows us to shed additional light on the underlying channels. The previous section suggests that tourism has strong positive effects on local economic activity, both directly and indirectly, i.e. through its effect on manufacturing production. To what extent are these multiplier effects a sign of possible productivity spillovers between the development of the local services sector through tourism and traded goods production? The answer is a priori unclear, as this result could be driven by neoclassical local demand effects alone: local population, input demand from the tourism sector and public investment increase, improving local demand and trade market access of local manufacturers. Furthermore, to the extent that these multiplier effects do in fact reflect productivity spillovers, it is also a priori unclear whether such localized effects on manufacturing may be offset in the aggregate by a decrease in agglomeration forces among non-touristic regions of the country. These questions naturally feed back into the welfare evaluation of tourism in the aggregate: depending on the sign and magnitude of within and cross-sector agglomeration forces, the aggregate gains from tourism can either be magnified or diminished compared to the conventional neoclassical gains from market integration in tourism.

We outline the theoretical framework in what follows, and Section 5.1 describes the model calibration and presents the counterfactual analysis. Appendix 3 provides additional details about the structure of the model.

\subsection{Model Setup}

The theoretical framework is a spatial equilibrium model in the spirit of Allen \& Arkolakis (2014) and Ahlfeldt et al. (2015), with multiple sectors and input-output linkages as in Caliendo et al. (2014). It adapts the framework in three dimensions that capture important features of our empirical context. First, in addition to trade in manufacturing goods and labor mobility, it allows 
for trade in tourism-related services through consumers who can travel to destination regions and consume non-traded tourism services on their trips. Second, the development of the local tourism sector is made possible by government investments in tourism infrastructure. These investments are financed by a federal tax. ${ }^{28}$ Third, in addition to the traditional within-sector source of agglomeration economies, the model features local cross-sector spillovers between the services sector and manufacturing.

In the model, regions within Mexico differ ex ante in three dimensions: their level of productivity for manufacturing goods, their level of attractiveness for tourism, and their level of local amenities for residents. Regions trade goods with each other and the rest of the world, and host international and domestic tourists that spend part of their income outside of their region of residence. Regions in the world are indexed by $n \in 1, \ldots, N$. Workers are mobile within Mexico. The share of workers in each Mexican region, $\frac{L_{n}}{L_{\mathcal{M}}}$ for $n \in \mathcal{M}$, is an endogenous outcome. For simplicity, we do not model intra-country heterogeneity for countries other than Mexico, whose population is exogenously given and equal to $L_{n}$ for $n \in \overline{\mathcal{M}}$. The model is static and aims at capturing the long-run steady-state of the economy. ${ }^{29}$

Household Preferences Each worker supplies one unit of labor inelastically. They earn labor income $w_{n}$, which is taxed at rate $\iota$ by the government to finance public investments. Workers derive utility from the consumption of a bundle of goods and services as well as from the local amenities of the region where they live, subject to idiosyncratic preference shocks. The utility of a worker living in region $n$ of her country is:

$$
U_{n}(\omega)=\varepsilon_{n}(\omega) C_{n} B_{n} L_{n}^{\epsilon}
$$

where $C_{n}$ is the consumption bundle of goods and services, $B_{n}$ is the exogenous amenity differences between regions, and term $L_{n}^{\epsilon}$ allows for that amenity to respond endogenously to how populated the region is. This aims to capture, in a reduced-form way, the notion that more populated regions can be either more congested, leading to a decrease in the utility of local residents (if $\epsilon \leq 0$ ), or more attractive, as the concentration of population gives rise endogenously to better local amenities (e.g. more sources of entertainment, variety in consumption, etc). Finally, each worker $\omega$ has a set of idiosyncratic preferences $\varepsilon_{n}(\omega)$ for living in different regions $n$ of her country. They are drawn from a Frechet distribution with mean 1 and dispersion parameter $\kappa$. Workers within Mexico choose to live in the region that maximizes their utility, so that worker $\omega^{\prime}$ s utility is $U(\omega)=\max _{n \in \mathcal{M}} \varepsilon_{n}(\omega) C_{n} B_{n} L_{n}^{\epsilon}$.

Workers consume a bundle of local non-traded services $\left(C_{s}\right)$, traded tourism-related services

\footnotetext{
${ }^{28}$ Fajgelbaum et al. (2015) develop a spatial equilibrium that features taxation and public investment by local governments. Here taxation and investments are made by the national government.

${ }^{29}$ To provide corroborating evidence, appendix Table A.18 documents that our instruments do not lead to systematically different local effects in 2010 compared to 2000 economic outcomes.
} 
$\left(C_{T}\right)$ and traded manufacturing goods $\left(C_{M}\right)$, according to the following preferences: ${ }^{30}$

$$
C_{n}=\left(\frac{1}{\alpha_{M T}}\left[C_{M, n}^{\frac{\rho-1}{\rho}}+C_{T, n}^{\frac{\rho-1}{\rho}}\right]^{\frac{\rho}{\rho-1}}\right)^{\alpha_{M T}}\left(\frac{1}{\alpha_{S}} C_{S, n}\right)^{\alpha_{S}},
$$

where the elasticity of substitution between tourism-related services and manufacturing goods is $\rho>1$, and $\alpha_{M T}+\alpha_{S}=1$. Workers spend a constant share of their income on local services. ${ }^{31}$ We write $P_{M, n}$ the price of the composite manufacturing good, and $P_{T, n}$ the price of the bundle of tourism-related services for a consumer located in region $n$. The composite traded price index for the bundle of manufactured goods and tourism services is then $P_{M T, n}=\left(P_{M, n}^{1-\rho}+P_{T, n}^{1-\rho}\right)^{\frac{1}{1-\rho}}$, and the share of total spending in region $n$ on manufactured goods is $\alpha_{M T} \chi_{n}$, where $\chi_{n} \equiv \frac{P_{M, n}^{1-\rho}}{P_{M T, n}^{1-\rho}}$.

Each worker has idiosyncratic preferences for the various destinations she could visit as a tourist, and makes a discrete choice of a region among all possible destination regions, including abroad. We make the following timing assumption: workers first set up their budget and the share of income they spend on tourism based on the expected utility derived from tourism. Then, their idiosyncratic preference draws are revealed and they choose their destination. ${ }^{32}$ The utility that a worker $\omega$ who lives in region $n$ derives from visiting region $i$ is:

$$
C_{T, n}(\omega)=\frac{A_{i} q_{T, i} a_{i}^{T}(\omega)}{t_{n i}},
$$

where $q_{T, i}$ is the quantity of tourism services she consumes in region $i, A_{i}$ is a tourism attractiveness shifter for each destination $i, a_{i}^{T}(\omega)$ is an idiosyncratic preference shock for region $i$ drawn from a Frechet distribution with shape parameter $\beta$ and mean 1 , and $t_{n i}$ is a utility cost that tourists from origin region $n$ incur when visiting region $i$. It captures travel costs from the region of residence to the region visited, as well as other potential barriers to tourism, such as cultural differences between regions or language barriers. Given the properties of the Frechet distribution, region $n$-workers' expected utility derived from tourism is:

$$
C_{T, n}=\left[\sum_{k=1}^{N}\left(\frac{A_{k} q_{T, k}}{t_{n k}}\right)^{\beta}\right]^{1 / \beta},
$$

and the corresponding price index for tourism services for travelers from region $n$ is $P_{T, n} \equiv$ $\left[\sum_{k=1}^{N} A_{k}\left(t_{n k} p_{T, k}\right)^{-\beta}\right]^{-\frac{1}{\beta}}$, where $p_{T, k}$ is the price of tourism in destination region $k$. In turn, the ${ }^{30}$ More generally, the demand function can be parametrized as $\left(\frac{\left[\beta_{M} C_{M, n}^{\frac{\rho-1}{\rho}}+\beta_{T} C_{T, n}^{\frac{\rho-1}{\rho}}\right]^{\frac{\rho}{\rho-1}}}{\alpha_{M T}}\right)^{\alpha_{T}}\left(\frac{C_{S, n}}{\alpha_{S}}\right)^{\alpha_{S}}$, but the preference weights $\beta_{M}$ and $\beta_{T}$ that capture the relative strength of consumer tastes for each good are not separately identified from difference in productivity between these two sectors, so we normalize these weights to 1 . The calibrated productivities in each sector should therefore be understood as capturing both a productivity effect as well as demand weights.

${ }^{31}$ This is consistent with the interpretation of this local spending as housing expenditure. For example, Davis \& Ortalo-Magné (2011) show that housing expenditure constitutes a nearly constant fraction of household income.

${ }^{32}$ The timing assumption is convenient to solve the model. In particular, it leads to expressions isomorphic to assuming CES demand. 
share of region $n$ workers who visit region $i$ (and the share of tourism spending by region $n$ workers that is spent in region $i$ ) is:

$$
\lambda_{n i}=\frac{A_{i}\left(t_{n i} p_{T, i}\right)^{-\beta}}{\sum_{k=1}^{n} A_{k}\left(t_{n k} p_{T, k}\right)^{-\beta}} .
$$

We now turn to the supply side of the economy. There are three sectors, indexed by $j$ : tourism services $(j=T)$, local non-traded services $(j=S)$, and manufacturing $(j=M)$. We also index labor, used as an input to production, using $L$.

Tourism Services The production of tourism services requires some investment in tourism capital (e.g. tourist information centers, museums, restorations, marketing costs to attract tourists). The government uses tax revenue to finance the provision of this local tourism capital, which enters as a productivity shifter in the production of tourism services. ${ }^{33}$ Tourism services are then produced under perfect competition by combining local labor, local services and a composite manufacturing input, according to the production function $q_{T, n}=Z_{T, n} \prod_{j \in L, M, S} m_{j, n}^{T} v_{T}^{j}$, where $Z_{T, n}$ is the productivity of tourism services in region $n, m_{j, n}^{T}$ is the input use of input $j$ in the production of tourism in region $n$, and $\sum_{j \in L, M, S} v_{T}^{j}=1 .^{34}$ The local productivity of tourism services is improved by public investment according to:

$$
Z_{T, n}=Z_{T, n}^{o\left(1-\alpha_{G}\right)} G_{n}^{\alpha_{G}}
$$

where $Z_{T, n}^{o}$ captures exogenous differences between regions, and $G_{n}$ is government spending to build tourism capital in region $n$. This investment in local tourism infrastructure $G_{n}$ is financed by an income tax $\iota$ levied on all workers in Mexico. The unit cost of production of tourism services provided in region $n$ is:

$$
c_{T, n}=\frac{\Psi_{T}\left(w_{n}\right)^{v_{T}^{L}} \prod_{j \in M, S} P_{j, n}^{v_{T}^{j}}}{Z_{T, n}^{01-\alpha_{G}} G_{n}^{\alpha_{G}}}
$$

where $\Psi_{T}=\prod_{j \in L, M, S}\left(v_{T}^{j}\right)-v_{T}^{j}$ is a constant. Given perfect competition, this is also the local price of tourism services, $p_{T, n}$, faced by tourists when they visit region $n$. In the calibration, we refer to $\widetilde{A_{i}}=A_{i} Z_{T, i}^{\beta}$ as the tourism attractiveness shifter in region $i$, which captures both a productivity and an amenity shifter. It follows that tourism trade shares can be written as:

$$
\lambda_{n i}=\frac{\widetilde{A_{i}}\left(t_{n i} w_{i}^{v_{T}^{L}} P_{M, i}^{v_{T}^{M}} P_{S, i}^{v_{T}^{S}}\right)^{-\beta}}{\sum_{k=1}^{N} \widetilde{A_{k}}\left(t_{n k} w_{k}^{v_{T}^{L}} P_{M, k}^{v_{T}^{M}} P_{S, k}^{v_{T}^{S}}\right)-\beta},
$$

\footnotetext{
${ }^{33}$ Equivalently, public investment could be modeled as shifting local tourism amenities $A_{n}$. The two formulations are isomorphic, as demand and productivity shifters for tourism play symmetric roles and are not separately identified.

${ }^{34}$ We revisit the assumption of perfect competition in Appendix 4.6, where we allow for positive rents in the tourism sector, part of which can be repatriated by multinational investors.
} 
and the price index for tourism services is:

$$
P_{T, n} \equiv\left[\sum_{k=1}^{N} \widetilde{A_{k}}\left(t_{n k} w_{k}^{v_{T}^{L}} P_{M, k}^{v_{T}^{M}} P_{S, k}^{v_{T}^{S}}\right)-\beta\right]^{-\frac{1}{\beta}} .
$$

Manufacturing Production Intermediate varieties from a continuum $x \in[0,1]$ are produced in each region, combining inputs to production indexed by $j \in\{L, S, M\}$. A competitive local sector aggregates intermediate varieties and sells this composite to i) local final consumers, ii) local intermediate producers in manufacturing and tourism who use it as an input to their production, and iii) the Mexican government who uses it to build a local tourism capital.

The production function for intermediate varieties is constant returns to scale $\left(\sum_{j \in L, M, S} v_{M}^{j}=\right.$

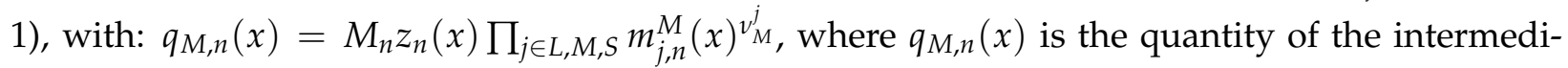
ate variety produced, $m_{j, n}^{M}$ is the input use of input $j$ for manufacturing production, $M_{n}$ is the local productivity in manufacturing, common to all varieties in region $n$, and $z_{n}(x)$ is the variety $x$-specific efficiency in region $n$ drawn from a Frechet distribution with shape parameter $\theta$ and mean 1: $F(z)=e^{-Z^{-\theta}}$. It will prove convenient to define the unit cost of the local input bundle for manufacturing in region $n$ as $c_{M, n}=\Psi_{M}\left(w_{n}\right)^{v_{M}^{L}} \prod_{j \in M, S} P_{j, n}^{v_{M}^{j}}$, where $\Psi_{M}$ is a constant ${ }^{35}$ and $P_{j, n}$ is the unit cost of input $j$. Firms incur an iceberg trade $\operatorname{cost} \tau_{n i}$ to ship the manufacturing good from region $i$ to region $n$. Firms behave competitively and therefore price at unit cost. A perfectly competitive local sector aggregates these varieties into a composite manufacturing good. They source across regions and countries and purchase intermediate varieties from the lowest cost supplier. The composite manufacturing good is a CES aggregate of individual varieties $x \in[0,1]$ with elasticity of substitution $\sigma_{M}$ and price index $P_{M, n}$ :

$$
Q_{M, n}=\left[\int q_{M, n}(x)^{\frac{\sigma_{M}-1}{\sigma_{M}}} d x\right]^{\frac{\sigma_{M}}{\sigma_{M}-1}} \quad ; \quad P_{M, n}=\left[\int p_{M, n}(x)^{1-\sigma_{M}} d x\right]^{\frac{1}{1-\sigma_{M}}},
$$

where $p_{M, n}(x)=\min _{i \in 1 \ldots N}\left\{\frac{c_{M, i} \tau_{n i}}{M_{i} z_{i}(x)}\right\}$ as local aggregators in region $n$ source from the lowest cost region. Given the properties of the Frechet distribution that governs local efficiency levels, the share of manufacturing spending that region $n$ spends on goods produced in region $i$ is:

$$
\pi_{n i}=\frac{\left(\tau_{n i} c_{M, i}\right)^{-\theta} M_{i}^{\theta}}{\sum_{k=1}^{N}\left(\tau_{n k} c_{M, k}\right)^{-\theta} M_{k}^{\theta}}
$$

and the price index for the composite manufacturing good in region $n$ is:

$$
P_{M, n}=\left[K_{1} \sum_{k=1}^{N}\left(\tau_{n k} c_{M, k}\right)^{-\theta} M_{k}^{\theta}\right]^{-\frac{1}{\theta}} .
$$

where $K_{1}=\left(\Gamma\left(\frac{\theta-\sigma_{M}+1}{\theta}\right)\right)^{\frac{1}{1-\sigma_{M}}}$ is a constant.

${ }^{35}$ Specifically, $\Psi_{M}=\prod_{j \in L, M, S}\left(v_{M}^{j}\right)^{-v_{M}^{j}}$. 
Agglomeration Forces We allow for the presence of different sources of local production externalities. In particular, the productivity of a region for manufacturing goods $M_{n}$ can be endogenous to the level of local economic activity. This externality can stem from the level of economic activity in the manufacturing sector $\left(L_{M, n}\right)$ and/or the level of economic activity in the services sector $\left(L_{S T, n}=L_{T, n}+L_{S, n}\right)$. In both cases, local productivity increases with the size of economic activity with a constant sector-specific elasticity (denoted respectively $\gamma_{M}$ and $\gamma_{S}$ ), so that:

$$
M_{n}=M_{n}^{o} L_{M, n}^{\gamma_{M}} L_{S T, n^{\prime}}^{\gamma_{S}}
$$

where $M_{n}^{o}$ is the exogenous component of local productivity. This expression captures in a reduced-form way the channels through which local tourism expenditures can have positive or negative effects on traded goods production in the long run, beyond their neoclassical demand linkages. For example, it has been argued that tourism could act as a special case of the "Dutch disease", shifting activity into stagnant services sectors and away from manufacturing with higher potential for productivity growth. Expression (11) allows for tourism to have such adverse longterm consequences if, for example, $\gamma_{M}>0$ but $\gamma_{S}=0$. In that case, the development of tourism attracts workers away from manufacturing, a sector in which scale matters for productivity, causing a decrease in productivity. On the other hand, tourism could give rise to productivity spillovers that would not have materialized otherwise -if, for example, $\gamma_{S}>0$ while $\gamma_{M}=0$. There are a number of channels through which the development of tourism can a priori lead to positive spillovers on the manufacturing sector. For example, the development of tourism can improve the provision of local business services, such as finance, accounting or consulting. Tourism revenues can also directly loosen the credit constraints of local firms. Alternatively, tourism could lead to a better-trained local workforce, spur more entrepreneurship by offering business opportunities, or facilitate domestic and international business networks through increased travel activity. All of these effects are summarized by the parameter $\gamma_{S}$.

Local Non-Traded Services Finally, local services are produced and consumed by local residents. They are produced using local labor with constant returns to scale and productivity $R_{n}$, so that $P_{S, n}=\frac{w_{n}}{R_{n}} .{ }^{36}$ Since $R_{n}$ is not identified independently from the level of local amenities $B_{n}$ in what follows, we choose to normalize $R_{n}=1$ and interpret $B_{n}$ as indicating a combination of the level of local amenities and the productivity of local non-traded services.

\subsection{Equilibrium}

Mexican workers choose in which region to live within Mexico. Given the properties of the Frechet distribution and the workers' utility maximization problem in (2), the share of workers

\footnotetext{
${ }^{36}$ These services can be interpreted as housing. Formally, modeling housing as in e.g. Redding (2016) leads to isomorphic expressions.
} 
who choose to live in region $n \in \mathcal{M}$ can be expressed as:

$$
\frac{L_{n}}{L_{\mathcal{M}}}=\frac{\left(B_{n}\left(\frac{w_{n}}{P_{M T, n}}\right)^{\alpha_{M T}}\right)^{\tilde{\kappa}}}{\sum_{k \in \mathcal{M}}\left(B_{k}\left(\frac{w_{k}}{P_{M T, k}}\right)^{\alpha_{M T}}\right)^{\tilde{\kappa}}} \text {, for } n \in \mathcal{M},
$$

where we define

$$
\tilde{\kappa} \equiv \frac{\kappa}{1-\kappa \epsilon} .
$$

Note that here, as for welfare below, the parameters $\kappa$ and $\epsilon$ enter only through their combined effect in $\widetilde{\kappa}$. The three market clearing conditions for the manufacturing goods market, the tourism services market and the market for local services lead to the following system of $3 \times N$ equations. For all regions $i \in(1, \ldots, N)$, and using the index $j=T$ for the tourism sector:

$$
\begin{aligned}
w_{i} L_{i, M} & =v_{M}^{L} \sum_{n=1}^{N}\left(\alpha_{M T} w_{n}(1-\iota) L_{n} \chi_{n}+\sum_{j \in T, M} \frac{v_{j}^{M}}{v_{j}^{L}} w_{n} L_{n, S}+G_{n}\right) \pi_{n i} \\
w_{i} L_{T, i} & =v_{T}^{L} \sum_{n=1}^{N} \alpha_{M T} w_{n}(1-\iota) L_{n}\left(1-\chi_{n}\right) \lambda_{n i} \\
w_{i} L_{S, i} & =\alpha_{S} w_{i}(1-\iota) L_{i}+\sum_{j \in T, M} \frac{v_{j}^{S}}{v_{j}^{L}} w_{i} L_{i, S}
\end{aligned}
$$

Finally, the government budget balance condition is: ${ }^{37}$

$$
\sum_{\mathcal{M}} G_{n}=\sum_{\mathcal{M}} \iota L_{n} w_{n}
$$

Equations (9)-(16) define an equilibrium of the economy. There could be a priori multiple such equilibria. We come back to this point below.

\subsection{Welfare Impact of Tourism Development}

The model lends itself naturally to welfare analysis. We use as a measure of welfare in a region the average utility level enjoyed by workers who live there. In any given spatial equilibrium, because of the free mobility of workers and the properties of the Frechet distribution, this level of welfare is equalized across all Mexican regions. Given the workers' utility maximization problem in (2), this common welfare level can be expressed as:

$$
U_{\mathcal{M}}=K_{2}\left[\sum_{k \in \mathcal{M}}\left(B_{k}(1-\iota)\left(\frac{w_{k}}{P_{M T, k}}\right)^{\alpha_{M T}}\right)^{\widetilde{\kappa}}\right]^{\frac{1}{\tilde{\kappa}}}=K_{3} B_{n}(1-\iota)\left(\frac{w_{n}}{P_{M T, n}}\right)^{\alpha_{M T}} L_{n}^{-\frac{1}{\tilde{\kappa}}}, \forall n \in \mathcal{M},
$$

where the constant $K_{2}$ equals $\Gamma\left(\frac{\kappa-1}{\kappa}\right) L_{\mathcal{M}}^{\epsilon}$ and the constant $K_{3}$ equals $\Gamma\left(\frac{\kappa-1}{\kappa}\right)^{-1} L_{\mathcal{M}}^{\frac{1}{\kappa}}$. Welfare

\footnotetext{
${ }^{37}$ We assume for simplicity that aggregate trade is balanced in Mexico. In the data, Mexico runs a very small trade deficit. The model can be readily adapted to account for this aggregate deficit in the spirit of Dekle et al. (2007) and Caliendo \& Parro (2014). We have experimented with this specification, allocating the aggregate deficit to regions in proportion to local GDP, and found that results remain stable when accounting for this deficit.
} 
is a power mean, across all Mexican regions, of a measure of local utility that includes local real income, net of taxes, and local amenities.

To quantify the welfare gains brought about by tourism in Mexico, we run the following thought experiment. We compare the level of welfare in Mexico in the current equilibrium to what it would be in a counterfactual equilibrium were tourism would be absent, all else equal. By doing so, we propose a measure of what would be the welfare losses that Mexicans would incur without the tourism sector. For ease of exposition, we then report the inverse of this measure as the "gains from tourism", with a slight abuse of terminology.

Counterfactual Equilibria To create this counterfactual equilibrium, we model a world with the exact same exogenous determinants as in the current-day baseline equilibrium, except that we assume that the Mexican government does not provide investments in the required tourism capital, so that tourism productivity is zero in all regions of Mexico. This shuts down both domestic and international tourism in Mexico. This approach provides a natural measure of the gains from tourism, ceteris paribus. In particular, it nets out from the gains from tourism the cost of deploying tourism infrastructure incurred by Mexican tax payers through the government. In the counterfactual equilibrium without tourism, there are no taxes levied on Mexican workers to finance tourism infrastructure. This force, ceteris paribus, tends to push real incomes up in the counterfactual equilibrium without tourism. ${ }^{38}$ Finally, since mobile workers relocate and arbitrage away differences in welfare across regions, the difference in welfare between these two equilibria is identical across all Mexican regions, irrespective of their level of exposure to tourism.

In order to study the impact of international tourism alone, we then consider a second counterfactual equilibrium. We assume that there are prohibitive travel frictions to international tourism, but that there is still inter-regional tourism within the borders of Mexico, and we compute the welfare changes between the current and this counterfactual equilibrium. In this second counterfactual, we assume that without international tourism, tourism investments by the government and the corresponding tax $\iota$ are scaled down in proportion to the relative size of international tourism to total tourism in the baseline equilibrium. ${ }^{39}$ In both counterfactuals, we assume that all other exogenous fundamentals of the economy stay unchanged between equilibria.

To solve for these counterfactual equilibria, we follow the methodology introduced by Dekle et al. (2007) and generalized to spatial equilibria in Caliendo et al. (2014) and Redding (2016), and express the equilibrium conditions of the model in changes relative to their baseline values. Appendix 3 describes the system of equations. This system allows us to solve for a counterfactual equilibrium of the economy corresponding to a change in tourism investment, as captured by a change in the income tax $\hat{\imath}=0$, and/or by a change in travel frictions $\widehat{t_{n i}}$, given the parameters of

\footnotetext{
${ }^{38} \mathrm{An}$ alternative approach would be to evaluate the gains from trade in tourism relative to a counterfactual equilibrium in which all travel frictions are prohibitively high. The counterfactual change from today's observed level of tourism to tourism autarky would be identical in all respects to the approach we adopt here, except for not taking account of the cost of public investments.

${ }^{39}$ That is:

$$
\hat{\imath}=\widehat{G_{n}}=\frac{\sum_{n \in \mathcal{M}} w_{n} L_{n}\left(1-\chi_{n}\right)\left(\sum_{i \in \mathcal{M}} \lambda_{n i}\right)}{\sum_{n=1}^{N} w_{n} L_{n}\left(1-\chi_{n}\right)\left(\sum_{i \in \mathcal{M}} \lambda_{n i}\right)} .
$$
}


the model $\left(v_{j}^{j^{\prime}}, \alpha_{M T}, \alpha_{G}, \beta, \theta, \rho, \widetilde{\kappa}\right)$ for $j, j^{\prime} \in L, M, S, T$ and the values of the endogenous variables $\left(\pi_{n j}, \lambda_{n j}, \chi_{n}, w_{n}, L_{M, n}, L_{T, n}, L_{S, n}, G_{n}\right)$ in the baseline equilibrium.

In the presence of within and cross-sector spillovers and input-output linkages, the uniqueness of the equilibrium is not guaranteed. ${ }^{40}$ To evaluate the welfare gains from tourism, we solve for the counterfactual equilibrium that is the closest to the baseline equilibrium we observe in the data. That is, we use the values of the variables from the current equilibrium as a starting point for the counterfactual equilibrium. The numerical procedure that looks for the counterfactual equilibrium then updates the candidate value of endogenous variables based on a weighted average of this initial guess and the new values that come out of solving the model. The procedure is iterated until new values and initial values converge.

\subsection{Role of Local Spillovers}

We close the description of the model with a discussion of how local and aggregate productivity endogenously changes between equilibria that differ in their degree of tourism development. To that end, we can rewrite local manufacturing productivity defined in (11) as:

$$
M_{n}=M_{n}^{o} s_{M, n}^{\gamma_{M}}\left(1-s_{M, n}\right)^{\gamma_{S}} L_{n}^{\gamma_{S}+\gamma_{M}}
$$

where $s_{M, n}$ denotes the share of workers of region $n$ working in manufacturing. Manufacturing productivity responds to i) the change in local scale of economic activity, captured by the term $L_{n}^{\gamma_{S}+\gamma_{M}}$ (the agglomeration effect), and ii) the change in the composition of economic activity, captured by the term $s_{M, n}^{\gamma_{M}}\left(1-s_{M, n}\right)^{\gamma_{S}}$ (the sectoral reallocation effect). We examine these two channels in turn.

Agglomeration Effect Assume that there is a positive shock to the tourism sector. In regions with high touristic attractiveness, the development of tourism tends to raise real wages and attract more workers. Through the classic agglomeration effect, this increase in population density boosts local manufacturing productivity. In the aggregate, however, increases in employment in touristic regions are counterbalanced by decreases in employment in other areas. Since productivity responds with constant elasticity to employment changes, productivity gains in some regions are thus offset by productivity losses in others. This is similar to Kline \& Moretti (2014): the classical agglomeration channel leads to muted effects in the aggregate because the total population is fixed.

Sectoral Reallocation Effect Our framework gives rise to an additional sectoral reallocation effect as tourism develops. Through $s_{M, n}^{\gamma_{M}}\left(1-s_{M, n}\right)^{\gamma_{s}}$ above, agglomeration spillovers operate more strongly when both local services and manufacturing sectors are sufficiently developed in an area, so that the manufacturing sector can benefit from both within and cross-sector spillovers. In particular, the value of the spillover parameters $\gamma_{S}$ and $\gamma_{M}$ determine what this optimal balance is.

\footnotetext{
${ }^{40}$ The model does not fit the assumptions of gravity models of trade in Allen et al. (2014), as the tourism and the manufacturing sectors are allowed to differ in trade elasticities. Alternatively, the proof of uniqueness of a multi-sector multi-country trade model developed in Allen et al. (n.d.) does not directly apply here, because our model has two additional layers: i) mobility of workers within Mexico, and ii) local productivity that is endogenous to the level of local economic activity.
} 
For example, when $\gamma_{S}=\gamma_{M}$, the optimal sectoral mix to maximize agglomeration forces is an equal balance of manufacturing and local services. In contrast, when $\gamma_{S}=0$, local agglomeration externalities are highest under full local specialization in traded goods production.

A positive shock to local tourism attracts workers away from manufacturing. For non-zero values of $\gamma_{S}$ and $\gamma_{M}$, the effect on local productivity through the re-allocation effect is a priori ambiguous. In regions with high pre-existing shares of manufacturing, the development of tourism is more likely to reinforce the classical agglomeration force, as the local economy moves closer to an optimal sectoral balance. In contrast, in regions with low pre-existing shares of manufacturing employment, the reallocation effect is more likely to work in the opposite direction of the classical agglomeration force, as we move further from the optimal balance. Again, the values of $\gamma_{S}$ and $\gamma_{M}$ govern what this balance is.

In the aggregate, the effect of tourism development on productivity will thus depend on the parameter values of $\gamma_{S}$ and $\gamma_{M}$, but also on the initial distribution of activity across sectors $s_{M, n}$ in each region, and how this geography is related to initial differences in local tourism attractiveness. Overall, in a framework featuring both within and cross-sector agglomeration forces, sectoral shocks across regions can in principle give rise to positive as well as negative productivity gains, both locally and in the aggregate.

\section{Calibration and Quantification}

\subsection{Calibration}

Adapting Redding (2016) to our setup (and in particular Proposition 6), leads to the following data requirements for the model calibration: given parameters $\left(v_{j}^{j^{\prime}}, \alpha_{M T}, \alpha_{G}, \beta, \theta, \rho, \widetilde{\kappa}, \gamma_{M}, \gamma_{S}\right)$, bilateral trade costs $\left(\tau_{n i}, t_{n i}\right)$ and regional data on wages, employment, sectoral employment shares, and public investment in tourism $\left(w_{n}, L_{n}, L_{M, n}, L_{T, n}, G_{n}\right)$, there exist unique values of residential amenities $\left(B_{n}\right)$, manufacturing productivities $\left(M_{n}^{0}\right)$ and tourism attractiveness shifters $\left(A_{n}\right)$ that are consistent with the data up to a normalization that corresponds to a choice of units in which to measure productivity and amenities.

The calibration of the model proceeds sequentially in three main steps. In the first step, we calibrate the model to today's reference equilibrium corresponding to the observed level of economic activity, trade and tourism. This allows us to recover a vector of -possibly endogenous- modelbased manufacturing productivities, $M_{n}$, and a set of local tourism shifters $A_{n}$. This step requires data on $\left(w_{n}, L_{n}, L_{M, n}, L_{T, n}, G_{n}\right)$ and parameters $\left(v_{j}^{j^{\prime}}, \alpha_{M T}, \alpha_{G}, \beta, \theta, \rho\right)$ together with a parameterization of bilateral trade costs, but does not require knowledge of the spatial labor supply elasticity $(\widetilde{\kappa})$ or agglomeration parameters $\left(\gamma_{M}, \gamma_{S}\right)$. In the second and third steps of the calibration, we use the calibrated model in combination the our instrumental variable strategy from Section 3 to estimate these parameters in turn. We describe the procedure and data below, and Appendix 4 provides additional details.

The model is calibrated to the mean of inflation-adjusted outcomes for 2000 and 2010 as the 
baseline period. ${ }^{41}$ In order to limit the computational requirement, we aggregate the data coming from each of the 2455 Mexican municipalities described in the motivating evidence into a set of 300 regions. Specifically, we keep the 150 coastal municipalities unchanged, but aggregate the interior municipalities to 150 economic centers located at the centroids of the largest 150 interior municipalities. This aggregation is largely inconsequential for our welfare quantification, as we discuss in Appendix 4.5 (Tables A.30 and A.31). ${ }^{42}$ For simplicity, we aggregate all countries but Mexico into a "Rest of the World" ("RoW") aggregate (see Appendix 4.1).

Regional Data and Measurement Error We use nominal wage and local employment data from the Mexican population censuses as our measures of $w_{n}$ and $L_{n} \cdot{ }^{43}$ To measure the size of the tourism, manufacturing and non-traded services sectors in each region, we combine information from the Censos Economicos at the local level with aggregate data. The aggregate data we use are the shares of total GDP represented by the tourism, manufacturing and services sectors from the Mexican national accounts, as well as input-output shares $\left(v_{s}^{s^{\prime}}\right)$ that we calibrate using the 2003 Mexican input-output table (see Appendix 4.2). With these data in hand, we first compute the Cobb-Douglas share of traded services $\alpha_{M T}$ and non-traded services $\alpha_{S}$ in consumption that ensures that in the aggregate the value-added share of traded and non-traded sectors match the data. This computation involves taking into account the input-output structure of the model (see Appendix 4.1.). We then calibrate the local shares of all sectors by region. To measure the relative regional shares of tourism and manufacturing value added, we use manufacturing GDP which is directly observable in all regions, and we use local hotel sales as a basis to calibrate local tourism GDP. We scale these hotel sales with a constant factor of proportion across all regions so that, in the aggregate, the relative size of tourism to manufacturing matches the ratio of tourism to manufacturing GDP in Mexico's national accounts data above. ${ }^{44}$ Having calibrated the relative size of tourism in the traded sector in each region, we then compute the share of non-traded services workers in each region, accounting again for the fact that local non-traded services are used both for final consumption, as well as for the production of tourism and manufacturing. This procedure allows us to calibrate $\left(L_{S, n}, L_{T, n}, L_{M, n}\right)$ in all Mexican regions in a way that is consistent with the structure of the model. Finally, to allow for measurement error in the data we input to the model, we bootstrap our whole quantification procedure after treating the regional data that we feed into the calibration (wages, population, hotel sales and manufacturing GDP) as point estimates with a signal-to-noise ratio of 80-20, rather than data points (see Appendix 4.4). ${ }^{45}$

\footnotetext{
${ }^{41}$ As discussed in Section 2, the population census data is for 2000 and 2010, while the economic census data is for 1998 and 2008.

${ }^{42}$ The key empirical moments we use to inform the calibration are based on variation among coastal municipalities (similar to the regression analysis above) that are unaffected by this aggregation.

${ }^{43}$ To aggregate interior regions, we take the sum of employment and the employment-weighted mean of wages.

${ }^{44}$ For the small number of regions for which this procedure predicts an employment in the tourism sector that is higher than the total employment in services reported in this region, we cap tourism employment at the level reported for the services sector as a whole.

${ }^{45}$ This procedure allows for a relatively large degree of measurement error in the national and regional accounts. We effectively draw regional outcomes from a normal distribution with mean equal to the observed regional values and a $95 \%$ confidence interval of $+/-40 \%$ of that value.
} 
Public Investment in Tourism To estimate the public investment in local tourism infrastructure $G_{n}$, we use data on the municipality stock of public investment in tourism development in Mexico that we convert into equivalent steady-state annual flows, consistent with our static model. We calibrate the share $\alpha_{G}$ from equation (5) using the ratio of government investment over total tourism GDP, which leads to $\alpha_{G}=0.057$. This is close to related elasticities estimated in e.g. Fajgelbaum et al. (2015). To calibrate the common tax level that allows to finance this public investment, we compute $\iota=0.5 \%$ as the share of Mexico's GDP represented by this total annualized investment $\left(\iota=\frac{\sum_{\mathcal{M}} G_{n}}{G D P}\right)$. Appendices 2 and 4.2. provides additional details about the data and calibration.

Trade Costs for Goods and Tourism Data on trade and tourism flows is available for international flows. We take aggregate trade flows for manufacturing and tourism between Mexico and RoW from the the World Bank's WITS database for cross-country trade in goods and services. We calibrate border frictions for trade in goods and tourism such that the model matches exactly the aggregate trade data in manufactured goods and tourism between Mexico and the rest of the world. ${ }^{46}$ Unfortunately, similar data is not available for intra-country flows within Mexico. We therefore parameterize trade costs within Mexico as following a function of regional bilateral distances, as in Redding (2016):

$$
\tau_{n j}^{-\theta}=d_{n j}^{-D_{M}} \text { and } t_{n j}^{-\beta}=d_{n j}^{-D_{T}} \text {, for }(n, j) \in \mathcal{M} \times \mathcal{M},
$$

where $d_{n j}$ is the distance between the centroid of the two regions $n$ and $j .{ }^{47}$ We calibrate the distance decay elasticity for trade in goods following the literature $\left(D_{M}=1\right)$. For tourism trade flows, we use the data on bilateral tourism exports described in Section 2 and Appendix 2 to estimate a gravity equation using PPML following Silva \& Tenreyro (2006) with log distance in addition to origin-by-year fixed effects, destination-by-year fixed effects, and dummies for common border, language, colonial ties and travel visa requirements on the right-hand side. ${ }^{48}$ As depicted in appendix Figure A.1, we find a distance elasticity for tourism trade $D_{T}=0.96$ (standard error of 0.043 clustered at the level of origin-destination pairs). To provide additional evidence whether the lack of data on within-country tourism flows is likely to affect counterfactuals, we have also used information on the top 5 Mexican origin states for tourism flows to three destination states reported in an internal report by SECTUR (2011). As reported in appendix Table A.20, we find that the calibrated model does a good job at capturing the top origin regions, providing some support that the assumption of gravity in domestic tourism flows is a reasonable approximation.

Additional Parameters For the value of the trade elasticity for flows of goods, we use the estimate $\theta=6.1$ from Adao et al. (2015). This estimate is also in line with other existing estimates

\footnotetext{
${ }^{46}$ Specifically, frictions between region $n$ in Mexico and RoW are $d_{n j}^{-D_{M}} \tau_{B o r d e r}$ for manufacturing, and $d_{n j}^{-D_{T}} t_{B o r d e r}$ for tourism. The parameters $\tau_{\text {Border }}$ and $t_{\text {Border }}$ are calibrated such that values of $\lambda_{i n}$ and $\pi_{\text {in }}$ summed over all Mexican regions match exactly the data for international flows.

${ }^{47}$ The within-region distance is normalized at the minimum of between-region distances.

${ }^{48}$ Data on bilateral travel visa requirements (dummy equal to 1 if no waiver for tourist visas applies) were provided for the year 2004 by Oxford's International Migration Institute (IMI).
} 
reported in the literature (Head \& Mayer, 2014). To estimate the parameter $\beta$ that governs the elasticity of substitution $(1+\beta)$ between destinations, we use the panel data on country-level bilateral tourism exports as detailed in Appendix 4.2. To be conservative in our quantification of the gains from tourism, we pick the upper bound of the estimate of the tourism trade elasticity supported by the data $(1+\beta=2.5)$. Finally, the value of the upper-nest elasticity of substitution between manufacturing and tourism has to be smaller than the lower-nest value. We set it at the same level $(\rho=2.5)$, again to be conservative.

\subsubsection{First Step: Calibration of Regional Fundamentals}

Using information on $\left(w_{n}, L_{M, n}, L_{S, n}, L_{T, n}, G_{n}\right)$ with parameters $\left(v_{j}^{j^{\prime}}, \alpha_{M T}, \alpha_{G}, \beta, \theta, \rho\right)$, we calibrate the baseline equilibrium according to equations (9), (10), (7), (8), (13), (14) and (15). Following Redding (2016), we invert the calibrated model to recover the unique tourism and manufacturing shifters $\widetilde{A_{n}}$ and $M_{n}$ (up to scale) that are consistent with the data. Using the above calibrated $\alpha_{G}$ and data on $G_{n}$, we can further decompose $\widetilde{A_{n}}\left(=A_{n} G_{n}^{\beta \alpha_{G}}\right)$ into a fundamental component $A_{n}$ and a part driven by government investment. ${ }^{49}$ As mentioned above, in the presence of spillovers there is a potential for multiple equilibria in the model. Conditional on the data we observe, though, the mapping to unobserved productivities and tourism shifters is unique. ${ }^{50}$

\subsubsection{Second Step: Spatial Labor Supply Elasticity}

The estimating equation for the long-run spatial labor supply elasticity is directly derived from Equation (12) of the model:

$$
\log L_{n}=K_{o}+\widetilde{\kappa} \log \left(\left(\frac{w_{n}}{P_{M T, n}}\right)^{\alpha_{M T}}\right)+\xi_{n} \text { for } n \in \mathcal{M}
$$

We estimate equation (18) instrumenting for $\log \left(\left(\frac{w_{n}}{P_{M T, n}}\right)^{\alpha_{M T}}\right)$ with our three tourism attractiveness instruments that we discuss in Section 3. This addresses the concern that the OLS estimate is likely downward-biased because it confounds variation in labor demand and supply in the estimation of the supply elasticity. Moreover, measurement error in real wages would also lead to a downward bias. As reported in appendix Table A.21, we find an IV point estimate of 6.35 that is indeed larger than in OLS (1.91). Both estimates are statistically significant at the 1 percent level. The IV estimate is larger than estimates of the short-run spatial labor supply elasticity that are commonly estimated in the literature to be around 2, but signals that even from a long-run perspective, there are significant frictions to mobility: the elasticity is far from infinite even though tourism has had decades to materialize into the current spatial equilibrium. ${ }^{51}$

Finally, as discussed in Section 3, we use the above empirical strategy to construct the regional

\footnotetext{
${ }^{49}$ We normalize $Z_{T, n}^{o}$ to 1 as it is not separately identified from $A_{n}$. We also verify the extent to which the modelbased measures of local tourism attractiveness are correlated with our tourism IVs and the calibrated regional hotel sales for both $\widetilde{A_{n}}$ and $A_{n}$. For all three IVs and hotel sales we find a statistically significant correlation as reported in appendix Table A.19.

${ }^{50}$ That is, the possibility of multiple equilibria arises when conducting counterfactual analysis, not at the calibration stage.

${ }^{51}$ See e.g. Fajgelbaum et al. (2015) for a discussion of the estimates of the labor supply elasticity in the literature.
} 
amenity measures used as the outcome variables in the model-based robustness regressions in Table A.5. In particular, we construct three different vectors of regional amenities. Each of them is computed as the residual variation in local population that is left unexplained by variation in real wages (i.e. the residual in specification (18)). We construct this variable three different times, using specification (18), in order to exclude each of the three instruments separately when estimating $\widetilde{\kappa}$. This ensures that we do not build in a mechanical orthogonality condition between local amenities and our instruments when testing whether or not our instruments are correlated with the model-based measures of the local amenities of residents.

\subsubsection{Third Step: Agglomeration Forces}

To fully characterize the effect of tourism on long-run economic outcomes, we require estimates of the within and cross-sector spillovers on manufacturing production $\left(\gamma_{M}, \gamma_{S}\right)$. To estimate these, we combine model-based indirect inference with the exclusion restrictions of the IV strategy that we develop in Section 3. In particular, we derive several moment conditions that must hold under the exclusion restrictions in a counterfactual spatial equilibrium in the absence of tourism activity. We then simulate the model and calibrate the combination of the within and cross-sector agglomeration elasticities such that these moments hold as close as possible through the lens of the calibrated model.

The exclusion restrictions of our empirical strategy above imply that each of the three IVs, which capture different types of ex ante tourism attractiveness, are orthogonal to i) the exogenous manufacturing productivity of places $M_{n}^{o}$, and ii) the counterfactual distribution of population in Mexico in the absence of tourism activity. ${ }^{52}$ Using these restrictions, we define the six following moment conditions:

$$
\begin{aligned}
E\left[z_{n}^{(j)} \log M_{n}^{o}\right] & =0 \text { for } \mathrm{j} \in\{1,2,3\} \text { and } \\
E\left[z_{n}^{(j)} \log L_{n}^{o}\right] & =0 \text { for } \mathrm{j} \in\{1,2,3\},
\end{aligned}
$$

where $\left\{L_{n}^{o}\right\}_{n \in \mathcal{M}}$ denotes the (counterfactual) distribution of population in Mexico absent tourism, $M_{n}^{o}$ is the exogenous component of local productivity, and $z_{n}^{(j)}$ for $j=1 . . .3$ denote the beach, island and ruins instrumental variables. We simulate a counterfactual equilibrium without tourism for a range of candidate parameters $\left(\gamma_{M}, \gamma_{S}\right)$ and compute the correlations corresponding to (19) and (20) in the simulated model. We then identify the parameters for which these correlations are as close as possible to zero. ${ }^{53}$

Importantly, this procedure is based on an otherwise fully calibrated model that matches the current-day equilibrium with tourism, but is computed here for a counterfactual equilibrium

\footnotetext{
${ }^{52}$ Conditional on orthogonality with respect to $M_{n}^{o}$ and $L_{n}^{o}$ in the no-tourism counterfactual equilibrium, no additional information would be provided by adding further orthogonality conditions (e.g. wages, GDP). As in Section 3 , orthogonality is conditional on the controls used in the empirical analysis that we continue to account for.

${ }^{53}$ Specifically, we measure these correlations by regressing the simulated $\log M_{n}^{o}$ and $\log L_{n}^{o}$ on each of the three IVs, conditional on the full set of controls as in Section 3. We then minimize a loss function that is the sum of these regression coefficients, weighted by the inverse of their standard errors. Appendix 4.3 provides additional details.
} 
without tourism. When estimating the agglomeration parameters, this counterfactual accounts and controls for all other general equilibrium forces through which tourism affects regional outcomes, such as input-output linkages to other sectors and migration. The procedure thus identifies the strength of cross and within-sector agglomeration forces required to fit the observed correlation between regional outcomes and the instruments in today's equilibrium reported in Section 3, while imposing zero correlations in the no-tourism counterfactual equilibrium.

The exclusion restrictions together with the structure of the model help us identify both the cross-sector spillover parameter, which requires variation in $L_{S T, n}$, and the within-sector spillover parameter that requires variation in $L_{M, n}$. Each of the three IVs impact both $L_{S T, n}$ and $L_{M, n}$. They impact $L_{S T, n}$ directly through tourism. Given the structure of the model, they also impact $L_{M, n}$ through spillovers and GE effects that make manufacturing employment a function of local tourism shifters. Furthermore, the two sets of moments we define in (19) and (20) provide distinct information to pin down the parameters. In the model, local population is a non-linear function not only of local productivity $M_{n}^{o}$, which corresponds to the first set of moments, but also, through GE linkages and migration, of all of the fundamentals of the calibrated economy. Figure 2 summarizes these forces at work. We show graphically that the six moment conditions jointly identify the two parameters of interest by plotting the loss function that we minimize in the procedure across a range of candidate combinations for $\left(\gamma_{M}, \gamma_{S}\right)$. We find a bowl shape with a single parameter combination that minimizes the loss function across the six moment conditions. To provide further intuition on this result, we also document what the observed local effects of tourism in today's equilibrium would have been under alternative values of $\gamma_{M}$ and $\gamma_{S}$, as we report in the quantification section below.

As depicted in Figure 2, we find that the best-fitting combination of parameters to match our moment conditions is $\widehat{\gamma_{M}}=.064$ (with a standard error of 0.035 ) and $\widehat{\gamma_{S}}=.087$ (s.e.: 0.034). ${ }^{54}$ The value of the within-sector spillover is on the higher end of measures of agglomeration externalities reported in Rosenthal \& Strange (2004), but well within the range of estimates reviewed in for example Melo et al. (2009), and somewhat lower than found in more recent studies (e.g. Adao et al. (2017) , Peters (2017) ). Our estimated cross-sector agglomeration force has no existing references in the literature to compare this to that we are aware of. As part of the quantification below, we also investigate counterfactual results across a range of alternative parameter combinations.

\subsubsection{Link Between Local Effects and Quantification}

As discussed in Section 3, we can at this stage also examine the implications of potential violations of the exclusion restriction in the context of the model-based quantification of the gains from tourism. Upward or downward-biased estimates of tourism's local effects on economic outcomes in today's observed equilibrium in Section 3 would lead to two potential biases in the model's estimation. First, the estimate of $\widetilde{\kappa}$ from regression (18) would be biased in the same direction as the local effects (upward or downward). Second, it would also lead to a bias of our estimate of $\gamma_{S}$ in

\footnotetext{
${ }^{54}$ To obtain standard errors, we bootstrap the procedure accounting for sampling error in both regional data and parameter estimates as described in Appendix 4.4 .
} 
the same direction, as the moment conditions in (20) would be violated. In case of upward-biased local effects, the stronger-than-actual counterfactual population change among touristic places would falsely load onto $\gamma_{S}$, and vice-versa in case of a downward bias. Using these insights, we can explore the sensitivity of our counterfactual analysis to alternative parameter combinations of $\widetilde{\kappa}$ and $\gamma_{S}$, relative to our preferred estimates as the baseline. As discussed below, we also explore a number of additional robustness exercises.

\subsection{Quantification}

Gains from Tourism Table 6 presents our baseline estimates of the welfare gains from tourism, following the methodology described in Section 4.3. ${ }^{55}$ The per-capita welfare gains brought about by tourism amount to 4.82 percent (95\% confidence interval 3.46-9.48). The development of international tourism contributes about 40 percent of these gains (1.84 percent), with the remainder stemming from the gains of inter-regional tourism within Mexico. As discussed in Section 4, these gains are net of the government investments made over time to develop tourism in Mexico, as those are accounted for in our model. In particular, there are a savings associated with moving to a no tourism equilibrium: the counterfactual equilibrium without tourism has no public spending on tourism, and no income tax taken on workers, contrary to the current equilibrium with trade in tourism. ${ }^{56}$

Role of Spillovers Table 6 decomposes these welfare results into the neoclassical gains from tourism development, and those due to agglomeration economies. Interestingly, while the spillovers lead to large regional re-allocations of production in Mexico (rationalizing the large observed local effects), their aggregate effect on Mexican welfare is more muted. In particular, in the absence of spillovers, the welfare gains from tourism development would have been 10 percent lower, at 4.45 percent.

To guide intuition as to what feature of the data is driving our results, we study in Table 7 a series of counterfactuals that correspond to alternative agglomeration forces. For each of these scenarios, Table 7 illustrates what would have been the outcome of the regression analysis of the local effects of tourism, and the corresponding aggregate welfare gains, if the data had been generated by the alternative parameterization of agglomeration forces, holding everything else constant. In particular, the table reports the estimated gains from tourism alongside the point estimates of the following regressions:

$$
\widetilde{\operatorname{sog} G D P_{n}^{j}}=\alpha_{\text {coast }}^{j}+\beta_{1}^{j} \log G D P \text { Tourism }_{n}+\beta^{j^{\prime}} X_{n}+\epsilon_{n}^{j},
$$

where the left-hand side measures model-based long-run regional changes in total GDP when moving from a no-tourism counterfactual equilibrium to today's spatial equilibrium. Each different parameterization of the agglomeration economies $\left(\gamma_{M}, \gamma_{S}\right)$, that we index by $j$ here, yields a

\footnotetext{
${ }^{55}$ The confidence intervals account for measurement error in the regional data we feed into the calibration in Section 5.1 and sampling error in the parameter estimates that enter the first step of the model calibration, as described in Appendix 4.4 .

${ }^{56}$ As discussed in Section 4, in the counterfactual without international tourism, government investments are scaled back in proportion to the calibrated share of foreign tourists across regions in the model.
} 
different cross-section of regional changes in local GDP on the left-hand side. On the right-hand side, we replicate the regression specification in (1), and instrument for local tourism GDP in today's equilibrium (which is equal to the counterfactual change in local tourism GDP in each of the $j$ counterfactuals) with the three IVs as previously in Section 3. ${ }^{57}$ As before, we report (21) both in reduced form (outcome on IVs) and as second-stage IV estimates.

Column 1 of Table 7 explores the case without any spillovers. In this case, tourism has an effect on local GDP that is about 60 percent the size of the effect we observe in the regression analysis ( 0.23 vs 0.4$)$. The effect of tourism on local manufacturing is actually negative in this scenario. In absence of agglomeration forces, the development of tourism increases local factor prices, which in turn adversely affects manufacturing. It also brings about increased local market access (through additional consumer and input demand by tourism), but this alone is insufficient to overturn this adverse effect on traded goods production. In Column 2, we shut down the crosssector agglomeration force $\left(\gamma_{S}=0\right)$, but allow for relatively strong agglomeration economies within manufacturing $\left(\gamma_{M}=0.15\right)$. In this case, the development of tourism barely leads to an increase in local GDP relative to other regions. The adverse local effect of tourism on manufacturing described above is now reinforced by the presence of within-sector agglomeration externalities in manufacturing. The overall welfare gains from tourism are reduced to 0.65 percent. In this case, tourism acts as a special case of the Dutch disease. Resources are reallocated away from manufacturing goods production which, due to economies of scale within manufacturing, has negative implications for manufacturing productivity. Column 3 reports the polar opposite case where only relatively strong cross-sector spillovers are at play $\left(\gamma_{S}=0.15\right)$. The development of tourism has a strong positive effect on local manufacturing productivity which leads to a net positive effect on manufacturing GDP and total local GDP, significantly overshooting the effect in the reducedform analysis and our preferred parameterization in column 4. In the aggregate, this leads to additional welfare benefits of the development of tourism due to a growth in manufacturing productivity that would not have otherwise occurred. Column 4 reports the results for the best fitting parameter values. The effect of tourism on local GDP is close to identical to what we observe in the regression analysis. About 60 percent of the effect of tourism on GDP (0.23) is driven by purely neoclassical channels, reported in column 1. The remainder is driven by agglomeration and co-agglomeration effects.

Finally, as shown in Table 6, an interesting contrast to these findings emerges when we focus on the gains from international-only tourism. Here, we find that the welfare gains brought about by international tourism are slightly dampened compared to what they would have been in the absence of spillovers. This asymmetry in the role of the agglomeration forces between the gains from tourism as a whole and the gains from international tourism relates to our discussion above in Section 4.4. In the case of international tourism, the regions most impacted have on average a lower share of manufacturing than the average regions impacted by domestic tourism across Mex-

\footnotetext{
${ }^{57}$ In these model-based regressions, the IV approach addresses the same types of concerns as discussed in Section 3: the vector of tourism attractiveness shifters $\left(A_{n}\right)$ could be correlated with other local advantages, such as the $M_{n}$ and $B_{n}$, and in addition tourists incur a travel cost so that variation in tourism is also correlated with local market access. To address these confounding factors in (21), we use the three IVs under the same identifying assumptions as before.
} 
ican regions. Because of this, the reallocation of resources away from the manufacturing sector and into the services sector brought about by tourism, moves the economy further away from the optimal mix of sectors, from a spillover standpoint. That is, spillovers losses induced by a lower scale in manufacturing dominate, because these regions start from an already low production point for manufacturing. Overall, these regions have more to loose by loosing manufacturing scale than by gaining scale in services. As a result, the estimated gains from international tourism are slightly lower than the gains that would have occurred in the absence of agglomeration economies (1.84 vs 2.39 percent).

\subsubsection{Extensions and Robustness}

In the final part of the analysis, we investigate the sensitivity of our findings to a number of alternative modeling assumptions and parameter values. In the following, we focus on three sets of additional results, while Appendix 4.6 presents additional results on the estimated gains when taking into account imperfect competition in the tourism sector and repatriation of the corresponding profits abroad. The appendix also explores what the local welfare effects of tourism would have been in the absence of labor mobility.

Alternative Parameter Values We first explore the sensitivity of our estimated gains from tourism to different assumptions about the key parameters determining the size of the estimated gains from tourism. In particular, appendix Table A.23 reports the estimated gains from tourism across a range of parameter combinations for the trade elasticity of tourism $(\beta)$, the spatial labor supply elasticity $(\widetilde{\kappa})$ and the cross-sector co-agglomeration force $\gamma_{S}$. All other parameters are held constant at their values of our baseline calibration discussed above. We render a more detailed discussion of this sensitivity analysis to Appendix 4.6, and focus here on the potential concern that residential amenities may be correlated with the IVs. As discussed above, this violation of the exclusion restriction would lead to upward-biased estimates of both $\widetilde{\kappa}$ and $\gamma_{S}$. Appendix Table A.23 documents two important insights on this question. First, these biases have opposite effects on the welfare gains from tourism: while larger values of the spatial labor supply elasticity result in lower estimated gains from tourism, the opposite is the case for tourism's cross-sector spillover. Second, the analysis sheds light on the sensitivity of our point estimates: for the range of values of $\widetilde{\kappa} \in(2.35,6.35)$ and $\gamma_{S} \in(0,0.087)$, the welfare gains from tourism are estimated to be in the range of 2.56 to 7.25 percent. $^{58}$

Non-Homotheticity With non-homothetic preferences for tourism-related services, part of the observed increase in Mexican tourism since the 1950s could be due to higher incomes. Although this would not invalidate the counterfactual we quantify above, it would matter for the interpretation of the results. To get a sense of the importance of such non-homotheticities, we use microdata from the Mexican income and expenditure surveys for the year 2004 and estimate the tourism Engel curve conditional on municipality-by-period fixed effects, as depicted in appendix

\footnotetext{
${ }^{58}$ For completeness, we also report a second Table $A .24$ where we keep $\gamma_{S}$ at the estimated 0.087 and report the gains from tourism across a range of values of $\widetilde{\kappa} \in(2.35,6.35)$ and $\gamma_{M} \in(0,0.064)$. The estimated gains are in the range of 4.46 and 8.98 .
} 
Figure A.2. Using the estimate of this slope, and the fact that Mexican real GDP per capita grew by 135 percent over the period 1960-2010 (source: World Development Indicators), we find that non-homotheticity in Mexican consumption of tourism contribute about 0.3 percentage points of the long-run change in Mexican tourism GDP. We then re-compute the welfare gains from tourism starting from a current-day equilibrium that assumes away this part of the demand for tourism services. We find that under this metric, non-homotheticities do not play a major role in shaping the welfare gains from tourism in our baseline counterfactual. As presented in appendix Table A.25, we find an estimate of the gains from tourism of 4.74 percent, which is very close to our baseline estimate (4.82).

Transportation Infrastructure The analysis in Section 3 suggests that, while the local effects of tourism are quite robust to conditioning on public spending, part of the positive effect could be driven by better access to transport infrastructure. In the context of our quantitative analysis, this gives rise to the concern that part of the impact of tourism on manufacturing comes from an endogenous reduction in transport costs rather than productivity spillovers. In turn, this could lead to over-stated welfare gains since the estimation of the cross-sector externality $\left(\gamma_{S}\right)$ could be upward biased due to this omitted increase in local market access. We explore the sensitivity of our results to this concern in three different ways. First, we repeat the whole quantitative analysis, but now assume that the development of tourism leads to the construction of federal highways between the top 20 percent of touristic municipalities along the coastline and their nearest state capital. Using GIS, we model this as a 50 percent reduction in bilateral trade costs between any pair of municipalities that are crossed by straight-line connections between the centroids of state capitals and tourism centers. ${ }^{59}$ Second, we instead assume that the development of tourism brings about a 50 percent reduction in the trade costs of these tourism centers with respect to of all of their bilateral trading partners (all domestic regions and RoW). Third, we apply the estimated effect of tourism on bilateral transport costs on the Mexican transport network from Section 3 (Table 5). In particular, we obtain the second-stage IV estimate of that elasticity and use the highest of the three point estimates (0.036 in Table A.26). We then make the assumption that each region's bilateral trade costs fell in proportion to their observed current-day levels of tourism, for regions above the 20th percentile of tourism activity. We assume that trade costs do not change for regions below. In all three counterfactual exercises, touristic regions thus experience an endogenous increase in their transport costs as we move from today's spatial equilibrium to the counterfactual equilibrium in the absence of tourism. As reported in Table A.27, we find estimates of $\gamma_{S}$ and $\gamma_{M}$ that are very close to our baseline estimates, ranging from 0.08-0.086 for $\gamma_{S}$ and 0.07-0.08 for $\gamma_{M}$. As expected, the spillovers from tourism $\gamma_{S}$ are somewhat weaker than in our baseline specification, but the magnitude of these changes is small across all three counterfactuals. In line with this, we find very similar gains from tourism that range between 4.74-5.23 compared to our baseline estimate of 4.82. Overall, these results provide some further reassurance that our findings are unlikely to be biased upwards due to omitted increases in local market access.

\footnotetext{
${ }^{59}$ Based differences in speed limits between Mexican federal highways and rural two-lane roads (110 vs $\left.90 \mathrm{~km} / \mathrm{h}\right)$, the 50 percent reduction would be an upper bound.
} 


\section{Conclusion}

We study the economic consequences of the development of tourism, a fast-growing services sector in developing countries. To do this convincingly and comprehensively, we combine a rich collection of Mexican microdata with a spatial equilibrium model of trade in goods and tourism services and a new empirical strategy. The analysis presents several findings. We find that tourism causes large and significant long-run local economic gains. Given that tourism has had more than five decades to shape relative regional economic outcomes in Mexico in a setting with labor mobility, the raw empirical moment speaking most directly to this effect is the fact that a 10 percent increase in local tourism revenues leads to a 2.5 percent increase in relative local employment and a 2 percent increase in the local population.

We find that these local effects are in part driven by sizable positive multiplier effects on manufacturing production. Taking account of other general equilibrium forces, such as input-output linkages and the gain in market access brought about by tourism, we find that these multiplier effects provide evidence of positive spillovers from the development of the local services sector on traded goods production. In particular, we estimate significant cross-sector spillovers in addition to within-sector localization economies within manufacturing. While these two sources of agglomeration economies reinforce one another locally, leading to the large observed re-allocations of manufacturing and total GDP towards tourism centers in the data, we find that they in part offset one another for the aggregate implications of tourism. That is, while tourism leads to sizable gains in agglomeration economies at the local level, these gains are muted at the national level. Spillover effects contribute to about 10 percent of the total gains from tourism and the aggregate welfare gains are mainly driven by a classical market integration effect.

The analysis serves to inform currently ongoing policy debates in two main ways. First, we provide credible empirical evidence on the long-term effects of tourism activity on economic outcomes. Given that most of the current tourism policies are targeted at investing in the local attractiveness for tourism (the $\widetilde{A_{n}}$ in our framework), our results on both the local and aggregate implications of tourism integration are directly related to these policies. Second, this research provides a useful methodology combining empirical evidence with a spatial equilibrium model to study the propagation of localized and sector-specific economic shocks to aggregate outcomes in other empirical contexts of interest.

\section{References}

Adao, R., Arkolakis, C., \& Esposito, F. (2017). Trade, agglomeration effects and labor markets: Theory and evidence. Yale University Working Paper.

Adao, R., Costinot, A., \& Donaldson, D. (2015). Nonparametric counterfactual predictions in neoclassical models of international trade (Tech. Rep.). National Bureau of Economic Research.

Ahlfeldt, G. M., Redding, S. J., Sturm, D. M., \& Wolf, N. (2015). The economics of density: Evidence from the Berlin wall. forthcoming, Econometrica. 
Allcott, H., \& Keniston, D. (2014). Dutch disease or agglomeration? the local economic effects of natural resource booms in modern america (Tech. Rep.). National Bureau of Economic Research.

Allen, T., \& Arkolakis, C. (2014). Trade and the topography of the spatial economy. The Quarterly Journal of Economics, 1085, 1139.

Allen, T., \& Arkolakis, C. (2016). Optimal city structure (Tech. Rep.).

Allen, T., Arkolakis, C., \& Li, X. (n.d.). On the existence and uniqueness of trade equilibria (Tech. Rep.). Citeseer.

Allen, T., Arkolakis, C., \& Takahashi, Y. (2014). Universal gravity. NBER Working Paper(w20787).

Arezki, R., Cherif, R., \& Piotrowski, J. (2009). Tourism specialization and economic development: Evidence from the unesco world heritage list (No. 9-176). International Monetary Fund.

Arkolakis, C., Costinot, A., \& Rodríguez-Clare, A. (2012). New trade models, same old gains? American Economic Review, 102(1), 94-130.

Atkin, D., Faber, B., \& Gonzalez-Navarro, M. (2015). Retail globalization and household welfare: Evidence from mexico. UC Berkeley mimeo.

Autor, D. H., Dorn, D., \& Hanson, G. H. (2013). The china syndrome: Local labor market effects of import competition in the United States. The American Economic Review, 103(6), 2121-2168.

Baumol, W. J. (1967). Macroeconomics of unbalanced growth: The anatomy of urban crisis. The American economic review, 57(3), 415-426.

Bryan, G., \& Morten, M. (2015). Economic development and the spatial allocation of labor: Evidence from Indonesia. Manuscript, London School of Economics and Stanford University.

Caliendo, L., Dvorkin, M., \& Parro, F. (2015a). The impact of trade on labor market dynamics (Tech. Rep.). National Bureau of Economic Research.

Caliendo, L., Dvorkin, M., \& Parro, F. (2015b). The impact of trade on labor market dynamics (Tech. Rep.).

Caliendo, L., \& Parro, F. (2014). Estimates of the trade and welfare effects of nafta. The Review of Economic Studies, rdu035.

Caliendo, L., Parro, F., Rossi-Hansberg, E., \& Sarte, P.-D. (2014). The impact of regional and sectoral productivity changes on the us economy (Tech. Rep.). National Bureau of Economic Research.

Caselli, F., \& Michaels, G. (2009). Do oil windfalls improve living standards? evidence from brazil (Tech. Rep.). National Bureau of Economic Research.

Copeland, B. R. (1991). Tourism, welfare and de-industrialization in a small open economy. Economica, 515-529.

Davis, M. A., \& Ortalo-Magné, F. (2011). Household expenditures, wages, rents. Review of Economic Dynamics, 14(2), 248-261.

Dekle, R., Eaton, J., \& Kortum, S. (2007). Unbalanced trade. American Economic Review, 97(2), 351-355.

Donaldson, D. (in press). Railroads of the raj: Estimating the impact of transportation infrastructure. American Economic Review. 
Donaldson, D., \& Hornbeck, R. (2015). Railroads and american economic growth: A "market access" approach. The Quarterly Journal of Economics, forthcoming.

Eilat, Y., \& Einav, L. (2004). Determinants of international tourism: a three-dimensional panel data analysis. Applied Economics, 36(12), 1315-1327.

Fajgelbaum, P. D., Morales, E., Serrato, J. C. S., \& Zidar, O. M. (2015). State taxes and spatial misallocation (Tech. Rep.). National Bureau of Economic Research.

FONATUR. (2011). Oportunidades de inversion en el sector turistico Mexicano. Fondo Nacional de Fomento al Turismo.

Francois, J., \& Hoekman, B. (2010). Services trade and policy. Journal of Economic Literature, 48(3), 642-692.

Galle, S., Rodriguez-Clare, A., \& Yi, M. (2014). Slicing the pie: Quantifying the aggregate and distributional effects of trade. Unpublished manuscript, UC Berkeley.

Hawkins, D. E., \& Mann, S. (2007). The world bank's role in tourism development. Annals of Tourism Research, 34(2), 348-363.

Head, K., \& Mayer, T. (2014). Gravity equations: Workhorse, toolkit, and cookbook. Handbook of International Economics, 4, 131.

Herrendorf, B., Rogerson, R., \& Valentinyi, Á. (2014). Growth and structural transformation. In P. Aghion \& S. N. Durlauf (Eds.), Handbook of economic growth (pp. 855-941).

Horowitz, J. L. (2001). The bootstrap. In J. J. Heckman \& E. Leamer (Eds.), Handbook of econometrics (Vol. 5, p. 3159 - 3228). Elsevier.

Hummels, D. (2007). Transportation costs and international trade in the second era of globalization. The Journal of Economic Perspectives, 21(3), 131-154.

Kline, P., \& Moretti, E. (2014). Local economic development, agglomeration economies, and the big push: 100 years of evidence from the tennessee valley authority*. Quarterly Journal of Economics, 129(1).

Leatherman, S. P. (1997). Beach rating: a methodological approach. Journal of coastal research, 253-258.

McGregor, T., \& Wills, S. (2017). Surfing a wave of economic growth. Oxford University Working Paper.

McMillan, M. S., \& Rodrik, D. (2011). Globalization, structural change and productivity growth (Tech. Rep.). National Bureau of Economic Research.

Melo, P. C., Graham, D. J., \& Noland, R. B. (2009). A meta-analysis of estimates of urban agglomeration economies. Regional science and urban Economics, 39(3), 332-342.

Mian, A., \& Sufi, A. (2009). The consequences of mortgage credit expansion: Evidence from the us mortgage default crisis. The Quarterly Journal of Economics, 124(4), 1449-1496.

Monte, F., Redding, S., \& Rossi-Hansberg, E. (2015). Commuting, migration and local employment elasticities (Tech. Rep.).

Peters, M. (2017). Refugees and local agglomeration: Evidence from germany's post-war population expulsions. Yale University Working Paper. 
Redding, S. J. (2016). Goods trade, factor mobility and welfare. Journal of International Economics, $101,148-167$.

Rosenthal, S., \& Strange, W. (2004). Evidence on the nature and sources of agglomeration economies. Handbook of Regional and Urban Economics, 4, 2119-2171.

SECTUR. (2011). Encuesta de flujos del turismo. SECTUR Report.

Sequeira, T. N., \& Macas Nunes, P. (2008). Does tourism influence economic growth? a dynamic panel data approach. Applied Economics, 40(18), 2431-2441.

Silva, J. S., \& Tenreyro, S. (2006). The log of gravity. The Review of Economics and statistics, 88(4), 641-658.

Topalova, P. (2010). Factor immobility and regional impacts of trade liberalization: Evidence on poverty from India. American Economic Journal: Applied Economics, 2(4), 1-41.

Weaver, D., Oppermann, M., et al. (2000). Tourism management. John Wiley and Sons. 


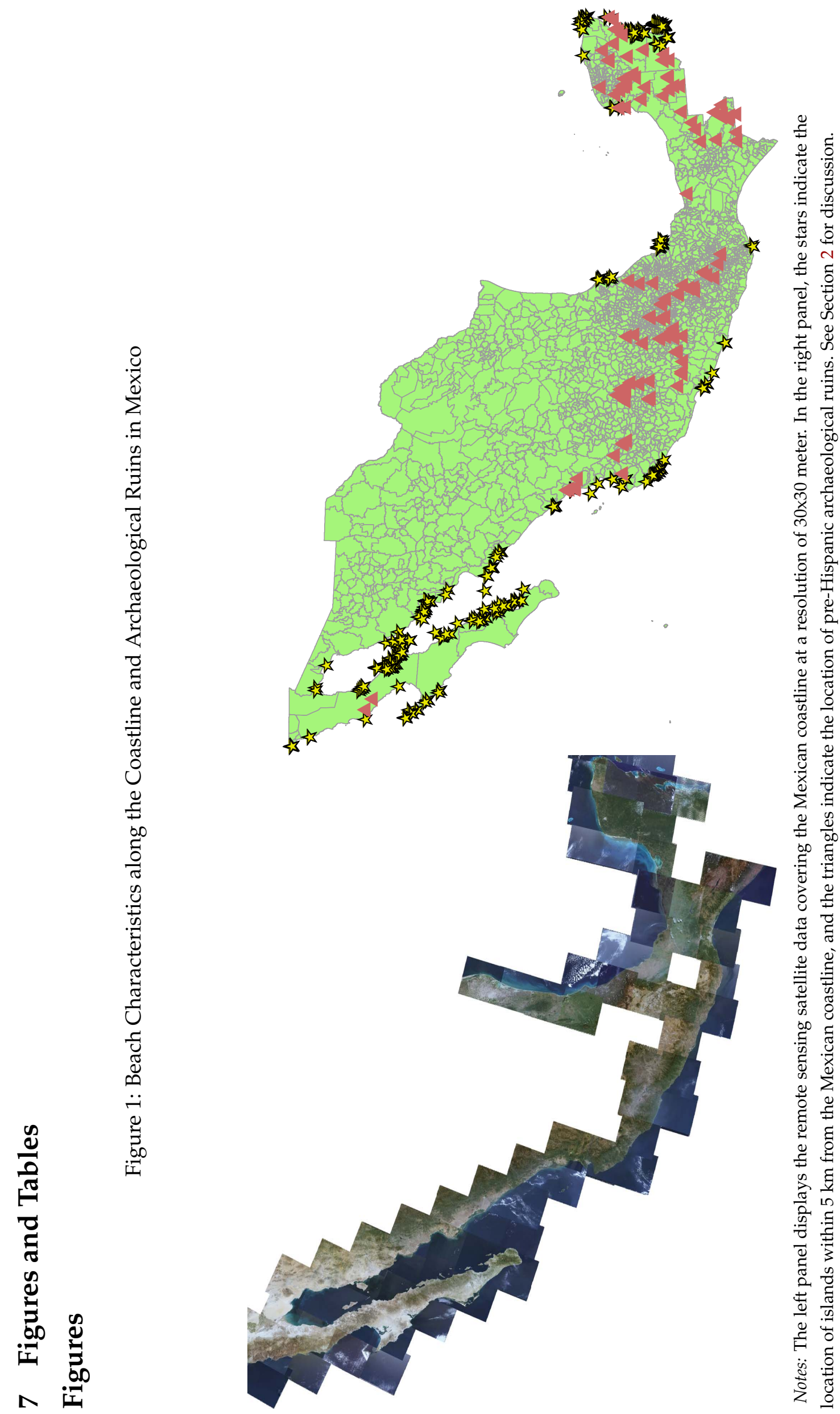


Figure 2: Indirect Inference for Best-Fitting Combination of Agglomeration Forces

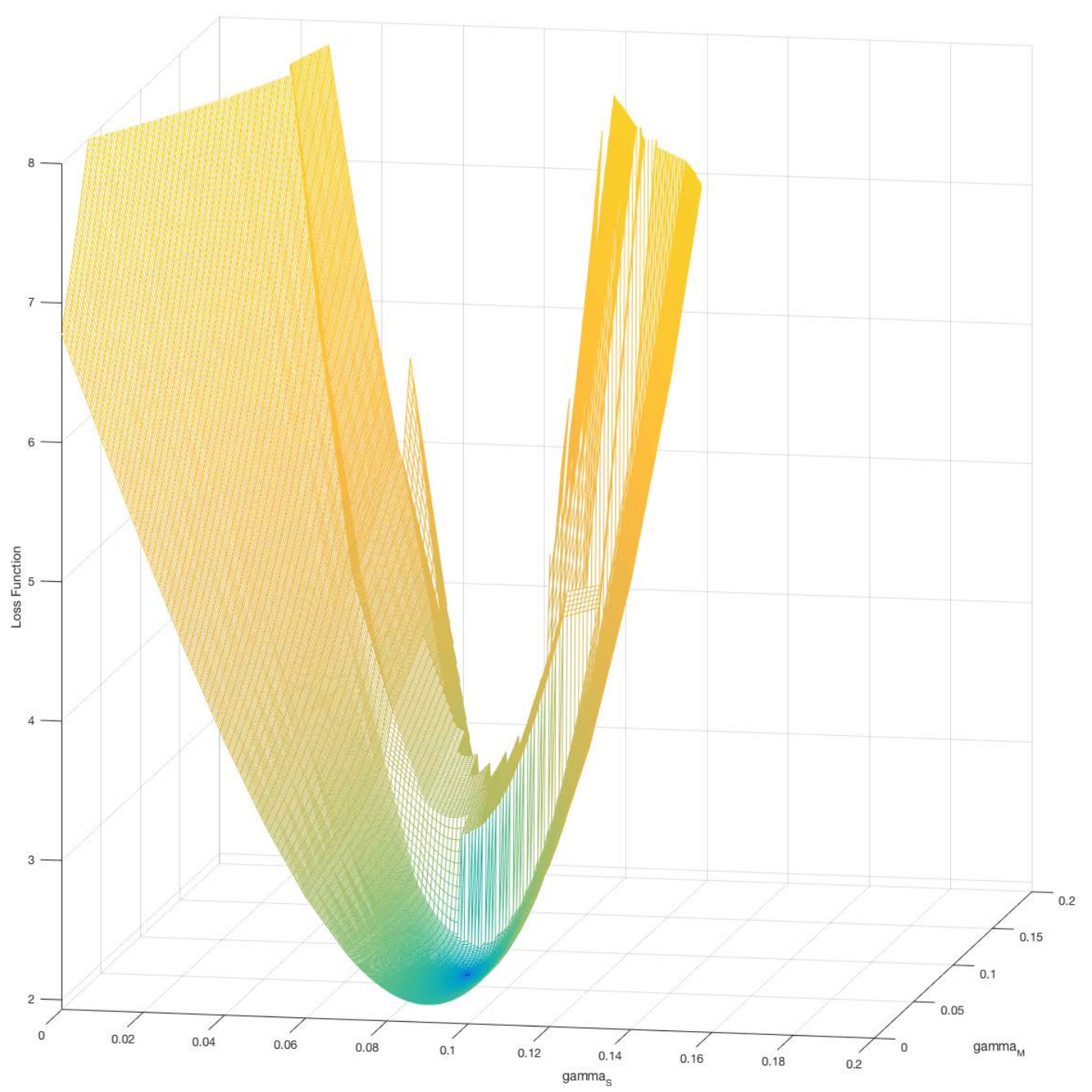

Notes: See Section 5.1 for discussion.

\section{Tables}

Table 1: Beach Tourism in Mexico

\begin{tabular}{lccc}
\hline & $\begin{array}{c}\text { Number of } \\
\text { Municipalities }\end{array}$ & $\begin{array}{c}\text { Sum of Hotel Revenues in 1998 } \\
\text { and 2008 (Thousands of Pesos) }\end{array}$ & $\begin{array}{c}\text { Share of National Hotel } \\
\text { Revenues 1998 and 2008 }\end{array}$ \\
\hline Inland Municipalities & 2305 & $46,070,000$ & 0.365 \\
Coastal Municipalities & 150 & $80,130,000$ & 0.635 \\
\hline
\end{tabular}

Notes: Source: Censos Economicos for 1998 and 2008. 
Table 2: Tourism's Effect on Municipality Employment and Population

\begin{tabular}{|c|c|c|c|c|c|c|c|c|c|c|c|c|}
\hline \multirow[t]{2}{*}{ Dependent variables: } & \multicolumn{10}{|c|}{ Log Municipality Employment 2000, 2010} & \multicolumn{2}{|c|}{$\begin{array}{c}\text { Log Municipality } \\
\text { Population } 2000,2010\end{array}$} \\
\hline & $\begin{array}{l}(1) \\
\text { OLS }\end{array}$ & $\begin{array}{l}\text { (2) } \\
\text { OLS }\end{array}$ & $\begin{array}{c}\text { (3) } \\
\text { Island IV }\end{array}$ & $\begin{array}{c}(4) \\
\text { Island IV }\end{array}$ & $\begin{array}{c}(5) \\
\text { Beach IV }\end{array}$ & $\begin{array}{c}(6) \\
\text { Beach IV }\end{array}$ & $\begin{array}{c}\text { (7) } \\
\text { Ruins IV }\end{array}$ & $\begin{array}{c}(8) \\
\text { Ruins IV }\end{array}$ & $\begin{array}{c}(9) \\
\text { Cobmined }\end{array}$ & $\begin{array}{c}(10) \\
\text { Combined }\end{array}$ & $\begin{array}{c}(11) \\
\text { Combined }\end{array}$ & $\begin{array}{c}(12) \\
\text { Combined }\end{array}$ \\
\hline \multicolumn{13}{|c|}{ Panel A: OLS and IV Regressions } \\
\hline Log Hotel Sales & $\begin{array}{l}0.236^{* * *} \\
(0.00605)\end{array}$ & $\begin{array}{l}0.218^{* * *} \\
(0.00568)\end{array}$ & $\begin{array}{c}0.295 * * * \\
(0.0890)\end{array}$ & $\begin{array}{c}0.323 * * * \\
(0.122)\end{array}$ & $\begin{array}{c}0.234 * * * \\
(0.0793)\end{array}$ & $\begin{array}{c}0.252 * * * \\
(0.0771)\end{array}$ & $\begin{array}{c}0.250 * * * \\
(0.0515)\end{array}$ & $\begin{array}{c}0.215 * * * \\
(0.0544)\end{array}$ & $\begin{array}{c}0.256 * * * \\
(0.0372)\end{array}$ & $\begin{array}{c}0.245 * * * \\
(0.0406)\end{array}$ & $\begin{array}{c}0.211^{* * *} \\
(0.0376)\end{array}$ & $\begin{array}{c}0.200^{* * * *} \\
(0.0416)\end{array}$ \\
\hline Log Distance to US Border & $\begin{array}{c}0.0790^{* *} \\
(0.0386)\end{array}$ & $\begin{array}{l}-0.0290 \\
(0.0416)\end{array}$ & $\begin{array}{l}0.105^{* *} \\
(0.0513)\end{array}$ & $\begin{array}{c}0.0206 \\
(0.0676)\end{array}$ & $\begin{array}{c}0.0783 \\
(0.0529)\end{array}$ & $\begin{array}{l}-0.0129 \\
(0.0547)\end{array}$ & $\begin{array}{l}0.0852 * \\
(0.0442)\end{array}$ & $\begin{array}{l}-0.0306 \\
(0.0484)\end{array}$ & $\begin{array}{c}0.0879 * * \\
(0.0404)\end{array}$ & $\begin{array}{c}-0.0163 \\
(0.0438)\end{array}$ & $\begin{array}{c}0.137^{* * *} \\
(0.0422)\end{array}$ & $\begin{array}{c}0.0341 \\
(0.0460)\end{array}$ \\
\hline Log Distance to Mexico City & $\begin{array}{c}-0.587 * * * \\
(0.0258)\end{array}$ & $\begin{array}{c}-0.578 * * * \\
(0.0284)\end{array}$ & $\begin{array}{c}-0.508^{* * *} \\
(0.122)\end{array}$ & $\begin{array}{c}-0.463 * * * \\
(0.137)\end{array}$ & $\begin{array}{c}-0.590^{* * * *} \\
(0.109)\end{array}$ & $\begin{array}{c}-0.541^{* * *} \\
(0.0882)\end{array}$ & $\begin{array}{c}-0.569^{* * *} \\
(0.0733)\end{array}$ & $\begin{array}{c}-0.581^{* * *} \\
(0.0660)\end{array}$ & $\begin{array}{c}-0.560^{* * *} \\
(0.0557)\end{array}$ & $\begin{array}{c}-0.549^{* * *} \\
(0.0526)\end{array}$ & $\begin{array}{c}-0.596^{* * *} \\
(0.0562)\end{array}$ & $\begin{array}{c}-0.591^{* * *} \\
(0.0539)\end{array}$ \\
\hline Log Municipality Area & $\begin{array}{l}0.340^{* * *} \\
(0.0172)\end{array}$ & $\begin{array}{l}0.351^{* * *} \\
(0.0169)\end{array}$ & $\begin{array}{c}0.263^{* *} \\
(0.118)\end{array}$ & $\begin{array}{c}0.223 \\
(0.150)\end{array}$ & $\begin{array}{c}0.342 * * * \\
(0.105)\end{array}$ & $\begin{array}{c}0.309 * * * \\
(0.0957)\end{array}$ & $\begin{array}{c}0.322 * * * \\
(0.0689)\end{array}$ & $\begin{array}{c}0.355^{* * *} \\
(0.0687)\end{array}$ & $\begin{array}{l}0.314 * * * \\
(0.0514)\end{array}$ & $\begin{array}{l}0.318^{* * * *} \\
(0.0525)\end{array}$ & $\begin{array}{c}0.365^{* * *} \\
(0.0523)\end{array}$ & $\begin{array}{c}0.370^{* * *} \\
(0.0540)\end{array}$ \\
\hline State Capital Dummy & & $\begin{array}{c}0.796^{* * *} \\
(0.191)\end{array}$ & & $\begin{array}{c}0.378 \\
(0.506)\end{array}$ & & $\begin{array}{l}0.660^{*} \\
(0.355)\end{array}$ & & $\begin{array}{c}0.810^{* * * *} \\
(0.294)\end{array}$ & & $\begin{array}{c}0.689 * * * \\
(0.242)\end{array}$ & & $\begin{array}{l}0.627^{* *} \\
(0.256)\end{array}$ \\
\hline Old City Dummy & & $\begin{array}{c}1.028^{* * *} \\
(0.229)\end{array}$ & & $\begin{array}{c}0.624 \\
(0.513)\end{array}$ & & $\begin{array}{l}0.897 * * \\
(0.364)\end{array}$ & & $\begin{array}{c}1.041 * * * \\
(0.313)\end{array}$ & & $\begin{array}{c}0.924 * * * \\
(0.268)\end{array}$ & & $\begin{array}{c}0.920^{* * * *} \\
(0.285)\end{array}$ \\
\hline Colonial Port Dummy & & $\begin{array}{c}0.699 * * * \\
(0.141)\end{array}$ & & $\begin{array}{l}0.300 \\
(0.509)\end{array}$ & & $\begin{array}{l}0.569^{*} \\
(0.321)\end{array}$ & & $\begin{array}{c}0.712 * * * \\
(0.246)\end{array}$ & & $\begin{array}{c}0.597 * * * \\
(0.205)\end{array}$ & & $\begin{array}{c}0.671^{* * *} \\
(0.216)\end{array}$ \\
\hline Log Average Precipitation & & $\begin{array}{c}0.263 * * * \\
(0.0402)\end{array}$ & & $\begin{array}{c}0.244 * * * \\
(0.0483)\end{array}$ & & $\begin{array}{c}0.257 * * * \\
(0.0423)\end{array}$ & & $\begin{array}{c}0.263 * * * \\
(0.0414)\end{array}$ & & $\begin{array}{l}0.258^{* * *} \\
(0.0409)\end{array}$ & & $\begin{array}{l}0.245^{* * *} \\
(0.0415)\end{array}$ \\
\hline Log Average Temperature & & $\begin{array}{c}0.233^{* *} \\
(0.106)\end{array}$ & & $\begin{array}{c}0.194 \\
(0.123)\end{array}$ & & $\begin{array}{c}0.221^{* *} \\
(0.110)\end{array}$ & & $\begin{array}{c}0.235^{* *} \\
(0.108)\end{array}$ & & $\begin{array}{l}0.223 * * \\
(0.107)\end{array}$ & & $\begin{array}{c}0.282^{* * *} \\
(0.106)\end{array}$ \\
\hline Year-By-Coast FX & $\checkmark$ & $\checkmark$ & $\checkmark$ & $\checkmark$ & $\checkmark$ & $\checkmark$ & $\checkmark$ & $\checkmark$ & $\checkmark$ & $\checkmark$ & $\checkmark$ & $\checkmark$ \\
\hline Observations & 4,889 & 4,889 & 4,889 & 4,889 & 4,889 & 4,889 & 4,889 & 4,889 & 4,889 & 4,889 & 4,889 & 4,889 \\
\hline R-squared & 0.659 & 0.682 & & & & & & & & & & \\
\hline Number of Municipalities & 2455 & 2455 & 2455 & 2455 & 2455 & 2455 & 2455 & 2455 & 2455 & 2455 & 2455 & 2455 \\
\hline First Stage F-Stat & & & 9.549 & 5.748 & 15.58 & 15.58 & 25.30 & 21.66 & 17.56 & 15.13 & 17.56 & 15.13 \\
\hline Over-ID Test P-Value & & & & & & & & & 0.879 & 0.662 & 0.834 & 0.699 \\
\hline \multicolumn{13}{|c|}{ Panel B: Reduced-Form Regressions } \\
\hline Island IV & & & $\begin{array}{l}0.587 * * \\
(0.235)\end{array}$ & $\begin{array}{l}0.506^{* *} \\
(0.226)\end{array}$ & & & & & $\begin{array}{c}0.516^{* *} \\
(0.236)\end{array}$ & $\begin{array}{c}0.458^{* *} \\
(0.225)\end{array}$ & $\begin{array}{l}0.448^{*} \\
(0.231)\end{array}$ & $\begin{array}{l}0.407^{*} \\
(0.223)\end{array}$ \\
\hline Beach IV & & & & & $\begin{array}{c}9.028^{* *} \\
(3.738)\end{array}$ & $\begin{array}{c}9.703 * * * \\
(3.534)\end{array}$ & & & $\begin{array}{l}8.617^{* *} \\
(4.016)\end{array}$ & $\begin{array}{c}9.459 * * \\
(3.776)\end{array}$ & $\begin{array}{c}6.375 \\
(4.191)\end{array}$ & $\begin{array}{l}7.217^{*} \\
(3.970)\end{array}$ \\
\hline Ruins IV & & & & & & & $\begin{array}{c}0.504 * * * \\
(0.148)\end{array}$ & $\begin{array}{c}0.366^{* * *} \\
(0.118)\end{array}$ & $\begin{array}{c}0.451 * * * \\
(0.151)\end{array}$ & $\begin{array}{c}0.317^{* * *} \\
(0.118)\end{array}$ & $\begin{array}{c}0.378^{* * *} \\
(0.142)\end{array}$ & $\begin{array}{l}0.258^{* *} \\
(0.114)\end{array}$ \\
\hline Year-By-Coast FX & & & $\checkmark$ & $\checkmark$ & $\checkmark$ & $\checkmark$ & $\checkmark$ & $\checkmark$ & $\checkmark$ & $\checkmark$ & $\checkmark$ & $\checkmark$ \\
\hline Full Set of Controls & & & & $\checkmark$ & & $\checkmark$ & & $\checkmark$ & & $\checkmark$ & & $\checkmark$ \\
\hline Observations & & & 4,889 & 4,889 & 4,889 & 4,889 & 4,889 & 4,889 & 4,889 & 4,889 & 4,889 & 4,889 \\
\hline R-squared & & & 0.400 & 0.478 & 0.399 & 0.478 & 0.401 & 0.478 & 0.403 & 0.480 & 0.409 & 0.476 \\
\hline Number of Municipalities & & & 2455 & 2455 & 2455 & 2455 & 2455 & 2455 & 2455 & 2455 & 2455 & 2455 \\
\hline
\end{tabular}

Notes: See Section 3 for discussion. Island IV is a dummy indicating whether an offshore island is within 5 km of the municipalities' coastline. Beach IV is the fraction of municipality area within $100 \mathrm{~m}$ of the coastline covered by white sand pixels that lie within the wavelength ranges of the 8 top-ranked Mexican beaches. Ruins IV is a dummy indicating the presence of pre-Hispanic archaeological ruins. Log hotel sales are measured with the hyperbolic inverse sine transformation as described in Section 3. Standard errors are clustered at the level of municipalities. ${ }^{*} 10 \%,{ }^{* *} 5 \%, * * * 1 \%$ significance levels. 
Table 3: Tourism's Effect on Municipality Wage Bill, GDP by Sector and Wages

\begin{tabular}{|c|c|c|c|c|c|c|c|c|c|c|c|c|c|c|}
\hline \multirow{4}{*}{ Dependent Variables: } & \multicolumn{12}{|c|}{ Censos Economicos 1998, 2008} & \multicolumn{2}{|c|}{ Population Census 2000, 2010} \\
\hline & (1) & (2) & (3) & (4) & (5) & (6) & \multirow{3}{*}{$\begin{array}{c}(7) \\
\text { Log GDP } \\
(\text { Manu+ } \\
\text { Mining) } \\
\text { OLS } \\
\end{array}$} & \multirow{3}{*}{$\begin{array}{c}(8) \\
\text { Log GDP } \\
\text { (Manu+ } \\
\text { Mining) } \\
\text { Three IVs }\end{array}$} & \multirow{3}{*}{$\begin{array}{c}(9) \\
\text { Log GDP } \\
\text { (Manu) } \\
\text { OLS }\end{array}$} & \multirow{3}{*}{$\begin{array}{c}(10) \\
\begin{array}{c}\text { Log GDP } \\
\text { (Manu) }\end{array} \\
\text { Three IVs } \\
\end{array}$} & \multirow{3}{*}{$\begin{array}{c}(11) \\
\text { Log GDP } \\
\text { (Agri) } \\
\text { OLS } \\
\end{array}$} & \multirow{3}{*}{$\begin{array}{c}(12) \\
\text { Log GDP } \\
\text { (Agri) } \\
\text { Three IVs } \\
\end{array}$} & \multirow{3}{*}{$\begin{array}{c}\text { (13) } \\
\text { Log Wage } \\
\text { Residual } \\
\text { OLS } \\
\end{array}$} & \multirow{3}{*}{$\begin{array}{c}(14) \\
\text { Log Wage } \\
\text { Residual } \\
\text { Three IVs } \\
\end{array}$} \\
\hline & $\begin{array}{l}\text { Log Labor } \\
\text { Income }\end{array}$ & $\begin{array}{l}\text { Log Labor } \\
\text { Income }\end{array}$ & Log GDP & Log GDP & $\begin{array}{c}\text { Log GDP } \\
\text { (w/o Hotel) }\end{array}$ & $\begin{array}{c}\text { Log GDP } \\
\text { (w/o Hotel) }\end{array}$ & & & & & & & & \\
\hline & OLS & Three IVs & OLS & Three IVs & OLS & Three IVs & & & & & & & & \\
\hline \multicolumn{15}{|c|}{ Panel A: OLS and IV Regressions } \\
\hline Log Hotel Sales & $\begin{array}{c}0.480 * * * \\
(0.0104)\end{array}$ & $\begin{array}{c}0.475 * * * \\
(0.0691)\end{array}$ & $\begin{array}{c}0.464 * * * \\
(0.0104)\end{array}$ & $\begin{array}{c}0.404 * * * \\
(0.0713)\end{array}$ & $\begin{array}{c}0.458^{* * *} \\
(0.0106)\end{array}$ & $\begin{array}{l}0.380 * * * \\
(0.0732)\end{array}$ & $\begin{array}{c}0.516^{* * *} \\
(0.0144)\end{array}$ & $\begin{array}{c}0.335 * * * \\
(0.102)\end{array}$ & $\begin{array}{c}0.530^{* * *} \\
(0.0146)\end{array}$ & $\begin{array}{c}0.394 * * * \\
(0.0939)\end{array}$ & $\begin{array}{c}0.291 * * * \\
(0.0164)\end{array}$ & $\begin{array}{c}0.102 \\
(0.150)\end{array}$ & $\begin{array}{c}0.0220 * * * \\
(0.00309)\end{array}$ & $\begin{array}{c}0.0446 * * * \\
(0.00572)\end{array}$ \\
\hline Log Distance to US Border & $\begin{array}{c}-0.364 * * * \\
(0.0713)\end{array}$ & $\begin{array}{c}-0.367 * * * \\
(0.0758)\end{array}$ & $\begin{array}{c}-0.299 * * * \\
(0.0691)\end{array}$ & $\begin{array}{c}-0.328^{* * *} \\
(0.0768)\end{array}$ & $\begin{array}{c}-0.304 * * * \\
(0.0696)\end{array}$ & $\begin{array}{c}-0.341^{* * *} \\
(0.0783)\end{array}$ & $\begin{array}{c}-0.290^{* * *} \\
(0.105)\end{array}$ & $\begin{array}{c}-0.376^{* * *} \\
(0.118)\end{array}$ & $\begin{array}{l}-0.181^{*} \\
(0.105)\end{array}$ & $\begin{array}{c}-0.245^{* *} \\
(0.116)\end{array}$ & $\begin{array}{c}0.267^{* *} \\
(0.107)\end{array}$ & $\begin{array}{c}0.178 \\
(0.136)\end{array}$ & $\begin{array}{c}-0.0550 * * * \\
(0.0106)\end{array}$ & $\begin{array}{c}-0.0403 * * * \\
(0.00889)\end{array}$ \\
\hline Log Distance to Mexico City & $\begin{array}{c}-0.641^{* * *} \\
(0.0510)\end{array}$ & $\begin{array}{c}-0.647 * * * \\
(0.0876)\end{array}$ & $\begin{array}{c}-0.705^{* * *} \\
(0.0489)\end{array}$ & $\begin{array}{c}-0.770 * * * \\
(0.0919)\end{array}$ & $\begin{array}{c}-0.711 * * * \\
(0.0494)\end{array}$ & $\begin{array}{c}-0.796^{* * *} \\
(0.0944)\end{array}$ & $\begin{array}{c}-0.871^{* * *} \\
(0.0678)\end{array}$ & $\begin{array}{c}-1.068 * * * \\
(0.132)\end{array}$ & $\begin{array}{c}-0.889 * * * \\
(0.0690)\end{array}$ & $\begin{array}{c}-1.038^{* * *} \\
(0.124)\end{array}$ & $\begin{array}{c}-0.231 * * * \\
(0.0753)\end{array}$ & $\begin{array}{c}-0.438^{* *} \\
(0.180)\end{array}$ & $\begin{array}{l}0.00860 \\
(0.0103)\end{array}$ & $\begin{array}{l}0.0188 * * \\
(0.00943)\end{array}$ \\
\hline Log Municipality Area & $\begin{array}{c}0.183 * * * \\
(0.0323)\end{array}$ & $\begin{array}{l}0.190^{* *} \\
(0.0901)\end{array}$ & $\begin{array}{c}0.217 * * * \\
(0.0310)\end{array}$ & $\begin{array}{l}0.290 * * * \\
(0.0929)\end{array}$ & $\begin{array}{c}0.221 * * * \\
(0.0313)\end{array}$ & $\begin{array}{c}0.316^{* * *} \\
(0.0954)\end{array}$ & $\begin{array}{c}0.181^{* * *} \\
(0.0430)\end{array}$ & $\begin{array}{c}0.402 * * * \\
(0.133)\end{array}$ & $\begin{array}{c}0.112 * * * \\
(0.0428)\end{array}$ & $\begin{array}{l}0.278 * * \\
(0.123)\end{array}$ & $\begin{array}{c}0.451 * * * \\
(0.0435)\end{array}$ & $\begin{array}{c}0.683 * * * \\
(0.186)\end{array}$ & $\begin{array}{l}-0.0167 * * \\
(0.00833)\end{array}$ & $\begin{array}{c}-0.0272 * * * \\
(0.00756)\end{array}$ \\
\hline State Capital Dummy & $\begin{array}{c}1.224 * * * \\
(0.207)\end{array}$ & $\begin{array}{c}1.247 * * * \\
(0.344)\end{array}$ & $\begin{array}{c}1.164 * * * \\
(0.210)\end{array}$ & $\begin{array}{c}1.403 * * * \\
(0.369)\end{array}$ & $\begin{array}{c}1.197 * * * \\
(0.214)\end{array}$ & $\begin{array}{c}1.508^{* * *} \\
(0.383)\end{array}$ & $\begin{array}{l}0.689 * * \\
(0.319)\end{array}$ & $\begin{array}{l}1.409 * * \\
(0.558)\end{array}$ & $\begin{array}{l}0.736^{* *} \\
(0.348)\end{array}$ & $\begin{array}{l}1.278 * * \\
(0.538)\end{array}$ & $\begin{array}{l}0.287 \\
(0.661)\end{array}$ & $\begin{array}{c}1.043 \\
(0.983)\end{array}$ & $\begin{array}{c}0.0233 \\
(0.0298)\end{array}$ & $\begin{array}{l}-0.0183 \\
(0.0286)\end{array}$ \\
\hline Old City Dummy & $\begin{array}{c}1.310^{* * *} \\
(0.240)\end{array}$ & $\begin{array}{c}1.332 * * * \\
(0.360)\end{array}$ & $\begin{array}{c}1.307 * * * \\
(0.242)\end{array}$ & $\begin{array}{c}1.537 * * * \\
(0.390)\end{array}$ & $\begin{array}{c}1.324 * * * \\
(0.246)\end{array}$ & $\begin{array}{c}1.624 * * * \\
(0.406)\end{array}$ & $\begin{array}{c}1.242 * * * \\
(0.363)\end{array}$ & $\begin{array}{c}1.937 * * * \\
(0.598)\end{array}$ & $\begin{array}{c}1.241 * * * \\
(0.394)\end{array}$ & $\begin{array}{c}1.764 * * * \\
(0.579)\end{array}$ & $\begin{array}{c}0.733 \\
(0.809)\end{array}$ & $\begin{array}{c}1.463 \\
(1.079)\end{array}$ & $\begin{array}{l}-0.00604 \\
(0.0299)\end{array}$ & $\begin{array}{c}-0.0685^{* *} \\
(0.0339)\end{array}$ \\
\hline Colonial Port Dummy & $\begin{array}{c}0.829^{* *} \\
(0.325)\end{array}$ & $\begin{array}{l}0.850^{* *} \\
(0.400)\end{array}$ & $\begin{array}{c}0.548 \\
(0.446)\end{array}$ & $\begin{array}{l}0.775^{*} \\
(0.448)\end{array}$ & $\begin{array}{c}0.551 \\
(0.486)\end{array}$ & $\begin{array}{l}0.848^{*} \\
(0.467)\end{array}$ & $\begin{array}{c}0.400 \\
(0.959)\end{array}$ & $\begin{array}{c}1.087 \\
(0.807)\end{array}$ & $\begin{array}{c}0.462 \\
(0.962)\end{array}$ & $\begin{array}{c}0.979 \\
(0.850)\end{array}$ & $\begin{array}{l}-0.873 \\
(0.739)\end{array}$ & $\begin{array}{c}-0.152 \\
(1.161)\end{array}$ & $\begin{array}{c}-0.132 * * * \\
(0.0435)\end{array}$ & $\begin{array}{l}-0.171^{* *} \\
(0.0707)\end{array}$ \\
\hline Log Average Precipitation & $\begin{array}{c}-0.629 * * * \\
(0.0807)\end{array}$ & $\begin{array}{c}-0.627 * * * \\
(0.0827)\end{array}$ & $\begin{array}{c}-0.578 * * * \\
(0.0760)\end{array}$ & $\begin{array}{c}-0.567 * * * \\
(0.0787)\end{array}$ & $\begin{array}{c}-0.577 * * * \\
(0.0765)\end{array}$ & $\begin{array}{c}-0.564 * * * \\
(0.0799)\end{array}$ & $\begin{array}{c}-0.960^{* * *} \\
(0.106)\end{array}$ & $\begin{array}{c}-0.928 * * * \\
(0.113)\end{array}$ & $\begin{array}{c}-0.937 * * * \\
(0.106)\end{array}$ & $\begin{array}{c}-0.913 * * * \\
(0.110)\end{array}$ & $\begin{array}{l}-0.182 \\
(0.111)\end{array}$ & $\begin{array}{l}-0.149 \\
(0.118)\end{array}$ & $\begin{array}{c}-0.0956 * * * \\
(0.0146)\end{array}$ & $\begin{array}{c}-0.0921 * * * \\
(0.0166)\end{array}$ \\
\hline Log Average Temperature & $\begin{array}{l}0.577 * * * \\
(0.197)\end{array}$ & $\begin{array}{l}0.578^{* * *} \\
(0.197)\end{array}$ & $\begin{array}{l}1.069^{* * *} \\
(0.184)\end{array}$ & $\begin{array}{l}1.092^{* * *} \\
(0.188)\end{array}$ & $\begin{array}{l}1.077^{* * *} \\
(0.186)\end{array}$ & $\begin{array}{l}1.107^{* * *} \\
(0.191)\end{array}$ & $\begin{array}{l}1.394 * * * \\
(0.270)\end{array}$ & $\begin{array}{l}1.463^{* * * *} \\
(0.282)\end{array}$ & $\begin{array}{l}1.437 * * * \\
(0.276)\end{array}$ & $\begin{array}{l}1.489^{* * *} \\
(0.283)\end{array}$ & $\begin{array}{l}2.367^{* * *} \\
(0.305)\end{array}$ & $\begin{array}{l}2.439 * * * \\
(0.319)\end{array}$ & $\begin{array}{c}-0.167^{* * *} \\
(0.0389)\end{array}$ & $\begin{array}{c}-0.232 * * * \\
(0.0479)\end{array}$ \\
\hline Year-By-Coast FX & $\checkmark$ & $\checkmark$ & $\checkmark$ & $\checkmark$ & $\checkmark$ & $\checkmark$ & $\checkmark$ & $\checkmark$ & $\checkmark$ & $\checkmark$ & $\checkmark$ & $\checkmark$ & $\checkmark$ & $\checkmark$ \\
\hline Observations & 4,596 & 4,596 & 4,889 & 4,889 & 4,889 & 4,889 & 4,889 & 4,889 & 4,889 & 4,889 & 4,889 & 4,889 & $5,490,558$ & $5,490,558$ \\
\hline R-squared & 0.636 & & 0.643 & & 0.636 & & 0.506 & & 0.507 & & 0.429 & & 0.390 & \\
\hline Number of Municipalities & 2385 & 2385 & 2455 & 2455 & 2455 & 2455 & 2455 & 2455 & 2455 & 2455 & 2455 & 2455 & 2455 & 2455 \\
\hline First Stage F-Stat & & 14.93 & & 15.13 & & 15.13 & & 15.13 & & 15.13 & & 15.13 & & 53.26 \\
\hline Over-ID Test P-Value & & 0.668 & & 0.302 & & 0.353 & & 0.271 & & 0.457 & & 0.307 & & 0.992 \\
\hline & & & & & Panel B & 3: Reduced-F & Form Regress & sions & & & & & & \\
\hline Island IV & & $\begin{array}{c}0.461 \\
(0.369)\end{array}$ & & $\begin{array}{c}0.280 \\
(0.377)\end{array}$ & & $\begin{array}{c}0.242 \\
(0.374)\end{array}$ & & $\begin{array}{l}-0.0746 \\
(0.457)\end{array}$ & & $\begin{array}{c}0.114 \\
(0.420)\end{array}$ & & $\begin{array}{l}0.764^{*} \\
(0.461)\end{array}$ & & $\begin{array}{c}0.0596 \\
(0.0372)\end{array}$ \\
\hline Beach IV & & $\begin{array}{c}19.63 * * * \\
(5.581)\end{array}$ & & $\begin{array}{c}19.67 * * * \\
(5.031)\end{array}$ & & $\begin{array}{c}18.38^{* * * *} \\
(5.006)\end{array}$ & & $\begin{array}{c}16.00 * * * \\
(5.384)\end{array}$ & & $\begin{array}{c}15.45 * * * \\
(5.081)\end{array}$ & & $\begin{array}{c}1.416 \\
(8.254)\end{array}$ & & $\begin{array}{c}1.981 * * * \\
(0.277)\end{array}$ \\
\hline Ruins IV & & $\begin{array}{c}0.735^{* * *} \\
(0.234)\end{array}$ & & $\begin{array}{c}0.601 * * * \\
(0.232)\end{array}$ & & $\begin{array}{c}0.578^{* *} \\
(0.233)\end{array}$ & & $\begin{array}{l}0.626^{* *} \\
(0.285)\end{array}$ & & $\begin{array}{c}0.745 * * * \\
(0.287)\end{array}$ & & $\begin{array}{l}-0.0246 \\
(0.395)\end{array}$ & & $\begin{array}{l}-0.0286 \\
(0.0263)\end{array}$ \\
\hline Year-By-Coast FX & & $\checkmark$ & & $\checkmark$ & & $\checkmark$ & & $\checkmark$ & & $\checkmark$ & & $\checkmark$ & & $\checkmark$ \\
\hline Full Set of Controls & & $\checkmark$ & & $\checkmark$ & & $\checkmark$ & & $\checkmark$ & & $\checkmark$ & & $\checkmark$ & & $\checkmark$ \\
\hline Observations & & 4,596 & & 4,889 & & 4,889 & & 4,889 & & 4,889 & & 4,889 & & $5,490,558$ \\
\hline R-squared & & 0.362 & & 0.382 & & 0.381 & & 0.287 & & 0.274 & & 0.365 & & 0.379 \\
\hline Number of Municipalities & & 2385 & & 2455 & & 2455 & & 2455 & & 2455 & & 2455 & & 2455 \\
\hline
\end{tabular}

Notes: See Section 3 for discussion. Regressions in the final two columns are weighted using population weights and also include controls for gender, ethnicity and 3rd-order polynomials for age and years of education. Standard errors are clustered at the level of municipalities. ${ }^{*} 10 \%, * * 5 \%$, *** $1 \%$ significance levels. 
Table 4: Placebo Falsification Tests

\begin{tabular}{|c|c|c|c|c|c|c|c|c|c|c|c|c|}
\hline \multirow{4}{*}{$\begin{array}{l}\text { Dependent Variable: } \\
\text { Census Years: }\end{array}$} & \multicolumn{12}{|c|}{ Log Municipality Census Population } \\
\hline & (1) & (2) & (3) & (4) & (5) & (6) & (7) & (8) & (9) & (10) & (11) & (12) \\
\hline & \multicolumn{2}{|c|}{$1921,1930,1940,1950$} & \multicolumn{2}{|c|}{2000,2010} & \multicolumn{2}{|c|}{$1921,1930,1940,1950$} & \multicolumn{2}{|c|}{2000,2010} & \multicolumn{2}{|c|}{$1921,1930,1940,1950$} & \multicolumn{2}{|c|}{2000,2010} \\
\hline & Island IV & Island IV & Island IV & Island IV & Beach IV & Beach IV & Beach IV & Beach IV & Ruins IV & Ruins IV & Ruins IV & Ruins IV \\
\hline \multicolumn{13}{|c|}{ Panel A: Left Hand Side with Inverse Hyperbolic Sine Transformation for Log Population } \\
\hline Instrumental Variable & $\begin{array}{l}-0.151 \\
(0.350)\end{array}$ & $\begin{array}{l}-0.197 \\
(0.347)\end{array}$ & $\begin{array}{c}0.510^{* *} \\
(0.233)\end{array}$ & $\begin{array}{l}0.430^{*} \\
(0.221)\end{array}$ & $\begin{array}{l}-15.69 * \\
(9.458)\end{array}$ & $\begin{array}{l}-15.67 \\
(9.639)\end{array}$ & $\begin{array}{c}6.601 \\
(4.031)\end{array}$ & $\begin{array}{l}6.635^{* *} \\
(3.091)\end{array}$ & $\begin{array}{l}-0.0152 \\
(0.234)\end{array}$ & $\begin{array}{l}-0.0770 \\
(0.236)\end{array}$ & $\begin{array}{c}0.437 * * * \\
(0.142)\end{array}$ & $\begin{array}{c}0.329^{* *} \\
(0.135)\end{array}$ \\
\hline Log Distance to US Border & $\begin{array}{c}0.121^{*} \\
(0.0636)\end{array}$ & $\begin{array}{l}0.149^{* *} \\
(0.0635)\end{array}$ & $\begin{array}{c}0.0415 \\
(0.0574)\end{array}$ & $\begin{array}{l}0.0909^{*} \\
(0.0534)\end{array}$ & $\begin{array}{l}0.126^{* *} \\
(0.0634)\end{array}$ & $\begin{array}{l}0.154 * * \\
(0.0632)\end{array}$ & $\begin{array}{c}0.0386 \\
(0.0578)\end{array}$ & $\begin{array}{c}0.0883 \\
(0.0538)\end{array}$ & $\begin{array}{c}0.122^{*} \\
(0.0623)\end{array}$ & $\begin{array}{l}0.152^{* *} \\
(0.0619)\end{array}$ & $\begin{array}{c}0.0258 \\
(0.0580)\end{array}$ & $\begin{array}{c}0.0788 \\
(0.0540)\end{array}$ \\
\hline Log Distance to Mexico City & $\begin{array}{c}-0.419^{* * *} \\
(0.0574)\end{array}$ & $\begin{array}{c}-0.394 * * * \\
(0.0571)\end{array}$ & $\begin{array}{c}-0.878 * * * \\
(0.0321)\end{array}$ & $\begin{array}{c}-0.836 * * * \\
(0.0326)\end{array}$ & $\begin{array}{c}-0.413 * * * \\
(0.0574)\end{array}$ & $\begin{array}{c}-0.388^{* * *} \\
(0.0570)\end{array}$ & $\begin{array}{c}-0.880^{* * * *} \\
(0.0322)\end{array}$ & $\begin{array}{c}-0.837 * * * \\
(0.0327)\end{array}$ & $\begin{array}{c}-0.419 * * * \\
(0.0576)\end{array}$ & $\begin{array}{c}-0.395 * * * \\
(0.0572)\end{array}$ & $\begin{array}{c}-0.873 * * * \\
(0.0322)\end{array}$ & $\begin{array}{c}-0.832 * * * \\
(0.0327)\end{array}$ \\
\hline Log Municipality Area & $\begin{array}{c}0.497 * * * \\
(0.0215)\end{array}$ & $\begin{array}{c}0.430^{* * * *} \\
(0.0220)\end{array}$ & $\begin{array}{c}0.633 * * * \\
(0.0205)\end{array}$ & $\begin{array}{c}0.515 * * * \\
(0.0205)\end{array}$ & $\begin{array}{c}0.495 * * * \\
(0.0214)\end{array}$ & $\begin{array}{c}0.427 * * * \\
(0.0220)\end{array}$ & $\begin{array}{c}0.637^{* * * *} \\
(0.0204)\end{array}$ & $\begin{array}{c}0.518^{* * *} \\
(0.0205)\end{array}$ & $\begin{array}{c}0.497 * * * \\
(0.0195)\end{array}$ & $\begin{array}{c}0.430 * * * \\
(0.0205)\end{array}$ & $\begin{array}{c}0.627 * * * \\
(0.0206)\end{array}$ & $\begin{array}{r}0.511 * * * \\
(0.0208)\end{array}$ \\
\hline Log Km of Major Roads 1940 & & $\begin{array}{c}0.117^{* * *} \\
(0.0116)\end{array}$ & & $\begin{array}{c}0.205^{* * *} \\
(0.0113)\end{array}$ & & $\begin{array}{c}0.117 * * * \\
(0.0116)\end{array}$ & & $\begin{array}{c}0.205 * * * \\
(0.0113)\end{array}$ & & $\begin{array}{c}0.117 * * * \\
(0.0114)\end{array}$ & & $\begin{array}{c}0.204 * * * \\
(0.0113)\end{array}$ \\
\hline Year-By-Coast FX & $\checkmark$ & $\checkmark$ & $\checkmark$ & $\checkmark$ & $\checkmark$ & $\checkmark$ & $\checkmark$ & $\checkmark$ & $\checkmark$ & $\checkmark$ & $\checkmark$ & $\checkmark$ \\
\hline Observations & 9,736 & 9,736 & 4,868 & 4,868 & 9,736 & 9,736 & 4,868 & 4,868 & 9,736 & 9,736 & 4,868 & 4,868 \\
\hline R-Squared & 0.231 & 0.256 & 0.400 & 0.469 & 0.234 & 0.260 & 0.399 & 0.469 & 0.230 & 0.256 & 0.401 & 0.469 \\
\hline Number of Municipalities & 2434 & 2434 & 2434 & 2434 & 2434 & 2434 & 2434 & 2434 & 2434 & 2434 & 2434 & 2434 \\
\hline \multicolumn{13}{|c|}{ Panel B: Left Hand Side with Log of One for Zero Population } \\
\hline Instrumental Variable & $\begin{array}{c}-0.144 \\
(0.337)\end{array}$ & $\begin{array}{l}-0.189 \\
(0.334)\end{array}$ & $\begin{array}{l}0.510 * * \\
(0.233)\end{array}$ & $\begin{array}{l}0.430^{*} \\
(0.221)\end{array}$ & $\begin{array}{l}-15.62 * \\
(9.413)\end{array}$ & $\begin{array}{l}-15.60 \\
(9.596)\end{array}$ & $\begin{array}{c}6.601 \\
(4.031)\end{array}$ & $\begin{array}{l}6.635^{* *} \\
(3.091)\end{array}$ & $\begin{array}{c}0.000341 \\
(0.223)\end{array}$ & $\begin{array}{l}-0.0611 \\
(0.225)\end{array}$ & $\begin{array}{c}0.437 * * * \\
(0.142)\end{array}$ & $\begin{array}{l}0.329^{* *} \\
(0.135)\end{array}$ \\
\hline Log Distance to US Border & $\begin{array}{c}0.116^{*} \\
(0.0607)\end{array}$ & $\begin{array}{l}0.144 * * \\
(0.0605)\end{array}$ & $\begin{array}{c}0.0415 \\
(0.0574)\end{array}$ & $\begin{array}{l}0.0909 * \\
(0.0534)\end{array}$ & $\begin{array}{l}0.120^{* *} \\
(0.0605)\end{array}$ & $\begin{array}{l}0.149 * * \\
(0.0603)\end{array}$ & $\begin{array}{c}0.0386 \\
(0.0578)\end{array}$ & $\begin{array}{c}0.0883 \\
(0.0538)\end{array}$ & $\begin{array}{c}0.116^{*} \\
(0.0595)\end{array}$ & $\begin{array}{l}0.146 * * \\
(0.0591)\end{array}$ & $\begin{array}{c}0.0258 \\
(0.0580)\end{array}$ & $\begin{array}{c}0.0788 \\
(0.0540)\end{array}$ \\
\hline Log Distance to Mexico City & $\begin{array}{c}-0.427 * * * \\
(0.0542)\end{array}$ & $\begin{array}{c}-0.403 * * * \\
(0.0538)\end{array}$ & $\begin{array}{c}-0.878 * * * \\
(0.0321)\end{array}$ & $\begin{array}{c}-0.836 * * * \\
(0.0326)\end{array}$ & $\begin{array}{c}-0.421 * * * \\
(0.0542)\end{array}$ & $\begin{array}{c}-0.397 * * * \\
(0.0538)\end{array}$ & $\begin{array}{c}-0.880 * * * \\
(0.0322)\end{array}$ & $\begin{array}{c}-0.837 * * * \\
(0.0327)\end{array}$ & $\begin{array}{c}-0.427 * * * \\
(0.0544)\end{array}$ & $\begin{array}{c}-0.404 * * * \\
(0.0540)\end{array}$ & $\begin{array}{c}-0.873 * * * \\
(0.0322)\end{array}$ & $\begin{array}{c}-0.832 * * * \\
(0.0327)\end{array}$ \\
\hline Log Municipality Area & $\begin{array}{c}0.499 * * * \\
(0.0205)\end{array}$ & $\begin{array}{c}0.431^{* * *} \\
(0.0211)\end{array}$ & $\begin{array}{c}0.633 * * * \\
(0.0205)\end{array}$ & $\begin{array}{c}0.515 * * * \\
(0.0205)\end{array}$ & $\begin{array}{c}0.496 * * * \\
(0.0205)\end{array}$ & $\begin{array}{c}0.429 * * * \\
(0.0211)\end{array}$ & $\begin{array}{c}0.637^{* * *} \\
(0.0204)\end{array}$ & $\begin{array}{c}0.518^{* * *} \\
(0.0205)\end{array}$ & $\begin{array}{c}0.498^{* * *} \\
(0.0187)\end{array}$ & $\begin{array}{c}0.432 * * * \\
(0.0196)\end{array}$ & $\begin{array}{c}0.627 * * * \\
(0.0206)\end{array}$ & $\begin{array}{c}0.511 * * * \\
(0.0208)\end{array}$ \\
\hline Log Km of Major Roads 1940 & & $\begin{array}{c}0.116^{* * *} \\
(0.0112)\end{array}$ & & $\begin{array}{c}0.205 * * * \\
(0.0113)\end{array}$ & & $\begin{array}{c}0.116^{* * *} \\
(0.0111)\end{array}$ & & $\begin{array}{c}0.205^{* * *} \\
(0.0113)\end{array}$ & & $\begin{array}{c}0.116^{* * *} \\
(0.0110)\end{array}$ & & $\begin{array}{r}0.204 * * * \\
(0.0113)\end{array}$ \\
\hline Year-By-Coast FX & $\checkmark$ & $\checkmark$ & $\checkmark$ & $\checkmark$ & $\checkmark$ & $\checkmark$ & $\checkmark$ & $\checkmark$ & $\checkmark$ & $\checkmark$ & $\checkmark$ & $\checkmark$ \\
\hline Observations & 9,736 & 9,736 & 4,868 & 4,868 & 9,736 & 9,736 & 4,868 & 4,868 & 9,736 & 9,736 & 4,868 & 4,868 \\
\hline R-Squared & 0.246 & 0.273 & 0.400 & 0.469 & 0.250 & 0.278 & 0.399 & 0.469 & 0.246 & 0.273 & 0.401 & 0.469 \\
\hline Number of Municipalities & 2434 & 2434 & 2434 & 2434 & 2434 & 2434 & 2434 & 2434 & 2434 & 2434 & 2434 & 2434 \\
\hline
\end{tabular}

Notes: See Section 5.2 for discussion. Island IV is a dummy indicating whether an offshore island is within $5 \mathrm{~km}$ of the municipalities' coastline. Beach IV is the fraction of municipality area within $100 \mathrm{~m}$ of the coastline covered by white sand pixels that lie within the wavelength ranges of the 8 top-ranked Mexican beaches. Ruins IV is a dummy indicating the presence of pre-Hispanic archaeological ruins. Standard errors are clustered at the level of Mexican states. ${ }^{*} 10 \%,{ }^{* *} 5 \%,{ }^{* * *} 1 \%$ significance levels. 
Table 5: Role of Public Investment and Transport Infrastructure

\begin{tabular}{|c|c|c|c|c|c|c|c|c|c|c|c|c|}
\hline \multirow[b]{2}{*}{ Dependent Variables: } & (1) & (2) & (3) & (4) & (5) & (6) & (7) & (8) & (9) & (10) & (11) & (12) \\
\hline & \multicolumn{3}{|c|}{$\begin{array}{l}\text { Log Stock of Public } \\
\text { Investment in Tourism }\end{array}$} & \multicolumn{3}{|c|}{$\begin{array}{l}\text { Log Distance from } \\
\text { Planned Tourism Center }\end{array}$} & \multicolumn{3}{|c|}{ Log Km of Paved Roads } & \multicolumn{3}{|c|}{$\begin{array}{c}\text { Log Distance to International } \\
\text { Airport }\end{array}$} \\
\hline Island IV & $\begin{array}{l}2.050 * * * \\
(0.672)\end{array}$ & & & $\begin{array}{r}-0.491 * * \\
(0.145)\end{array}$ & & & $\begin{array}{l}0.00789 \\
(0.0816)\end{array}$ & & & $\begin{array}{c}-0.387 * * \\
(0.157)\end{array}$ & & \\
\hline Beach IV & & $\begin{array}{l}31.50^{*} \\
(16.69)\end{array}$ & & & $\begin{array}{l}-5.757^{*} \\
(3.218)\end{array}$ & & & $\begin{array}{l}2.678^{* * *} \\
(0.717)\end{array}$ & & & $\begin{array}{l}-5.064^{*} \\
(3.030)\end{array}$ & \\
\hline Ruins IV & & & $\begin{array}{l}0.972 * * * \\
(0.236)\end{array}$ & & & $\begin{array}{l}-0.0152 \\
(0.0653)\end{array}$ & & & $\begin{array}{l}0.194 * * * \\
(0.0570)\end{array}$ & & & $\begin{array}{c}-0.111 \\
(0.0754)\end{array}$ \\
\hline Year-By-Coast FX & $\checkmark$ & $\checkmark$ & $\checkmark$ & $\checkmark$ & $\checkmark$ & $\checkmark$ & $\checkmark$ & $\checkmark$ & $\checkmark$ & $\checkmark$ & $\checkmark$ & $\checkmark$ \\
\hline Full Set of Controls & $\checkmark$ & $\checkmark$ & $\checkmark$ & $\checkmark$ & $\checkmark$ & $\checkmark$ & $\checkmark$ & $\checkmark$ & $\checkmark$ & $\checkmark$ & $\checkmark$ & $\checkmark$ \\
\hline Observations & 4,889 & 4,889 & 4,889 & 4,889 & 4,889 & 4,889 & 4,889 & 4,889 & 4,889 & 4,889 & 4,889 & 4,889 \\
\hline R-Squared & 0.654 & 0.653 & 0.652 & 0.422 & 0.417 & 0.413 & 0.619 & 0.619 & 0.620 & 0.226 & 0.224 & 0.223 \\
\hline \multirow[t]{2}{*}{ Number of Municipalities } & 2455 & 2455 & 2455 & 2455 & 2455 & 2455 & 2455 & 2455 & 2455 & 2455 & 2455 & 2455 \\
\hline & (13) & (14) & (15) & (16) & (17) & (18) & (19) & (20) & $(21)$ & & & \\
\hline Dependent Variables: & \multicolumn{3}{|c|}{$\begin{array}{l}\text { Log Transport Time } \\
\text { (Simple Average) }\end{array}$} & \multicolumn{3}{|c|}{$\begin{array}{c}\text { Log Transport Time } \\
\text { (Population-Weighted Average) }\end{array}$} & \multicolumn{3}{|c|}{$\begin{array}{c}\text { Log Transport Time } \\
\text { (GDP-Weighted Average) }\end{array}$} & & & \\
\hline Island IV & $\begin{array}{l}-0.0591 * * \\
(0.0241)\end{array}$ & & & $\begin{array}{l}0.00692 \\
(0.0407)\end{array}$ & & & $\begin{array}{c}0.0193 \\
(0.0464)\end{array}$ & & & & & \\
\hline Beach IV & & $\begin{array}{r}-1.085^{* *} \\
(0.266)\end{array}$ & & & $\begin{array}{r}-0.495^{*} \\
(0.234)\end{array}$ & & & $\begin{array}{l}-0.648^{*} \\
(0.351)\end{array}$ & & & & \\
\hline Ruins IV & & & $\begin{array}{c}-0.0406 * * * \\
(0.0108)\end{array}$ & & & $\begin{array}{c}-0.0825 * * * \\
(0.0200)\end{array}$ & & & $\begin{array}{l}-0.109 * * * \\
(0.0262)\end{array}$ & & & \\
\hline Year-By-Coast FX & $\checkmark$ & $\checkmark$ & $\checkmark$ & $\checkmark$ & $\checkmark$ & $\checkmark$ & $\checkmark$ & $\checkmark$ & $\checkmark$ & & & \\
\hline Full Set of Controls & $\checkmark$ & $\checkmark$ & $\checkmark$ & $\checkmark$ & $\checkmark$ & $\checkmark$ & $\checkmark$ & $\checkmark$ & $\checkmark$ & & & \\
\hline Observations & 4,889 & 4,889 & 4,889 & 4,889 & 4,889 & 4,889 & 4,889 & 4,889 & 4,889 & & & \\
\hline R-Squared & 0.641 & 0.641 & 0.641 & 0.528 & 0.529 & 0.531 & 0.355 & 0.355 & 0.359 & & & \\
\hline Number of Municipalities & 2455 & 2455 & 2455 & 2455 & 2455 & 2455 & 2455 & 2455 & 2455 & & & \\
\hline
\end{tabular}

Notes: See Section 3 for discussion. Island IV is a dummy indicating whether an offshore island is within 5 km of the municipalities' coastline. Beach IV is the fraction of municipality area within $100 \mathrm{~m}$ of the coastline covered by white sand pixels that lie within the wavelength ranges of the 8 top-ranked Mexican beaches. Ruins IV is a dummy indicating the presence of pre-Hispanic archaeological ruins. "Transport Time" refers to the mean (or weighted mean as indicated) of municipality travel times to other municipalities and border crossings on the full terrestrial Mexican transport network. Standard errors are clustered at the level of municipalities. * $10 \%$, ** $5 \%$, *** $1 \%$ significance levels. 
Table 6: The Gains from Tourism

\begin{tabular}{lcc}
\hline & Estimated & No Spillovers \\
Parameters & $\gamma_{\mathrm{S}}=0.087$ & $\gamma_{\mathrm{S}}=0$ \\
& $\gamma_{\mathrm{M}}=0.064$ & $\gamma_{\mathrm{M}}=0$ \\
\hline \multirow{3}{*}{ Gains from All Tourism } & $4.82 \%$ & \\
& $(3.46,9.48)$ & $(3.24,7.45)$ \\
& {$[3.85,8.97]$} & {$[3.42,6.65]$} \\
Gains from International Tourism & $1.84 \%$ & $2.39 \%$ \\
& $(-0.01,5.02)$ & $(1.88,3.37)$ \\
& {$[1.35,4.72]$} & {$[2.0,3.19]$} \\
\hline
\end{tabular}

Notes: See Section 5.2 and Appendix 4.4 for discussion. 95\% confidence intervals below point estimates in round brackets, and $90 \%$ confidence intervals in square brackets.

Table 7: The Role of Agglomeration Forces for Local and Aggregate Effects

\begin{tabular}{lcccc}
\hline Dependent variable: & \multicolumn{5}{c}{ Counterfactual Change in Log Total GDP } \\
& $(1)$ & $(2)$ & $(3)$ & $(4)$ \\
Parameters & $\gamma_{\mathrm{S}}=0$ & $\gamma_{\mathrm{S}}=0$ & $\gamma_{\mathrm{S}}=0.15$ & $\gamma_{\mathrm{S}}=0.087$ \\
& $\gamma_{\mathrm{M}}=0$ & $\gamma_{\mathrm{M}}=0.15$ & $\gamma_{\mathrm{M}}=0$ & $\gamma_{\mathrm{M}}=0.064$ \\
\hline \multirow{4}{*}{ Panel A: IV Estimates } & & \\
Log Tourism GDP & $0.232^{* * *}$ & $0.0478^{* * *}$ & $0.657^{* * *}$ & $0.409^{* * *}$ \\
& $(0.0549)$ & $(0.0123)$ & $(0.144)$ & $(0.0900)$ \\
Coast FX & $\checkmark$ & $\checkmark$ & $\checkmark$ & $\checkmark$ \\
Full Set of Controls & $\checkmark$ & $\checkmark$ & $\checkmark$ & $\checkmark$ \\
Observations & 300 & 300 & 300 & 300 \\
Number of Clusters & 32 & 32 & 32 & 32 \\
\hline & $\underline{\text { Panel B: Reduced-Form Regressions }}$ & \\
Island IV & $0.321^{* * *}$ & $0.0640^{* * *}$ & $0.918^{* * *}$ & $0.561^{* * *}$ \\
& $(0.0832)$ & $(0.0159)$ & $(0.238)$ & $(0.146)$ \\
Beach IV & $5.542^{* * *}$ & $1.204^{* * *}$ & $15.37^{* * *}$ & $10.02^{* * *}$ \\
& $(1.456)$ & $(0.278)$ & $(4.160)$ & $(2.552)$ \\
Ruins IV & 0.0136 & 0.00546 & 0.0332 & 0.0213 \\
& $(0.125)$ & $(0.0239)$ & $(0.357)$ & $(0.219)$ \\
Coast FX & $\checkmark$ & $\checkmark$ & $\checkmark$ & $\checkmark$ \\
Full Set of Controls & $\checkmark$ & $\checkmark$ & $\checkmark$ & $\checkmark$ \\
Observations & 300 & 300 & 300 & 300 \\
Number of Clusters & 32 & 32 & 32 & 32 \\
\hline Gains from Tourism & $\mathbf{0 . 0 4 4 5}$ & $\mathbf{0 . 0 0 6 4 7}$ & $\mathbf{0 . 0 7 0 4}$ & $\mathbf{0 . 0 4 8 2}$ \\
\hline
\end{tabular}

Notes: See Section 5.2 for discussion. The point estimates are from an IV regression using the island, beach and ruins instruments. Standard errors are clustered at the level of Mexican states. ${ }^{*} 10 \%,{ }^{* *} 5 \%,{ }^{* * *} 1 \%$ significance levels. 


\section{Appendix - For Online Publication}

\section{Appendix 1: Additional Figures and Tables}

Figure A.1: Tourism's Distance Decay

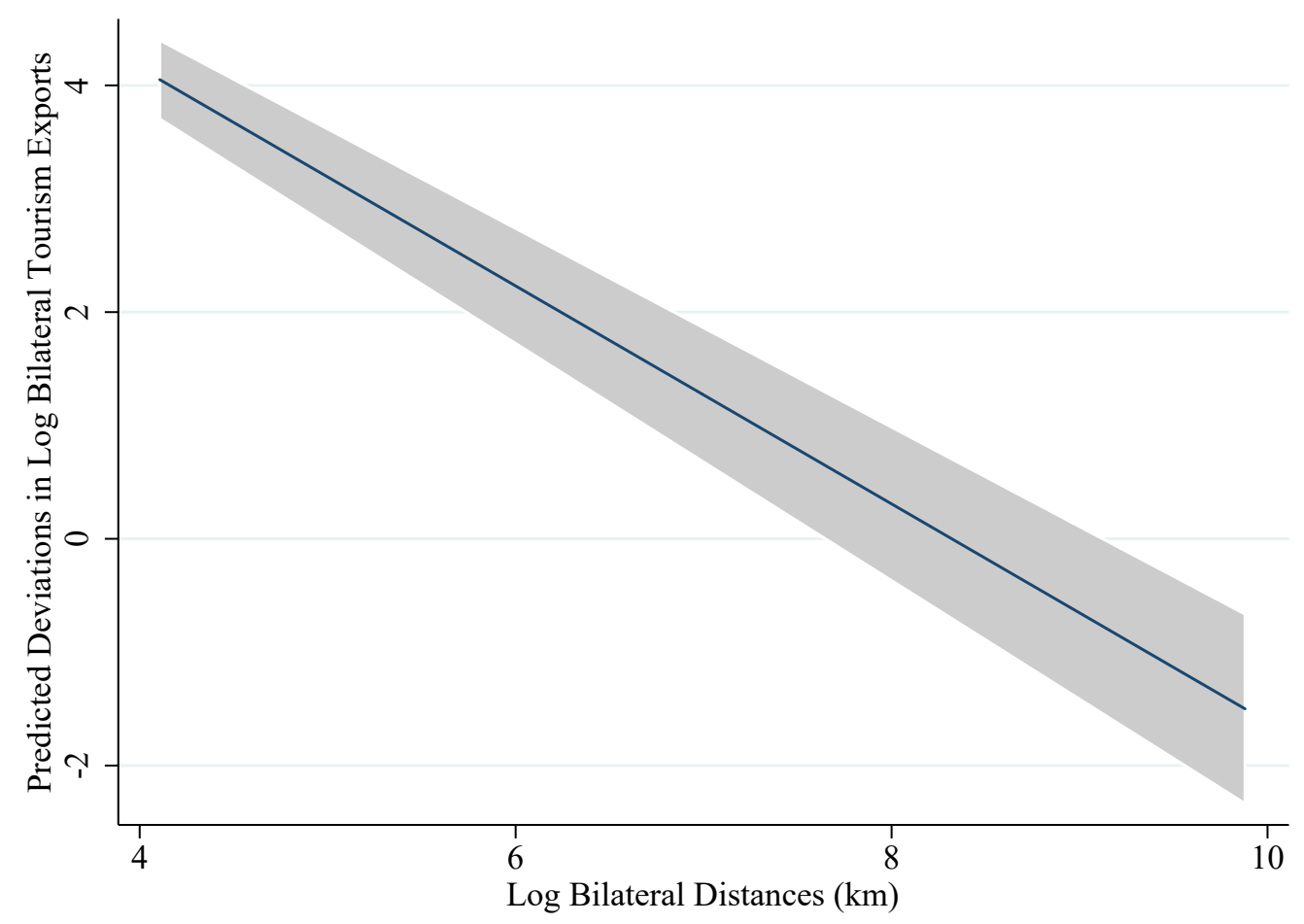

Notes: The estimated slope and confidence interval are based on the partial prediction from a PPML regression with bilateral tourism exports on the left-hand side and log bilateral distances in addition to origin-by-year fixed effects, destination-by-year fixed effects, and dummies for common border, language, colonial ties and travel visa requirements on the right-hand side. The figure depicts $95 \%$ confidence intervals based on standard errors that are clustered at the level of origin-destination pairs. 


\section{Figure A.2: Tourism Engel Curve}

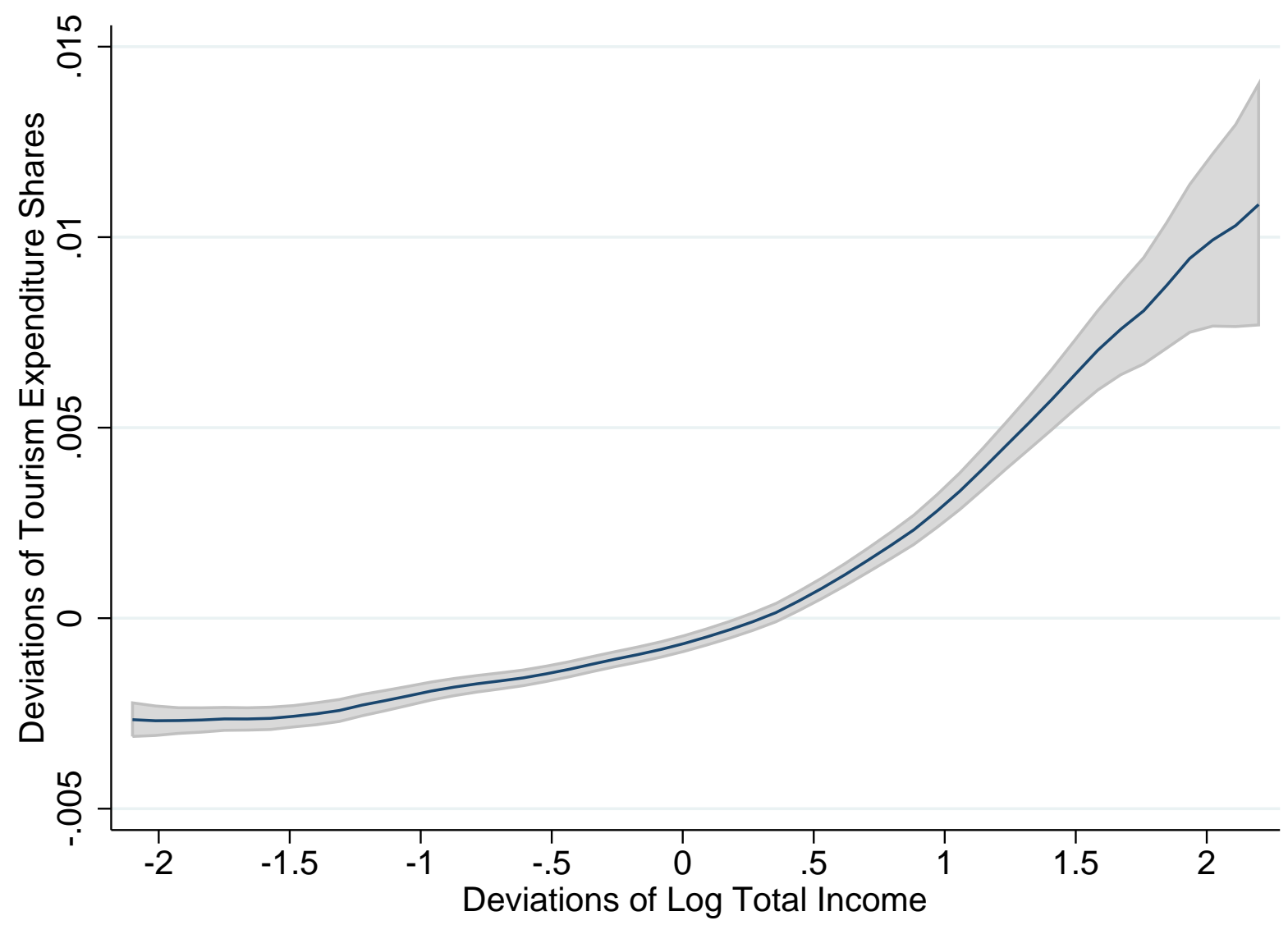

Notes: See Section 5.2 for discussion. The graph depicts a non-parametric plot of deviations of tourism expenditure shares (y-axis) against deviations of log household income, both relative to municipality-by-period means. The data source is the Mexican household income and expenditure survey 2004 (ENIGH). The graph also depicts confidence intervals based on standard errors that are clustered at the level of municipalities. The number of household observations is 22,595 , and the point estimate of the slope is 0.0033 estimated with a t-statistic of 11.09. 
Table A.1: Descriptive Statistics

\begin{tabular}{|c|c|c|c|c|c|c|c|c|c|c|c|}
\hline \multirow{2}{*}{ Data Source } & \multirow{2}{*}{ Variable } & \multicolumn{5}{|c|}{1998 Censos Economicos or 2000 Population Census } & \multicolumn{5}{|c|}{2008 Censos Economicos or 2010 Population Census } \\
\hline & & $\mathrm{N}$ & mean & sd & $\min$ & $\max$ & $\mathrm{N}$ & mean & sd & $\min$ & $\max$ \\
\hline \multirow{6}{*}{$\begin{array}{l}0 \\
.0 \\
0 \\
0 \\
0 \\
0 \\
0 \\
01 \\
0 \\
0 \\
0 \\
0 \\
0\end{array}$} & state id & 2,434 & 19.30 & 7.32 & 1.00 & 32.00 & 2,455 & 19.26 & 7.34 & 1.00 & 32.00 \\
\hline & gdp & 2,434 & $1,528,000.00$ & $9,613,000.00$ & 6.00 & $251,800,000.00$ & 2,455 & $4,480,000.00$ & $27,220,000.00$ & 21.00 & $704,200,000.00$ \\
\hline & $\log g d p$ & 2,434 & 9.92 & 2.97 & 1.79 & 19.34 & 2,455 & 10.92 & 2.96 & 3.05 & 20.37 \\
\hline & hotel sales & 2,434 & $12,847.00$ & $138,994.00$ & 0.00 & $5,230,000.00$ & 2,455 & $38,668.00$ & $433,757.00$ & 0.00 & $13,730,000.00$ \\
\hline & log hotel sales & 2,434 & 3.28 & 3.92 & 0.00 & 16.16 & 2,455 & 4.53 & 4.26 & 0.00 & 17.13 \\
\hline & number of hotels & 2,434 & 4.42 & 18.53 & 0.00 & 431.00 & 2,455 & 7.51 & 26.72 & 0.00 & 457.00 \\
\hline \multirow{4}{*}{ 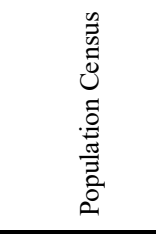 } & population & 2,434 & $39,832.00$ & $119,060.00$ & 105.00 & $1,763,000.00$ & 2,455 & $45,603.00$ & $132,175.00$ & 90.00 & $1,794,000.00$ \\
\hline & $\log$ population & 2,434 & 9.34 & 1.50 & 4.65 & 14.38 & 2,455 & 9.42 & 1.56 & 4.50 & 14.40 \\
\hline & employment & 2,434 & $14,542.00$ & $48,042.00$ & 34.00 & $825,945.00$ & 2,455 & $17,999.00$ & $60,391.00$ & 37.00 & $874,120.00$ \\
\hline & $\log$ employment & 2,434 & 8.17 & 1.56 & 3.53 & 13.62 & 2,455 & 8.27 & 1.64 & 3.61 & 13.68 \\
\hline \multirow{6}{*}{ 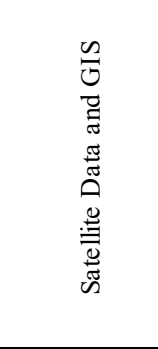 } & coast id & 2,434 & 0.06 & 0.24 & 0.00 & 1.00 & 2,455 & 0.06 & 0.24 & 0.00 & 1.00 \\
\hline & island dummy & 2,434 & 0.0189 & 0.136 & 0 & 1 & 2,455 & 0.0191 & 0.137 & 0 & 1 \\
\hline & share of nice beach within $100 \mathrm{~m}$ of coast & 2,434 & 0.000367 & 0.00602 & 0 & 0.177 & 2,455 & 0.000366 & 0.00599 & 0 & 0.177 \\
\hline & presence of pre-Hispanic ruins & 2,434 & 0.0312 & 0.174 & 0 & 1 & 2,455 & 0.0318 & 0.175 & 0 & 1 \\
\hline & distance to northern border $(\mathrm{km})$ & 2,434 & 753.40 & 265.80 & 6.59 & $1,348.00$ & 2,455 & 755.10 & 266.00 & 6.59 & $1,348.00$ \\
\hline & distance to Mex City $(\mathrm{km})$ & 2,434 & 453.70 & 372.50 & 2.30 & $2,271.00$ & 2,455 & 454.20 & 372.10 & 2.30 & $2,271.00$ \\
\hline \multirow{5}{*}{ 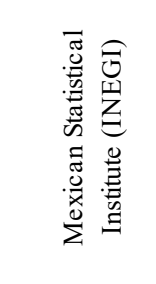 } & state capital dummy & 2,434 & 0.02 & 0.14 & 0.00 & 1.00 & 2,455 & 0.02 & 0.14 & 0.00 & 1.00 \\
\hline & old city dummy & 2,434 & 0.02 & 0.13 & 0.00 & 1.00 & 2,455 & 0.02 & 0.13 & 0.00 & 1.00 \\
\hline & colonial port dummy & 2,434 & 0.00 & 0.03 & 0.00 & 1.00 & 2,455 & 0.00 & 0.03 & 0.00 & 1.00 \\
\hline & average monthly temperature (Celsius $\mathrm{x} 10$ ) & 2,434 & 197.30 & 40.30 & 104.50 & 290.30 & 2,455 & 197.40 & 40.36 & 104.50 & 290.30 \\
\hline & average monthly precipitation $(\mathrm{mm})$ & 2,434 & 88.79 & 50.57 & 5.99 & 336.50 & 2,455 & 89.15 & 50.77 & 5.99 & 336.50 \\
\hline
\end{tabular}

See Section 2 for a description of the datasets. 
Table A.2: Accommodation Share in Total Mexican Tourism Expenditure 2003-2013

\begin{tabular}{cc}
\hline Year & $\begin{array}{c}\text { Share of Accommodation in } \\
\text { Total Tourism Expenditure }\end{array}$ \\
\hline 2003 & 0.130 \\
2004 & 0.125 \\
2005 & 0.126 \\
2006 & 0.124 \\
2007 & 0.126 \\
2008 & 0.126 \\
2009 & 0.125 \\
2010 & 0.127 \\
2011 & 0.127 \\
2012 & 0.127 \\
2013 & 0.129 \\
\hline Average 2003-13 & 0.127 \\
\hline
\end{tabular}

Notes: The data source is the tourism satellite account of Mexico's national account statistics.

Table A.3: Wavelength Ranges Among the Top-Ranked Beaches in Mexico

\begin{tabular}{lcccccccccccc}
\hline \multirow{2}{*}{ Beaches } & \multicolumn{2}{c}{ Bandwidth 1 } & \multicolumn{2}{c}{ Bandwidth 2 } & \multicolumn{2}{c}{ Bandwidth 3 } & \multicolumn{2}{c}{ Bandwidth 4 } & \multicolumn{2}{c}{ Bandwidth 5 } & \multicolumn{2}{c}{ Bandwidth 6} \\
$\min$ & $\max$ & $\min$ & $\max$ & $\min$ & $\max$ & $\min$ & $\max$ & $\min$ & $\max$ & $\min$ & $\max$ \\
\hline Playa del Carmen & 72 & 125 & 67 & 110 & 79 & 120 & 119 & 175 & 69 & 142 & 41 & 93 \\
Tulum & 81 & 106 & 74 & 94 & 99 & 120 & 121 & 153 & 97 & 133 & 56 & 84 \\
Cozumel & 71 & 111 & 66 & 101 & 78 & 102 & 113 & 157 & 96 & 138 & 59 & 86 \\
Cancun & 81 & 111 & 72 & 101 & 74 & 102 & 38 & 149 & 15 & 125 & 7 & 71 \\
Acapulco & 50 & 53 & 56 & 59 & 64 & 67 & 76 & 78 & 80 & 94 & 60 & 76 \\
Mazatlan & 50 & 53 & 56 & 60 & 64 & 68 & 76 & 81 & 81 & 81 & 55 & 57 \\
Puerto Vallarta & 56 & 58 & 71 & 73 & 87 & 89 & 101 & 105 & 120 & 125 & 103 & 108 \\
Los Cabos & 55 & 59 & 78 & 97 & 84 & 89 & 86 & 105 & 85 & 121 & 59 & 101 \\
\hline
\end{tabular}

Notes: See Section 3 for discussion. The table presents the wavelength ranges of the top 8 beaches in Mexico as identified by U.S. News. The data source are LandSat satellite data from 1980s and 90s at a resolution of 30x30 meters. 
Table A.4: Robustness

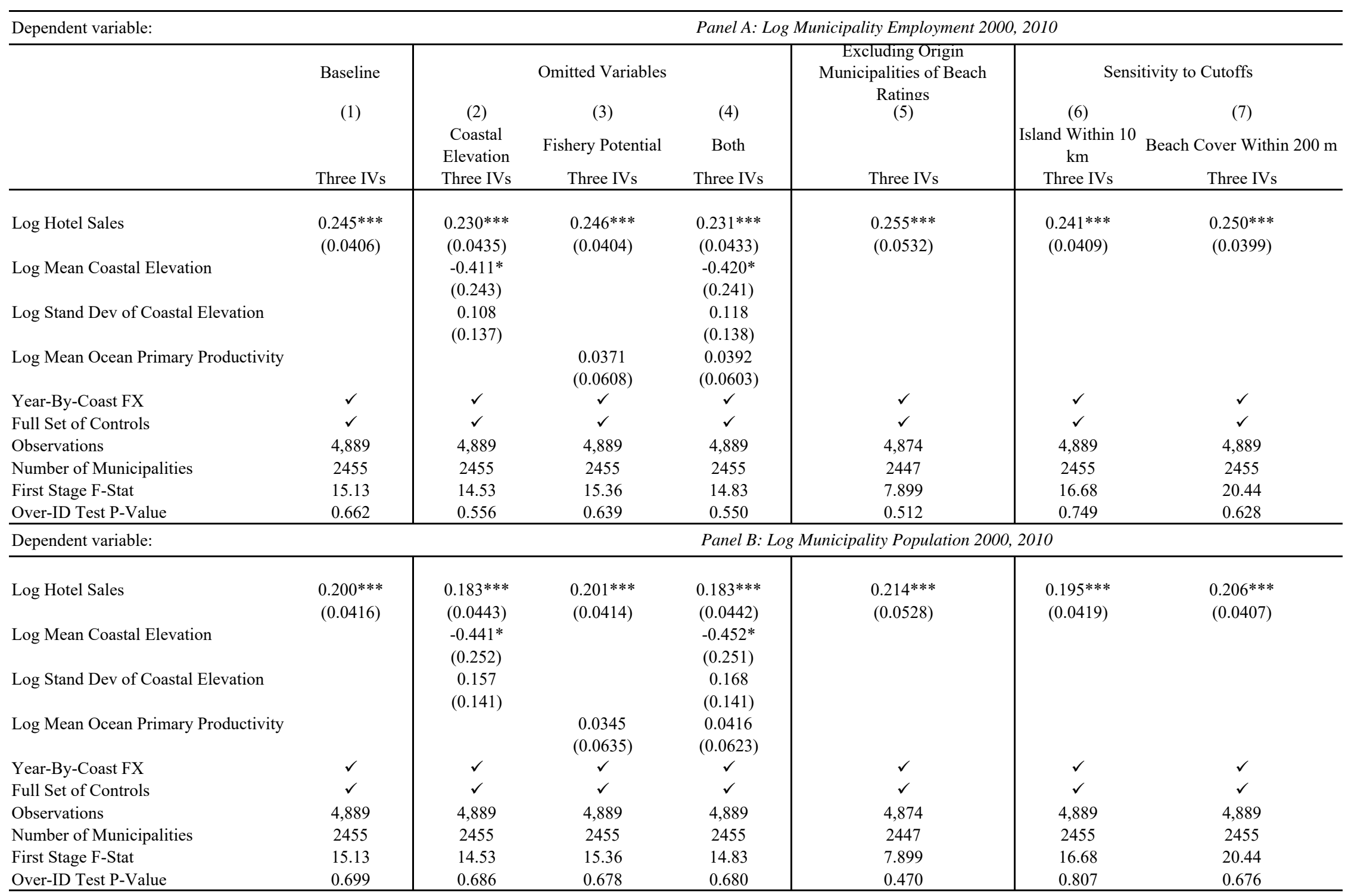

Notes: See Section 3 for discussion. Standard errors are clustered at the level of municipalities. ${ }^{*} 10 \%,{ }^{* *} 5 \%$, ${ }^{* * *} 1 \%$ significance levels. 
Table A.5: Model-Based Test of Direct Effect on Local Residential Amenities

\begin{tabular}{lccc}
\hline Dependent variable: & \multicolumn{3}{c}{ Log Municipality Residential Amenities } \\
& $(1)$ & $(2)$ & $(3)$ \\
& Not Using Island IV & Not Using Beach IV & Not Using Ruins IV \\
\hline & & & \\
Left -Out IV & -0.0238 & 0.0997 & 0.183 \\
& $(0.323)$ & $(2.958)$ & $(0.365)$ \\
Coast FX & $\checkmark$ & $\checkmark$ & $\checkmark$ \\
Full Set of Controls & $\checkmark$ & $\checkmark$ & 300 \\
Observations & 300 & 0.354 & 0.349 \\
R-Squared & 0.344 & 32 & 32 \\
Number of Clusters & 32 & &
\end{tabular}

Notes: See Sections 3 and 5.1 for discussion. Island IV is a dummy indicating whether an offshore island is within 5 $\mathrm{km}$ of the municipalities' coastline. Beach IV is the fraction of municipality area within $100 \mathrm{~m}$ of the coastline covered by white sand pixels that lie within the wavelength ranges of the 8 top-ranked Mexican beaches. Ruins IV is a dummy indicating the presence of pre-Hispanic archaeological ruins. Standard errors are clustered at the level of Mexican states. ${ }^{*} 10 \%, * * 5 \%, * * 1 \%$ significance levels.

Table A.6: Checking Correlations of Amenity Measures

\begin{tabular}{|c|c|c|c|c|c|c|c|}
\hline $\begin{array}{c}\text { Dependent Variable: Log of Estimated } \\
\text { Municipality Amenities } \\
\end{array}$ & (1) & (2) & (3) & (4) & (5) & (6) & (7) \\
\hline Log Average Temperature & $\begin{array}{c}3.087 * * * \\
(1.107)\end{array}$ & & & & & & \\
\hline Log Fraction of Green Land in Municipality & & $\begin{array}{c}0.336^{* * *} \\
(0.110)\end{array}$ & & & & & \\
\hline Log Robberies Per Capita & & & $\begin{array}{l}-0.334 \\
(0.216)\end{array}$ & & & & \\
\hline Log Density of Cars (Cars per Capita) & & & & $\begin{array}{c}-0.674 * * * \\
(0.238)\end{array}$ & & & \\
\hline Log Square Km of Water Bodies in Municipality & & & & & $\begin{array}{l}0.265 * * * \\
(0.0636)\end{array}$ & & \\
\hline Log Number of Water Bodies in Municipality & & & & & & $\begin{array}{l}0.340^{* * *} \\
(0.0888)\end{array}$ & \\
\hline Log Distance to Ocean & & & & & & & $\begin{array}{r}-0.251 * * \\
(0.0996)\end{array}$ \\
\hline Coast FX & $\checkmark$ & $\checkmark$ & $\checkmark$ & $\checkmark$ & $\checkmark$ & $\checkmark$ & $\checkmark$ \\
\hline Observations & 300 & 288 & 276 & 275 & 300 & 300 & 300 \\
\hline R-Squared & 0.171 & 0.186 & 0.098 & 0.155 & 0.237 & 0.237 & 0.110 \\
\hline Number of State Clusters & 32 & 32 & 32 & 32 & 32 & 32 & 32 \\
\hline
\end{tabular}

Notes: See Section 2 and Appendix 2 for description of the data and Sections 3 and 5.1 for discussion. The data on parcels of green land relative to total land, the number of robberies and the number of registered vehicles are from the year 2005 and were provided to us as part of INEGI's Sistema Estatal y Municipal de Bases de Datos (SIMBAD). Access to inland bodies of water and ocean stem from aerial surface data from INEGI's geo-statistics division. Where applicable, distance is defined in terms of centroids. Standard errors are clustered at the level of Mexican states. * $10 \%$, ** $5 \%, * * * 1 \%$ significance levels. 
Table A.7: Controlling for Local Crime and Security

\begin{tabular}{|c|c|c|c|c|c|c|}
\hline \multirow{4}{*}{ Dependent Variables: } & \multicolumn{6}{|c|}{ Population Census 2000,2010} \\
\hline & (1) & (2) & (3) & (4) & (5) & (6) \\
\hline & \multicolumn{3}{|c|}{ Log Employment } & \multicolumn{3}{|c|}{ Log Population } \\
\hline & Baseline & $\begin{array}{l}\text { Control for } \\
\text { Total Crime }\end{array}$ & $\begin{array}{c}\text { Refined Crime } \\
\text { Controls }\end{array}$ & Baseline & $\begin{array}{l}\text { Control for } \\
\text { Total Crime }\end{array}$ & $\begin{array}{c}\text { Refined Crime } \\
\text { Controls }\end{array}$ \\
\hline Log Hotel Sales & $\begin{array}{l}0.245^{* * *} \\
(0.0406)\end{array}$ & $\begin{array}{l}0.244 * * * \\
(0.0406)\end{array}$ & $\begin{array}{l}0.232 * * * \\
(0.0425)\end{array}$ & $\begin{array}{l}0.200^{* * *} \\
(0.0416)\end{array}$ & $\begin{array}{c}0.199 * * * \\
(0.0416)\end{array}$ & $\begin{array}{l}0.186 * * * \\
(0.0437)\end{array}$ \\
\hline Total Reported Crimes Per Capita & & $\begin{array}{c}-13.04 * * * \\
(5.007)\end{array}$ & & & $\begin{array}{l}-4.066 \\
(5.100)\end{array}$ & \\
\hline Robberies Per Capita & & & $\begin{array}{c}52.94 \\
(43.37)\end{array}$ & & & $\begin{array}{c}75.87 \\
(48.69)\end{array}$ \\
\hline Homicides Per Capita & & & $\begin{array}{c}-99.41 * * * \\
(14.04)\end{array}$ & & & $\begin{array}{c}-86.63^{* * *} \\
(17.29)\end{array}$ \\
\hline Battery (Physical Violence) Per Capita & & & $\begin{array}{c}37.25 \\
(129.9)\end{array}$ & & & $\begin{array}{c}47.65 \\
(127.2)\end{array}$ \\
\hline Assault Per Capita & & & $\begin{array}{c}-107.8 * * \\
(49.31)\end{array}$ & & & $\begin{array}{l}-82.01 * \\
(47.88)\end{array}$ \\
\hline Extorsion Per Capita & & & $\begin{array}{c}-54.77 * * * \\
(13.73)\end{array}$ & & & $\begin{array}{c}-52.23 * * * \\
(13.29)\end{array}$ \\
\hline Fraud & & & $\begin{array}{c}44.13 \\
(73.19)\end{array}$ & & & $\begin{array}{c}96.29 \\
(84.19)\end{array}$ \\
\hline Drug-Related Offenses Per Capita & & & $\begin{array}{c}332.7 \\
(559.8)\end{array}$ & & & $\begin{array}{l}1,047^{*} \\
(546.7)\end{array}$ \\
\hline Year-By-Coast FX & $\checkmark$ & $\checkmark$ & $\checkmark$ & $\checkmark$ & $\checkmark$ & $\checkmark$ \\
\hline Full Set of Controls (Not Shown) & $\checkmark$ & $\checkmark$ & $\checkmark$ & $\checkmark$ & $\checkmark$ & $\checkmark$ \\
\hline Observations & 4,889 & 4,889 & 4,889 & 4,889 & 4,889 & 4,889 \\
\hline Number of Municipalities & 2455 & 2455 & 2455 & 2455 & 2455 & 2455 \\
\hline First Stage F-Stat & 15.13 & 15.89 & 15.31 & 15.13 & 15.89 & 15.31 \\
\hline Over-ID Test P-Value & 0.662 & 0.640 & 0.727 & 0.699 & 0.691 & 0.825 \\
\hline
\end{tabular}

Notes: See Section 2 for description of the data and Sections 3 and 5.1 for discussion. The data on different types of local crimes were provided to us as part of INEGI's Sistema Estatal y Municipal de Bases de Datos (SIMBAD). Crimes refer to both local and federal convictions occurring in the municipality. Standard errors are clustered at the level of municipalities. * $10 \%, * * 5 \%, * * * 1 \%$ significance levels. 
Table A.8: Heterogeneity of the Reduced Form

\begin{tabular}{|c|c|c|c|c|c|c|c|c|c|c|c|c|}
\hline \multirow[b]{2}{*}{ Dependent Variable: } & (1) & (2) & (3) & (4) & $(5)$ & (6) & (7) & $(8)$ & \multirow{2}{*}{$\begin{array}{l}\text { (9) } \\
\text { Inicipality } \\
\text { Retired) }\end{array}$} & \multirow{2}{*}{\multicolumn{3}{|c|}{$\begin{array}{l}(10) \quad(11) \\
\text { Log Number of Municipality } \\
\text { Immigrants (Active and Retired) }\end{array}$}} \\
\hline & Number of & $\begin{array}{l}\text { Municipalit } \\
\text { tive \& Ret }\end{array}$ & $\begin{array}{l}\text { Immigrants } \\
\text { d) }\end{array}$ & $\begin{array}{l}\text { Log (IHS) } \\
\text { Immigra }\end{array}$ & $\begin{array}{l}\text { Number of } \\
\text { nts (Active a }\end{array}$ & $\begin{array}{l}\text { Municipality } \\
\text { nd Retired) }\end{array}$ & $\begin{array}{r}\text { Log }(0+1 \\
\text { Immigra }\end{array}$ & $\begin{array}{l}\text { Number of } \\
\text { nts (Active }\end{array}$ & & & & \\
\hline Island IV & $\begin{array}{c}3,050 * * \\
(1,477)\end{array}$ & & & $\begin{array}{c}2.077 * * * \\
(0.301)\end{array}$ & & & $\begin{array}{c}2.093 * * * \\
(0.298)\end{array}$ & & & $\begin{array}{c}1.617 * * * \\
(0.315)\end{array}$ & & \\
\hline Island IV * Retired Dummy & $\begin{array}{c}-3,636^{* *} \\
(1,446)\end{array}$ & & & $\begin{array}{c}-1.870^{* * *} \\
(0.194)\end{array}$ & & & $\begin{array}{r}-2.024 * * \\
(0.178)\end{array}$ & & & $\begin{array}{c}-1.838^{* * *} \\
(0.237)\end{array}$ & & \\
\hline Beach IV & & $\begin{array}{l}102,405 \\
(65,179)\end{array}$ & & & $\begin{array}{c}17.39 * * \\
(7.633)\end{array}$ & & & $\begin{array}{l}17.64 * * \\
(7.595)\end{array}$ & & & $\begin{array}{c}11.91 \\
(8.364)\end{array}$ & \\
\hline Beach IV * Retired Dummy & & $\begin{array}{r}-108,599 * \\
(62,905)\end{array}$ & & & $\begin{array}{l}-7.848 \\
(5.091)\end{array}$ & & & $\begin{array}{r}-11.70^{* *} \\
(4.571)\end{array}$ & & & $\begin{array}{r}-18.29 * * \\
(3.252)\end{array}$ & \\
\hline Ruins IV & & & $\begin{array}{c}936.6 * * \\
(462.4)\end{array}$ & & & $\begin{array}{c}1.390 * * * \\
(0.212)\end{array}$ & & & $\begin{array}{c}1.374 * * * \\
(0.212)\end{array}$ & & & $\begin{array}{c}1.187 * * * \\
(0.211)\end{array}$ \\
\hline Ruins IV * Retired Dummy & & & $\begin{array}{c}-1,015^{* *} \\
(460.4)\end{array}$ & & & $\begin{array}{c}-0.960 * * * \\
(0.163)\end{array}$ & & & $\begin{array}{c}-1.033^{* * *} * \\
(0.156)\end{array}$ & & & $\begin{array}{c}-0.889 * * * \\
(0.269)\end{array}$ \\
\hline Coast-By-Period FX & $\checkmark$ & $\checkmark$ & $\checkmark$ & $\checkmark$ & $\checkmark$ & $\checkmark$ & $\checkmark$ & $\checkmark$ & $\checkmark$ & $\checkmark$ & $\checkmark$ & $\checkmark$ \\
\hline Observations & 9,778 & 9,778 & 9,778 & 9,778 & 9,778 & 9,778 & 9,778 & 9,778 & 9,778 & 5,545 & 5,545 & 5,545 \\
\hline R-Squared & 0.048 & 0.068 & 0.035 & 0.599 & 0.596 & 0.599 & 0.562 & 0.557 & 0.561 & 0.158 & 0.151 & 0.159 \\
\hline Number of Municipality Clusters & 2455 & 2455 & 2455 & 2455 & 2455 & 2455 & 2455 & 2455 & 2455 & 2432 & 2432 & 2432 \\
\hline
\end{tabular}

Notes: See Section 2 and Appendix 2 for description of the data and Section 3 for discussion. Island IV is a dummy indicating whether an offshore island is within $5 \mathrm{~km}$ of the municipalities' coastline. Beach IV is the fraction of municipality area within $100 \mathrm{~m}$ of the coastline covered by white sand pixels that lie within the wavelength ranges of the 8 top-ranked Mexican beaches. Ruins IV is a dummy indicating the presence of pre-Hispanic archaeological ruins. Standard errors are clustered at the level of municipalities. ${ }^{*} 10 \%,{ }^{* *} 5 \%,{ }^{* * *} 1 \%$ significance levels. 
Table A.9: Using Panel Variation to Estimate Effect of Tourism on Population (Decadal Changes)

\begin{tabular}{|c|c|c|c|c|c|c|c|c|c|c|c|c|}
\hline \multirow{4}{*}{$\begin{array}{l}\text { Dependent Variable: } \\
\text { Log Municipality Population }\end{array}$} & \multicolumn{12}{|c|}{ Population Censuses 1921-2010 } \\
\hline & (1) & (2) & (3) & (4) & $(5)$ & (6) & (7) & $(8)$ & (9) & $(10)$ & (11) & (12) \\
\hline & \multicolumn{4}{|c|}{ Island IV } & \multicolumn{4}{|c|}{ Beach IV } & \multicolumn{4}{|c|}{ Pre-Hispanic Ruins IV } \\
\hline & OLS & OLS & Shift-Share IV & Shift-Share IV & OLS & OLS & Shift-Share IV & Shift-Share IV & OLS & OLS & Shift-Share IV & Shift-Share IV \\
\hline Log Tourist Arrivals Interacted with Instrument & $\begin{array}{l}0.155 * * \\
(0.0681)\end{array}$ & $\begin{array}{l}0.176 * * \\
(0.0749)\end{array}$ & $\begin{array}{l}0.149 * * \\
(0.0668)\end{array}$ & $\begin{array}{l}0.172 * * \\
(0.0741)\end{array}$ & \begin{tabular}{|l}
3.516 \\
$(2.705)$
\end{tabular} & $\begin{array}{l}4.486^{*} \\
(2.553)\end{array}$ & $\begin{array}{l}4.215 \\
(2.841)\end{array}$ & $\begin{array}{l}5.187^{*} \\
(2.698)\end{array}$ & $\begin{array}{l}0.103 * * \\
(0.0446)\end{array}$ & $\begin{array}{c}0.0562 \\
(0.0447)\end{array}$ & $\begin{array}{l}0.116^{* *} \\
(0.0464)\end{array}$ & $\begin{array}{c}0.0701 \\
(0.0463)\end{array}$ \\
\hline Year-By-Coast FX & $\checkmark$ & $\checkmark$ & $\checkmark$ & $\checkmark$ & $\checkmark$ & $\checkmark$ & $\checkmark$ & $\checkmark$ & $\checkmark$ & $\checkmark$ & $\checkmark$ & $\checkmark$ \\
\hline Municipality FX & $\checkmark$ & $\checkmark$ & $\checkmark$ & $\checkmark$ & $\checkmark$ & $\checkmark$ & $\checkmark$ & $\checkmark$ & $\checkmark$ & $\checkmark$ & $\checkmark$ & $\checkmark$ \\
\hline Full Set of Controls Interacted with Time FX & $x$ & $\checkmark$ & $x$ & $\checkmark$ & $x$ & $\checkmark$ & $x$ & $\checkmark$ & $x$ & $\checkmark$ & $x$ & $\checkmark$ \\
\hline Observations & 24,340 & 24,340 & 24,340 & 24,340 & 24,340 & 24,340 & 24,340 & 24,340 & 24,340 & 24,340 & 24,340 & 24,340 \\
\hline Number of Municipalities & 2434 & 2434 & 2434 & 2434 & 2434 & 2434 & 2434 & 2434 & 2434 & 2434 & 2434 & 2434 \\
\hline
\end{tabular}

Notes: See Section 2 for description of the data and Section 3 for discussion. The table is based on 10 rounds of decadal census data for consistent spatial units starting in 1921 and ending in 2010. Shift-share IV uses time series data on US airfares in constant USD to instrument for international tourist arrivals to Mexico. Island IV is a dummy indicating whether an offshore island is within $5 \mathrm{~km}$ of the municipalities' coastline. Beach IV is the fraction of municipality area within $100 \mathrm{~m}$ of the coastline covered by white sand pixels that lie within the wavelength ranges of the 8 top-ranked Mexican beaches. Ruins IV is a dummy indicating the presence of pre-Hispanic archaeological ruins. Standard errors are clustered at the level of municipalities. ${ }^{*} 10 \%,{ }^{* *} 5 \%$, $* * * 1 \%$ significance levels. 
Table A.10: Share of Accommodation Expenses and Professional Travel across Destinations

\begin{tabular}{|c|c|c|c|c|c|c|}
\hline Dependent Variables: & \multicolumn{2}{|c|}{$\begin{array}{l}\text { Share of Accommodation } \\
\text { Expenditure in Tourism } \\
\text { Expenditure at Destination }\end{array}$} & \multicolumn{3}{|c|}{ Share of Hotel Nights from Professional Travel } & Travel \\
\hline Share of Hotel Nights Spent & 0.0154 & 0.0180 & $-0.0741 * * *$ & $-0.0723 * * *$ & -0.00218 & -0.00511 \\
\hline in Coastal Regions & $(0.0147)$ & $(0.0135)$ & $(0.0111)$ & $(0.0103)$ & $(0.0218)$ & $(0.0200)$ \\
\hline Indicator for Top Third of & & & & & $-0.0671 * * *$ & $-0.0627 * * *$ \\
\hline Destinations & & & & & $(0.0161)$ & $(0.0155)$ \\
\hline Year Fixed Effects & $\checkmark$ & $\checkmark$ & $\checkmark$ & $\checkmark$ & $\checkmark$ & $\checkmark$ \\
\hline Origin Fixed Effects & $x$ & $\checkmark$ & $x$ & $\checkmark$ & $x$ & $\checkmark$ \\
\hline Observations & 1,218 & 1,218 & 5,519 & 5,519 & 5,519 & 5,519 \\
\hline R-Squared & 0.006 & 0.595 & 0.134 & 0.211 & 0.141 & 0.218 \\
\hline Number of Origin Clusters & 28 & 28 & 30 & 30 & 30 & 30 \\
\hline
\end{tabular}

Notes: See Section 3 for discussion. Regressions in columns 1 and 2 are based on EuroStat data that provide us with accommodation shares in tourist expenditures from a given European origin country across different European destination countries for the years 2012, 2013 and 2014 and for 30 European countries. Accommodation shares are relative to local tourist expenditures at the destination (excluding travel costs to get there). Regressions in columns 3-6 are based on Eurostat data on the share of hotel nights for professional travel from a given European origin country across 30 different European destination countries for the years 1999-2015. On the right hand side in all regressions, we use the Eurostat data on the share of total hotel nights spent by non-residents in a destination country that are located in coastal NUTS 2 regions within the destination country relative to non-coastal NUTS 2 regions. Standard errors are clustered at the level of origin countries. ${ }^{*} 10 \%,{ }^{* *} 5 \%,{ }^{* * *} 1 \%$ significance levels. 
Table A.11: Tourism's Effect on Municipality Employment and Population: Not Using IHS Transformation

\begin{tabular}{|c|c|c|c|c|c|c|}
\hline \multirow[t]{4}{*}{ Dependent variables: } & \multicolumn{3}{|c|}{ Log Municipality Employment 2000, 2010} & \multicolumn{3}{|c|}{ Log Municipality Population 2000, 2010} \\
\hline & (1) & $(2)$ & (3) & (4) & $(5)$ & $(6)$ \\
\hline & $\begin{array}{l}\text { Baseline Specification } \\
\text { (IHS Transformation) }\end{array}$ & $\begin{array}{l}\text { Log Hotel Sales } \\
(+1 \text { for Zeroes })\end{array}$ & $\begin{array}{l}\text { Log Hotel Sales } \\
\text { (Ignore Zeroes) }\end{array}$ & $\begin{array}{l}\text { Baseline Specification } \\
\text { (IHS Transformation) }\end{array}$ & $\begin{array}{l}\text { Log Hotel Sales } \\
(+1 \text { for Zeroes })\end{array}$ & $\begin{array}{l}\text { Log Hotel Sales } \\
\text { (Ignore Zeroes) }\end{array}$ \\
\hline & Three IVs & Three IVs & Three IVs & Three IVs & Three IVs & Three IVs \\
\hline Log Hotel Sales & $0.245 * * *$ & $0.254 * * *$ & $0.263 * * *$ & $0.200 * * *$ & $0.208 * * *$ & $0.214 * * *$ \\
\hline & $(0.0406)$ & $(0.0413)$ & $(0.0574)$ & $(0.0416)$ & $(0.0426)$ & $(0.0624)$ \\
\hline Log Distance to US Border & -0.0163 & -0.0185 & 0.0630 & 0.0341 & 0.0324 & 0.0920 \\
\hline & $(0.0438)$ & $(0.0432)$ & $(0.0535)$ & $(0.0460)$ & $(0.0456)$ & $(0.0573)$ \\
\hline Log Distance to Mexico City & $-0.549 * * *$ & $-0.562 * * *$ & $-0.449 * * *$ & $-0.591 * * *$ & $-0.602 * * *$ & $-0.480 * * *$ \\
\hline & $(0.0526)$ & $(0.0499)$ & $(0.0446)$ & $(0.0539)$ & $(0.0514)$ & $(0.0482)$ \\
\hline Log Municipality Area & $0.318^{* * *}$ & $0.335 * * *$ & $0.253 * * *$ & $0.370 * * *$ & $0.383 * * *$ & $0.284 * * *$ \\
\hline & $(0.0525)$ & $(0.0489)$ & $(0.0291)$ & $(0.0540)$ & $(0.0505)$ & $(0.0315)$ \\
\hline State Capital Dummy & $0.689 * * *$ & $0.666^{* * *}$ & $0.759 * * *$ & $0.627 * *$ & $0.607 * *$ & $0.683^{* *}$ \\
\hline & $(0.242)$ & $(0.241)$ & $(0.256)$ & $(0.256)$ & $(0.256)$ & $(0.277)$ \\
\hline Old City Dummy & $0.924 * * *$ & $0.925 * * *$ & $0.961 * * *$ & $0.920 * * *$ & $0.920 * * *$ & $0.911 * * *$ \\
\hline & $(0.268)$ & $(0.265)$ & $(0.257)$ & $(0.285)$ & $(0.282)$ & $(0.278)$ \\
\hline Colonial Port Dummy & $0.597 * * *$ & $0.558 * * *$ & $0.688 * * *$ & $0.671 * * *$ & $0.639 * * *$ & $0.776^{* * *}$ \\
\hline & $(0.205)$ & $(0.209)$ & $(0.246)$ & $(0.216)$ & $(0.218)$ & $(0.273)$ \\
\hline Log Average Precipitation & $0.258 * * *$ & $0.266^{* * *}$ & $0.106^{* *}$ & $0.245^{* * *}$ & $0.251 * * *$ & $0.101^{*}$ \\
\hline & $(0.0409)$ & $(0.0404)$ & $(0.0519)$ & $(0.0415)$ & $(0.0412)$ & $(0.0541)$ \\
\hline Log Average Temperature & $0.223 * *$ & $0.222 * *$ & 0.195 & $0.282 * * *$ & $0.281 * * *$ & 0.210 \\
\hline & $(0.107)$ & $(0.107)$ & $(0.131)$ & $(0.106)$ & $(0.105)$ & $(0.134)$ \\
\hline Year-By-Coast FX & $\checkmark$ & $\checkmark$ & $\checkmark$ & $\checkmark$ & $\checkmark$ & $\checkmark$ \\
\hline Observations & 4,889 & 4,889 & 2,613 & 4,889 & 4,889 & 2,613 \\
\hline Number of Municipalities & 2455 & 2455 & 1489 & 2455 & 2455 & 1489 \\
\hline First Stage F-Stat & 15.13 & 15.46 & 14.86 & 15.13 & 15.46 & 14.86 \\
\hline Over-ID Test P-Value & 0.662 & 0.731 & 0.843 & 0.699 & 0.749 & 0.813 \\
\hline
\end{tabular}

Notes: See Section 3 for discussion. Standard errors are clustered at the level of municipalities. ${ }^{*} 10 \%$, ${ }^{* *} 5 \%$, ${ }^{* * *} 1 \%$ significance levels. 
Table A.12: Tourism's Effect on Municipality Employment and Population: Using Number of Tourists

\begin{tabular}{|c|c|c|c|c|}
\hline \multirow[t]{4}{*}{ Dependent variables: } & \multicolumn{2}{|c|}{$\begin{array}{l}\text { Log Municipality Employment } \\
\text { 2000, } 2010\end{array}$} & \multicolumn{2}{|c|}{$\begin{array}{l}\text { Log Municipality Population } \\
\text { 2000, } 2010\end{array}$} \\
\hline & (1) & $(2)$ & (3) & (4) \\
\hline & Baseline & $\begin{array}{l}\text { Log Number } \\
\text { Tourists }\end{array}$ & Baseline & $\begin{array}{l}\text { Log Number } \\
\text { Tourists }\end{array}$ \\
\hline & Three IVs & Three IVs & Three IVs & Three IVs \\
\hline \multirow[t]{2}{*}{ Log Hotel Sales } & $0.245 * * *$ & & $0.200 * * *$ & \\
\hline & $(0.0406)$ & & $(0.0416)$ & \\
\hline \multirow[t]{2}{*}{ Log Number of Tourists } & & $0.276 * * *$ & & $0.227 * * *$ \\
\hline & & $(0.0737)$ & & $(0.0656)$ \\
\hline \multirow[t]{2}{*}{ Log Distance to US Border } & -0.0163 & $-0.231 * * *$ & 0.0341 & $-0.142 * *$ \\
\hline & $(0.0438)$ & $(0.0576)$ & $(0.0460)$ & $(0.0563)$ \\
\hline \multirow[t]{2}{*}{ Log Distance to Mexico City } & $-0.549 * * *$ & $-0.876 * * *$ & $-0.591 * * *$ & $-0.859 * * *$ \\
\hline & $(0.0526)$ & $(0.0381)$ & $(0.0539)$ & $(0.0365)$ \\
\hline \multirow[t]{2}{*}{ Log Municipality Area } & $0.318 * * *$ & $0.516 * * *$ & $0.370 * * *$ & $0.530 * * *$ \\
\hline & $(0.0525)$ & $(0.0335)$ & $(0.0540)$ & $(0.0308)$ \\
\hline \multirow[t]{2}{*}{ State Capital Dummy } & $0.689 * * *$ & 0.110 & $0.627 * *$ & 0.144 \\
\hline & $(0.242)$ & $(0.476)$ & $(0.256)$ & $(0.423)$ \\
\hline \multirow[t]{2}{*}{ Old City Dummy } & $0.924 * * *$ & $0.777 * *$ & $0.920 * * *$ & $0.793 * *$ \\
\hline & $(0.268)$ & $(0.396)$ & $(0.285)$ & $(0.358)$ \\
\hline \multirow[t]{2}{*}{ Colonial Port Dummy } & $0.597 * * *$ & $-1.318^{*}$ & $0.671 * * *$ & -0.910 \\
\hline & $(0.205)$ & $(0.799)$ & $(0.216)$ & $(0.707)$ \\
\hline \multirow[t]{2}{*}{ Log Average Precipitation } & $0.258 * * *$ & $0.394 * * *$ & $0.245 * * *$ & $0.356 * * *$ \\
\hline & $(0.0409)$ & $(0.0579)$ & $(0.0415)$ & $(0.0550)$ \\
\hline \multirow[t]{2}{*}{ Log Average Temperature } & $0.223 * *$ & $0.680 * * *$ & $0.282 * * *$ & $0.657 * * *$ \\
\hline & $(0.107)$ & $(0.164)$ & $(0.106)$ & $(0.153)$ \\
\hline Year-By-Coast FX & $\checkmark$ & $\checkmark$ & $\checkmark$ & $\checkmark$ \\
\hline Observations & 4,889 & 4,889 & 4,889 & 4,889 \\
\hline Number of Municipalities & 2455 & 2455 & 2455 & 2455 \\
\hline First Stage F-Stat & 15.13 & 4.730 & 15.13 & 4.730 \\
\hline Over-ID Test P-Value & 0.662 & 0.959 & 0.699 & 0.960 \\
\hline
\end{tabular}

Notes: See Section 3 for discussion. Both log hotel revenues and log number of tourists are computed with the inverse hyperbolic sine transformation. Standard errors are clustered at the level of municipalities. ${ }^{*} 10 \%,{ }^{* *} 5 \%,{ }^{* * *} 1 \%$ significance levels. 
Table A.13: Tourism's Effect on Municipality Population: Using 100\% Census Samples

\begin{tabular}{|c|c|c|c|c|}
\hline \multirow[t]{4}{*}{ Dependent variable: } & \multicolumn{4}{|c|}{ Log Census Population 2000 and 2010} \\
\hline & (1) & (2) & (3) & (4) \\
\hline & \multicolumn{2}{|c|}{$10 \%$ Sample Data (IPUMS) } & \multicolumn{2}{|c|}{$100 \%$ Sample Data (INEGI) } \\
\hline & OLS & Three IVs & OLS & Three IVs \\
\hline \multirow[t]{2}{*}{ Log Hotel Sales } & $0.200 * * *$ & $0.200 * * *$ & $0.200 * * *$ & $0.202 * * *$ \\
\hline & $(0.00564)$ & $(0.0416)$ & $(0.00563)$ & $(0.0413)$ \\
\hline \multirow[t]{2}{*}{ Log Distance to US Border } & 0.0341 & 0.0341 & 0.0300 & 0.0310 \\
\hline & $(0.0427)$ & $(0.0460)$ & $(0.0425)$ & $(0.0457)$ \\
\hline \multirow{2}{*}{ Log Distance to Mexico City } & $-0.592 * * *$ & $-0.591 * * *$ & $-0.590 * * *$ & $-0.588 * * *$ \\
\hline & $(0.0284)$ & $(0.0539)$ & $(0.0283)$ & $(0.0537)$ \\
\hline \multirow[t]{2}{*}{ Log Municipality Area } & $0.370 * * *$ & $0.370 * * *$ & $0.369 * * *$ & $0.367 * * *$ \\
\hline & $(0.0171)$ & $(0.0540)$ & $(0.0170)$ & $(0.0537)$ \\
\hline \multirow[t]{2}{*}{ State Capital Dummy } & $0.627 * * *$ & $0.627 * *$ & $0.632 * * *$ & $0.624 * *$ \\
\hline & $(0.195)$ & $(0.256)$ & $(0.195)$ & $(0.255)$ \\
\hline \multirow[t]{2}{*}{ Old City Dummy } & $0.920 * * *$ & $0.920 * * *$ & $0.920 * * *$ & $0.912 * * *$ \\
\hline & $(0.233)$ & $(0.285)$ & $(0.233)$ & $(0.283)$ \\
\hline \multirow[t]{2}{*}{ Colonial Port Dummy } & $0.672 * * *$ & $0.671 * * *$ & $0.673 * * *$ & $0.665 * * *$ \\
\hline & $(0.143)$ & $(0.216)$ & $(0.143)$ & $(0.214)$ \\
\hline \multirow[t]{2}{*}{ Log Average Precipitation } & $0.245 * * *$ & $0.245 * * *$ & $0.246 * * *$ & $0.245 * * *$ \\
\hline & $(0.0407)$ & $(0.0415)$ & $(0.0407)$ & $(0.0414)$ \\
\hline \multirow[t]{2}{*}{ Log Average Temperature } & $0.282 * * *$ & $0.282 * * *$ & $0.280 * * *$ & $0.279 * * *$ \\
\hline & $(0.104)$ & $(0.106)$ & $(0.104)$ & $(0.106)$ \\
\hline Year-By-Coast FX & $\checkmark$ & $\checkmark$ & $\checkmark$ & $\checkmark$ \\
\hline Observations & 4,889 & 4,889 & 4,889 & 4,889 \\
\hline Number of Municipalities & 2455 & 2455 & 2455 & 2455 \\
\hline First Stage F-Stat & & 15.13 & & 15.13 \\
\hline Over-ID Test P-Value & & 0.699 & & 0.701 \\
\hline
\end{tabular}

Notes: See Section 3 for discussion. Standard errors are clustered at the level of municipalities. ${ }^{*} 10 \%,{ }^{* *} 5 \%, * * * 1 \%$ significance levels. 
Table A.14: Coastal vs Inland Variation

\begin{tabular}{|c|c|c|c|c|c|c|}
\hline \multirow[t]{5}{*}{ Dependent variable: } & \multicolumn{3}{|c|}{ Log Municipality Employment 2000, 2010} & \multicolumn{3}{|c|}{ Log Municipality Population 2000, 2010} \\
\hline & (1) & (2) & (3) & (4) & (5) & (6) \\
\hline & $\begin{array}{c}\text { All } \\
\text { Municipalities }\end{array}$ & $\begin{array}{c}\text { Coastal } \\
\text { Municipalities } \\
\text { Only }\end{array}$ & $\begin{array}{l}\text { Interacted } \\
\text { Controls }\end{array}$ & $\begin{array}{c}\text { All } \\
\text { Municipalities }\end{array}$ & $\begin{array}{c}\text { Coastal } \\
\text { Municipalities } \\
\text { Only }\end{array}$ & $\begin{array}{c}\text { Interacted } \\
\text { Controls }\end{array}$ \\
\hline & Island and & Island and & Island and & Island and & Island and & Island and \\
\hline & Beach IVs & Beach IVs & Beach IVs & Beach IVs & Beach IVs & Beach IVs \\
\hline \multirow[t]{2}{*}{ Log Hotel Sales } & $0.279 * * *$ & $0.279 * * *$ & $0.257 * * *$ & $0.241 * * *$ & $0.241 * * *$ & $0.218 * * *$ \\
\hline & $(0.0493)$ & $(0.0493)$ & $(0.0661)$ & $(0.0514)$ & $(0.0514)$ & $(0.0706)$ \\
\hline Year-By-Coast FX & $\checkmark$ & $\checkmark$ & $\checkmark$ & $\checkmark$ & $\checkmark$ & $\checkmark$ \\
\hline Full Set of Controls Interacted with Coast FX & & & $\checkmark$ & & & $\checkmark$ \\
\hline Observations & 4,889 & 297 & 4,889 & 4,889 & 297 & 4,889 \\
\hline Number of Municipalities & 2455 & 150 & 2455 & 2455 & 150 & 2455 \\
\hline First Stage F-Stat & 15.72 & 15.48 & 10.63 & 15.72 & 15.48 & 10.63 \\
\hline Over-ID Test P-Value & 0.178 & 0.178 & 0.469 & 0.178 & 0.178 & 0.469 \\
\hline
\end{tabular}

Notes: See Section 3 for discussion. Island IV is a dummy indicating whether an offshore island is within $5 \mathrm{~km}$ of the municipalities' coastline. Beach IV is the fraction of municipality area within $100 \mathrm{~m}$ of the coastline covered by white sand pixels that lie within the wavelength ranges of the 8 top-ranked Mexican beaches. Standard errors are clustered at the level of municipalities. ${ }^{*} 10 \%,{ }^{* *} 5 \%,{ }^{* * *} 1 \%$ significance levels.

Table A.15: Tourism's Effect on Municipality Employment and Population: 2SLS vs LIML

\begin{tabular}{|c|c|c|c|c|}
\hline \multirow[t]{4}{*}{ Dependent variable: } & \multicolumn{2}{|c|}{ Log Municipality Employment 2000, 2010} & \multicolumn{2}{|c|}{ Log Municipality Population 2000, 2010} \\
\hline & (1) & (2) & (3) & (4) \\
\hline & 2SLS & LIML & 2SLS & LIML \\
\hline & Three IVs & Three IVs & Three IVs & Three IVs \\
\hline \multirow[t]{2}{*}{ Log Hotel Sales } & $0.24497 * * *$ & $0.24570 * * *$ & $0.19978 * * *$ & $0.19978 * * *$ \\
\hline & $(0.04059)$ & $(0.04169)$ & $(0.04156)$ & $(0.04273)$ \\
\hline \multirow[t]{2}{*}{ Log Distance to US Border } & -0.01629 & -0.01594 & 0.03410 & 0.03410 \\
\hline & $(0.04385)$ & $(0.04402)$ & $(0.04598)$ & $(0.04618)$ \\
\hline \multirow[t]{2}{*}{ Log Distance to Mexico City } & $-0.54851 * * *$ & $-0.54770 * * *$ & $-0.59145 * * *$ & $-0.59144 * * *$ \\
\hline & $(0.05261)$ & $(0.05364)$ & $(0.05393)$ & $(0.05503)$ \\
\hline \multirow[t]{2}{*}{ Log Municipality Area } & $0.31818 * * *$ & $0.31728 * * *$ & $0.36955^{* * *}$ & $0.36954 * * *$ \\
\hline & $(0.05253)$ & $(0.05383)$ & $(0.05397)$ & $(0.05534)$ \\
\hline \multirow[t]{2}{*}{ State Capital Dummy } & $0.68907 * * *$ & $0.68614 * * *$ & $0.62698 * *$ & $0.62697 * *$ \\
\hline & $(0.24213)$ & $(0.24492)$ & $(0.25613)$ & $(0.25920)$ \\
\hline \multirow{2}{*}{ Old City Dummy } & $0.92440 * * *$ & $0.92156^{* * *}$ & $0.91992 * * *$ & $0.91991 * * *$ \\
\hline & $(0.26803)$ & $(0.27030)$ & $(0.28497)$ & $(0.28758)$ \\
\hline \multirow{2}{*}{ Colonial Port Dummy } & $0.59672 * * *$ & $0.59392 * * *$ & $0.67134 * * *$ & $0.67133 * * *$ \\
\hline & $(0.20499)$ & $(0.20822)$ & $(0.21552)$ & $(0.21892)$ \\
\hline \multirow[t]{2}{*}{ Log Average Precipitation } & $0.25810 * * *$ & $0.25797 * * *$ & $0.24461 * * *$ & $0.24461 * * *$ \\
\hline & $(0.04088)$ & $(0.04093)$ & $(0.04148)$ & $(0.04153)$ \\
\hline \multirow[t]{2}{*}{ Log Average Temperature } & $0.22324 * *$ & $0.22296^{* *}$ & $0.28170 * * *$ & $0.28170 * * *$ \\
\hline & $(0.10748)$ & $(0.10756)$ & $(0.10585)$ & $(0.10592)$ \\
\hline Year-By-Coast FX & $\checkmark$ & $\checkmark$ & $\checkmark$ & $\checkmark$ \\
\hline Observations & 4,889 & 4,889 & 4,889 & 4,889 \\
\hline Number of Municipalities & 2455 & 2455 & 2455 & 2455 \\
\hline
\end{tabular}

Notes: See Section 3 for discussion. Standard errors are clustered at the level of municipalities. ${ }^{*} 10 \%,{ }^{* *} 5 \%,{ }^{* * *} 1 \%$ significance levels. 
Table A.16: Excluding or Controlling for Planned Tourism Centers

\begin{tabular}{|c|c|c|c|c|c|c|c|c|c|c|c|c|}
\hline \multirow[b]{3}{*}{ Dependent Variables: } & \multicolumn{6}{|c|}{ Population Census 2000, 2010} & \multicolumn{6}{|c|}{ Censos Economicos 1998, 2008} \\
\hline & (1) & (2) & (3) & (4) & $(5)$ & (6) & (7) & $(8)$ & (9) & (10) & (11) & $(12)$ \\
\hline & \multicolumn{3}{|c|}{ Log Employment } & \multicolumn{3}{|c|}{ Log Population } & \multicolumn{3}{|c|}{ Log GDP } & \multicolumn{3}{|c|}{ Log Manu GDP } \\
\hline & (Baseline) & & & (Baseline) & & & (Baseline) & & & (Baseline) & & \\
\hline Log Hotel Sales & $\begin{array}{c}0.245 * * * \\
(0.0406)\end{array}$ & $\begin{array}{r}0.265 * * * \\
(0.0508)\end{array}$ & $\begin{array}{r}0.238 * * * \\
(0.0533)\end{array}$ & $\begin{array}{r}0.200^{* * *} \\
(0.0416)\end{array}$ & $\begin{array}{r}0.222 * * * \\
(0.0510)\end{array}$ & $\begin{array}{r}0.193 * * * \\
(0.0533)\end{array}$ & $\begin{array}{r}0.404 * * * \\
(0.0713)\end{array}$ & $\begin{array}{r}0.416^{* * *} \\
(0.0895)\end{array}$ & $\begin{array}{r}0.354 * * * \\
(0.0936)\end{array}$ & $\begin{array}{r}0.394 * * * \\
(0.0939)\end{array}$ & $\begin{array}{c}0.484 * * * \\
(0.127)\end{array}$ & $\begin{array}{c}0.411 * * * \\
(0.134)\end{array}$ \\
\hline Year-By-Coast FX & $\checkmark$ & $\checkmark$ & $\checkmark$ & $\checkmark$ & $\checkmark$ & $\checkmark$ & $\checkmark$ & $\checkmark$ & $\checkmark$ & $\checkmark$ & $\checkmark$ & $\checkmark$ \\
\hline Full Set of Controls & $\checkmark$ & $\checkmark$ & $\checkmark$ & $\checkmark$ & $\checkmark$ & $\checkmark$ & $\checkmark$ & $\checkmark$ & $\checkmark$ & $\checkmark$ & $\checkmark$ & $\checkmark$ \\
\hline $\begin{array}{l}\text { Add Controls for Planned } \\
\text { Centers and Distance }\end{array}$ & & $\checkmark$ & & & $\checkmark$ & & & $\checkmark$ & & & $\checkmark$ & \\
\hline Drop Planned Centers & & & $\checkmark$ & & & $\checkmark$ & & & $\checkmark$ & & & $\checkmark$ \\
\hline Observations & 4,889 & 4,889 & 4,875 & 4,889 & 4,889 & 4,875 & 4,889 & 4,889 & 4,875 & 4,889 & 4,889 & 4,875 \\
\hline Number of Municipalities & 2455 & 2455 & 2448 & 2455 & 2455 & 2448 & 2455 & 2455 & 2448 & 2455 & 2455 & 2448 \\
\hline First Stage F-Stat & 15.13 & 8.899 & 7.956 & 15.13 & 8.899 & 7.956 & 15.13 & 8.899 & 7.956 & 15.13 & 8.899 & 7.956 \\
\hline Over-ID Test P-Value & 0.662 & 0.160 & 0.323 & 0.699 & 0.194 & 0.294 & 0.302 & 0.540 & 0.859 & 0.457 & 0.861 & 0.747 \\
\hline
\end{tabular}

Notes: See Section 3.3 for discussion. The table presents second-stage IV point estimates using the three IVs combined. The first column for each outcome variable presents the baseline estimate. The second column presents the estimate after controlling for FONATUR's planned tourism centers and log distance to them. The third column drops planned tourism centers. Standard errors are clustered at the level of municipalities. ${ }^{*} 10 \%,{ }^{* *} 5 \%,{ }^{* * *} 1 \%$ significance levels. 
Table A.17: Tourism's Effect on Traded Sector Production By Degree of Input Intensity

\begin{tabular}{|c|c|c|c|c|}
\hline \multirow{3}{*}{$\begin{array}{l}\text { Dependent variable: Log } \\
\text { Manufacturing GDP }\end{array}$} & (1) & (2) & (3) & (4) \\
\hline & $\begin{array}{l}\text { Below Median Input Intensity } \\
\text { (10 Sectors) }\end{array}$ & $\begin{array}{l}\text { Above Median Input Intensity } \\
\text { (11 Sectors) }\end{array}$ & $\begin{array}{c}\text { Sectors Not in Tourism Satellite } \\
\text { Use Table (16 Sectors) }\end{array}$ & $\begin{array}{c}\text { Sectors in Tourism Satellite Use } \\
\text { Table ( } 5 \text { Sectors) }\end{array}$ \\
\hline & Three IVs & Three IVs & Three IVs & Three IVs \\
\hline \multicolumn{5}{|c|}{ Panel A: Left Hand Side with IHS Transformation } \\
\hline Log Hotel Sales & $\begin{array}{l}0.497 * * * \\
(0.0984)\end{array}$ & $\begin{array}{l}0.529 * * * \\
(0.102)\end{array}$ & $\begin{array}{l}0.448 * * * \\
(0.0930)\end{array}$ & $\begin{array}{l}0.672 * * * \\
(0.113)\end{array}$ \\
\hline Year-By-Coast-By-Sector FX & $\checkmark$ & $\checkmark$ & $\checkmark$ & $\checkmark$ \\
\hline Full Set of Controls & $\checkmark$ & $\checkmark$ & $\checkmark$ & $\checkmark$ \\
\hline Observations & 53,779 & 48,890 & 73,335 & 29,334 \\
\hline Number of Municipalities & 2455 & 2455 & 2455 & 2455 \\
\hline First Stage F-Stat & 15.16 & 15.16 & 15.16 & 15.15 \\
\hline Over-ID Test P-Value & 0.323 & 0.502 & 0.387 & 0.493 \\
\hline \multicolumn{5}{|c|}{ Panel B: Left Hand Side with Log(Zero+1) } \\
\hline Log Hotel Sales & $\begin{array}{l}0.466 * * * \\
(0.0929)\end{array}$ & $\begin{array}{l}0.491 * * * \\
(0.0962)\end{array}$ & $\begin{array}{l}0.418 * * * \\
(0.0873)\end{array}$ & $\begin{array}{l}0.629 * * * \\
(0.107)\end{array}$ \\
\hline Year-By-Coast-By-Sector FX & $\checkmark$ & $\checkmark$ & $\checkmark$ & $\checkmark$ \\
\hline Full Set of Controls & $\checkmark$ & $\checkmark$ & $\checkmark$ & $\checkmark$ \\
\hline Observations & 53,779 & 48,890 & 73,335 & 29,334 \\
\hline Number of Municipalities & 2455 & 2455 & 2455 & 2455 \\
\hline First Stage F-Stat & 15.16 & 15.16 & 15.16 & 15.15 \\
\hline Over-ID Test P-Value & 0.315 & 0.483 & 0.374 & 0.481 \\
\hline \multicolumn{5}{|c|}{ Panel C: Left Hand Side with Simple Logs (Dropping Zeroes) } \\
\hline Log Hotel Sales & $\begin{array}{l}0.359 * * * \\
(0.0721)\end{array}$ & $\begin{array}{l}0.457 * * * \\
(0.0714)\end{array}$ & $\begin{array}{l}0.388 * * * \\
(0.0619)\end{array}$ & $\begin{array}{l}0.431 * * * \\
(0.0944)\end{array}$ \\
\hline Year-By-Coast-By-Sector FX & $\checkmark$ & $\checkmark$ & $\checkmark$ & $\checkmark$ \\
\hline Full Set of Controls & $\checkmark$ & $\checkmark$ & $\checkmark$ & $\checkmark$ \\
\hline Observations & 19,637 & 13,516 & 21,184 & 11,969 \\
\hline Number of Municipalities & 2224 & 2057 & 2161 & 2203 \\
\hline First Stage F-Stat & 14.83 & 14.57 & 16.33 & 12.45 \\
\hline Over-ID Test P-Value & 0.460 & 0.739 & 0.552 & 0.771 \\
\hline
\end{tabular}

Notes: See Section 3.3 for discussion. Standard errors are clustered at the level of municipalities. ${ }^{*} 10 \%,{ }^{* *} 5 \%$, *** $1 \%$ significance levels. 
Table A.18: Checking Effect of IVs in 2000 vs 2010

\begin{tabular}{|c|c|c|c|c|c|c|c|c|c|c|c|c|}
\hline & (1) & (2) & (3) & (4) & (5) & (6) & (7) & (8) & (9) & (10) & (11) & (12) \\
\hline Dependent variables: & \multicolumn{3}{|c|}{ Employment } & \multicolumn{3}{|c|}{ Population } & \multicolumn{3}{|c|}{ GDP } & \multicolumn{3}{|c|}{ Manufacturing GDP } \\
\hline Island IV & $\begin{array}{c}0.526^{* *} \\
(0.222)\end{array}$ & & & $\begin{array}{c}0.435^{* *} \\
(0.222)\end{array}$ & & & $\begin{array}{c}0.329 \\
(0.374)\end{array}$ & & & $\begin{array}{c}0.193 \\
(0.417)\end{array}$ & & \\
\hline Island IV x 2010 & $\begin{array}{l}-0.0401 \\
(0.0381)\end{array}$ & & & $\begin{array}{c}0.0227 \\
(0.0318)\end{array}$ & & & $\begin{array}{c}0.0794 \\
(0.0979)\end{array}$ & & & $\begin{array}{l}0.0810 \\
(0.134)\end{array}$ & & \\
\hline Beach IV & & $\begin{array}{c}9.215^{* * *} \\
(3.354)\end{array}$ & & & $\begin{array}{l}6.627^{*} \\
(3.684)\end{array}$ & & & $\begin{array}{c}21.27 * * * \\
(4.691)\end{array}$ & & & $\begin{array}{c}18.13^{* * *} \\
(4.016)\end{array}$ & \\
\hline Beach IV x 2010 & & $\begin{array}{c}0.969 \\
(0.709)\end{array}$ & & & $\begin{array}{c}1.551^{* * *} \\
(0.545)\end{array}$ & & & $\begin{array}{l}-1.849 \\
(1.368)\end{array}$ & & & $\begin{array}{l}-3.506 \\
(3.423)\end{array}$ & \\
\hline Ruins IV & & & $\begin{array}{c}0.391 * * * \\
(0.115)\end{array}$ & & & $\begin{array}{c}0.291 * * * \\
(0.109)\end{array}$ & & & $\begin{array}{c}0.689 * * * \\
(0.239)\end{array}$ & & & $\begin{array}{c}0.824 * * * \\
(0.294)\end{array}$ \\
\hline Ruins IV x 2010 & & & $\begin{array}{l}-0.0492 \\
(0.0502)\end{array}$ & & & $\begin{array}{c}0.0170 \\
(0.0221)\end{array}$ & & & $\begin{array}{l}-0.0755 \\
(0.0888)\end{array}$ & & & $\begin{array}{c}-0.0944 \\
(0.136)\end{array}$ \\
\hline Year-By-Coast FX & $\checkmark$ & $\checkmark$ & $\checkmark$ & $\checkmark$ & $\checkmark$ & $\checkmark$ & $\checkmark$ & $\checkmark$ & $\checkmark$ & $\checkmark$ & $\checkmark$ & $\checkmark$ \\
\hline Full Set of Controls & $\checkmark$ & $\checkmark$ & $\checkmark$ & $\checkmark$ & $\checkmark$ & $\checkmark$ & $\checkmark$ & $\checkmark$ & $\checkmark$ & $\checkmark$ & $\checkmark$ & $\checkmark$ \\
\hline Observations & 4,889 & 4,889 & 4,889 & 4,889 & 4,889 & 4,889 & 4,889 & 4,889 & 4,889 & 4,889 & 4,889 & 4,889 \\
\hline R-squared & 0.478 & 0.478 & 0.478 & 0.475 & 0.475 & 0.475 & 0.380 & 0.381 & 0.381 & 0.272 & 0.273 & 0.274 \\
\hline Number of Municipalities & 2455 & 2455 & 2455 & 2455 & 2455 & 2455 & 2455 & 2455 & 2455 & 2455 & 2455 & 2455 \\
\hline
\end{tabular}

Notes: Island IV is a dummy indicating whether an offshore island is within $5 \mathrm{~km}$ of the municipalities' coastline. Beach IV is the fraction of municipality area within $100 \mathrm{~m}$ of the coastline covered by white sand pixels that lie within the wavelength ranges of the 8 top-ranked Mexican beaches. Ruins IV is a dummy indicating the presence of pre-Hispanic archaeological ruins. Standard errors are clustered at the level of municipalities. ${ }^{*} 10 \%,{ }^{* *} 5 \%,{ }^{* *} 1 \%$ significance levels.

Table A.19: Checking Correlations of Tourism Shifters with IVs and Hotel Sales

\begin{tabular}{|c|c|c|c|c|c|c|c|c|}
\hline & (1) & (2) & (3) & (4) & (5) & (6) & (7) & (8) \\
\hline Dependent Variables: & $\log (\tilde{A} n)$ & $\log (\tilde{A} n)$ & $\log (\tilde{A} n)$ & $\begin{array}{c}\text { Log Hotel } \\
\text { Sales }\end{array}$ & $\log (A n)$ & $\log (A n)$ & $\log (A n)$ & $\begin{array}{c}\text { Log Hotel } \\
\text { Sales } \\
\end{array}$ \\
\hline Island IV & $\begin{array}{c}1.328 * * * \\
(0.411)\end{array}$ & & & & $\begin{array}{c}1.242 * * * \\
(0.414)\end{array}$ & & & \\
\hline Beach IV & & $\begin{array}{l}22.45^{*} \\
(10.81)\end{array}$ & & & & $\begin{array}{c}20.86^{*} \\
(10.39)\end{array}$ & & \\
\hline Ruins IV & & & $\begin{array}{l}0.963 * \\
(0.485)\end{array}$ & & & & $\begin{array}{l}0.924 * \\
(0.482)\end{array}$ & \\
\hline $\log (\tilde{A} n)$ & & & & $\begin{array}{c}0.974 * * * \\
(0.0512)\end{array}$ & & & & \\
\hline $\log (A n)$ & & & & & & & & $\begin{array}{c}0.984 * * * \\
(0.0523)\end{array}$ \\
\hline Full Set of Controls & $\checkmark$ & $\checkmark$ & $\checkmark$ & $\checkmark$ & $\checkmark$ & $\checkmark$ & $\checkmark$ & $\checkmark$ \\
\hline Number of Regions & 150 & 150 & 300 & 300 & 150 & 150 & 300 & 300 \\
\hline R-Squared & 0.359 & 0.363 & 0.227 & 0.804 & 0.349 & 0.353 & 0.226 & 0.793 \\
\hline
\end{tabular}

Notes: See Section 5.2 for discussion. Island IV is a dummy indicating whether an offshore island is within $5 \mathrm{~km}$ of the municipalities' coastline. Beach IV is the fraction of municipality area within $100 \mathrm{~m}$ of the coastline covered by white sand pixels that lie within the wavelength ranges of the 8 top-ranked Mexican beaches. Ruins IV is a dummy indicating the presence of pre-Hispanic archaeological ruins. Standard errors are clustered at the level of Mexican states. ${ }^{*} 10 \%$, ${ }^{* *}$ $5 \%, * * * 1 \%$ significance levels. 
Table A.20: Within-Country Tourism Flows

\begin{tabular}{|c|c|c|c|c|c|}
\hline $\begin{array}{c}\text { Reported Top } 5 \\
\text { Domestic Tourist } \\
\text { Origin States Visiting } \\
\text { Ciudad de Mexico } \\
\end{array}$ & $\begin{array}{c}\text { Predicted Rank of } \\
\text { Origins to Ciudad de } \\
\text { Mexico in Calibrated } \\
\text { Model } \\
\end{array}$ & $\begin{array}{c}\text { Reported Top } 5 \\
\text { Domestic Tourist } \\
\text { Origin States Visiting } \\
\text { Veracruz } \\
\end{array}$ & $\begin{array}{l}\text { Predicted Rank of } \\
\text { Origins to Veracruz in } \\
\text { Calibrated Model }\end{array}$ & $\begin{array}{c}\text { Reported Top 5 } \\
\text { Domestic Tourist } \\
\text { Origin States Visiting } \\
\text { Quintana Roo } \\
\end{array}$ & $\begin{array}{c}\text { Predicted Rank } \\
\text { ofOrigins to Quinatana } \\
\text { Roo in Calibrated } \\
\text { Model }\end{array}$ \\
\hline Mexico State & 1 & Ciudad de Mexico & 1 & Ciudad de Mexico & 1 \\
\hline Puebla & 2 & Mexico State & 2 & Mexico State & 2 \\
\hline Veracruz & 4 & Jalisco & 4 & Veracruz & 4 \\
\hline Michoacan & 8 & Michoacan & 10 & Michoacan & 13 \\
\hline Guerrero & 10 & Guerrero & 12 & Guerrero & 15 \\
\hline
\end{tabular}

Notes: See Section 5.1 for discussion. 
Table A.21: Spatial Labor Supply Elasticity

\begin{tabular}{|c|c|c|c|c|}
\hline \multirow[t]{2}{*}{ Dependent Variable: } & \multicolumn{4}{|c|}{ Log Municipality Employment 2000, 2010} \\
\hline & $\begin{array}{c}(1) \\
\text { OLS } \\
\end{array}$ & $\begin{array}{c}(2) \\
\text { Three IVs } \\
\end{array}$ & $\begin{array}{c}(3) \\
\text { OLS } \\
\end{array}$ & $\begin{array}{c}(4) \\
\text { Three IVs }\end{array}$ \\
\hline Log Nominal Wage & $\begin{array}{c}1.163 * * * \\
(0.262)\end{array}$ & $\begin{array}{l}5.150 * * \\
(2.362)\end{array}$ & & \\
\hline Log Real Wage & & & $\begin{array}{c}1.910 * * * \\
(0.348)\end{array}$ & $\begin{array}{c}6.353 * * \\
(2.608)\end{array}$ \\
\hline Log Distance to US Border & $\begin{array}{c}0.0325 \\
(0.0986)\end{array}$ & $\begin{array}{c}0.441 \\
(0.308)\end{array}$ & $\begin{array}{c}0.0584 \\
(0.0926)\end{array}$ & $\begin{array}{c}0.396 \\
(0.259)\end{array}$ \\
\hline Log Distance to Mexico City & $\begin{array}{l}-0.0291 \\
(0.142)\end{array}$ & $\begin{array}{l}0.0640 \\
(0.144)\end{array}$ & $\begin{array}{l}0.0554 \\
(0.130)\end{array}$ & $\begin{array}{c}0.315 \\
(0.224)\end{array}$ \\
\hline Log Municipality Area & $\begin{array}{c}0.297 * * * \\
(0.105)\end{array}$ & $\begin{array}{l}0.202^{* *} \\
(0.0905)\end{array}$ & $\begin{array}{c}0.302 * * * \\
(0.0963)\end{array}$ & $\begin{array}{c}0.248 * * * \\
(0.0801)\end{array}$ \\
\hline State Capital Dummy & $\begin{array}{c}0.916^{* * *} \\
(0.312)\end{array}$ & $\begin{array}{l}-0.308 \\
(0.784)\end{array}$ & $\begin{array}{c}0.716^{* *} \\
(0.296)\end{array}$ & $\begin{array}{l}-0.579 \\
(0.805)\end{array}$ \\
\hline Old City Dummy & $\begin{array}{l}-0.321 \\
(0.479)\end{array}$ & $\begin{array}{l}-1.041 \\
(0.640)\end{array}$ & $\begin{array}{l}-0.367 \\
(0.450)\end{array}$ & $\begin{array}{l}-0.961^{*} \\
(0.544)\end{array}$ \\
\hline Colonial Port Dummy & $\begin{array}{c}2.906^{* * *} * \\
(0.298)\end{array}$ & $\begin{array}{c}2.481 * * * \\
(0.417)\end{array}$ & $\begin{array}{c}2.702 * * * \\
(0.282)\end{array}$ & $\begin{array}{c}1.940 * * * \\
(0.545)\end{array}$ \\
\hline Log Average Precipitation & $\begin{array}{l}0.375^{*} \\
(0.211)\end{array}$ & $\begin{array}{l}0.680^{*} \\
(0.393)\end{array}$ & $\begin{array}{c}0.350 \\
(0.210)\end{array}$ & $\begin{array}{c}0.500 \\
(0.343)\end{array}$ \\
\hline Log Average Temperature & $\begin{array}{l}-0.313 \\
(0.897)\end{array}$ & $\begin{array}{c}0.311 \\
(0.986)\end{array}$ & $\begin{array}{l}-0.250 \\
(0.866)\end{array}$ & $\begin{array}{c}0.321 \\
(0.905)\end{array}$ \\
\hline Coast FX & $\checkmark$ & $\checkmark$ & $\checkmark$ & $\checkmark$ \\
\hline Observations & 300 & 300 & 300 & 300 \\
\hline Number of Clusters & 32 & 32 & 32 & 32 \\
\hline First Stage F-Stat & & 3.723 & & 3.594 \\
\hline Over-ID Test P-Value & & 0.890 & & 0.856 \\
\hline
\end{tabular}

Notes: See Section 5.1 and Appendix 4 for discussion. Standard errors are clustered at the level of Mexican states. * $10 \%, * * 5 \%,{ }^{* * *} 1 \%$ significance levels. 
Table A.22: Tourism's Trade Elasticity

\begin{tabular}{|c|c|c|c|c|c|c|c|}
\hline \multirow{3}{*}{ Dependent Variables: } & \multirow{3}{*}{$\begin{array}{c}(1) \\
\text { Same Year } \\
\text { OLS }\end{array}$} & \multicolumn{6}{|c|}{ Log Tourism Exports from Origin to Destination } \\
\hline & & $(2)$ & (3) & (4) & (5) & (6) & $(7)$ \\
\hline & & $\begin{array}{c}\text { Same Year } \\
\text { IV }\end{array}$ & $\begin{array}{c}\text { 1-Year Lag } \\
\text { IV }\end{array}$ & $\begin{array}{c}\text { 2-Year Lag } \\
\text { IV }\end{array}$ & $\begin{array}{c}\text { 3-Year Lag } \\
\text { IV }\end{array}$ & $\begin{array}{c}\text { 4-Year Lag } \\
\text { IV }\end{array}$ & $\begin{array}{c}\text { 5-Year Lag } \\
\text { IV }\end{array}$ \\
\hline \multicolumn{8}{|l|}{ Panel A: All Destinations } \\
\hline \multirow[t]{2}{*}{ Log Inverse Consumption PPP } & $-0.140 * * *$ & -0.201 & $-0.419^{*}$ & $-0.550 * *$ & $-0.715^{* *}$ & $-0.710 * *$ & -0.351 \\
\hline & $(0.0402)$ & $(0.205)$ & $(0.227)$ & $(0.222)$ & $(0.281)$ & $(0.301)$ & $(0.227)$ \\
\hline \multirow{2}{*}{ Log Destination GDP } & $0.438 * * *$ & $0.410 * * *$ & $0.238 * *$ & 0.0699 & -0.104 & -0.102 & 0.0216 \\
\hline & $(0.0492)$ & $(0.103)$ & $(0.121)$ & $(0.121)$ & $(0.152)$ & $(0.165)$ & $(0.129)$ \\
\hline Origin-by-Destination FX & $\checkmark$ & $\checkmark$ & $\checkmark$ & $\checkmark$ & $\checkmark$ & $\checkmark$ & $\checkmark$ \\
\hline Origin-by-Period FX & $\checkmark$ & $\checkmark$ & $\checkmark$ & $\checkmark$ & $\checkmark$ & $\checkmark$ & $\checkmark$ \\
\hline Observations & 25,089 & 25,089 & 20,935 & 18,328 & 16,084 & 14,361 & 12,497 \\
\hline Number of Orig-Dest Pairs & 2899 & 2899 & 2596 & 2513 & 2265 & 2169 & 2098 \\
\hline First Stage F-Stat & & 171.5 & 159.9 & 136.4 & 72.74 & 76.19 & 102.5 \\
\hline \multicolumn{8}{|c|}{ Panel B: Touristic Destinations Only } \\
\hline \multirow[t]{2}{*}{ 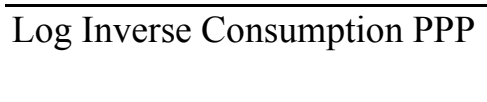 } & $-0.114 * * *$ & -0.298 & $-0.488 * *$ & $-0.571^{* *}$ & $-0.656^{* *}$ & $-0.616^{*}$ & -0.361 \\
\hline & $(0.0442)$ & $(0.204)$ & $(0.249)$ & $(0.251)$ & $(0.311)$ & $(0.339)$ & $(0.293)$ \\
\hline \multirow[t]{2}{*}{ Log Destination GDP } & $0.402 * * *$ & $0.312 * * *$ & 0.132 & -0.00375 & -0.141 & -0.159 & -0.109 \\
\hline & $(0.0631)$ & $(0.110)$ & $(0.138)$ & $(0.137)$ & $(0.162)$ & $(0.182)$ & $(0.162)$ \\
\hline Origin-by-Destination FX & $\checkmark$ & $\checkmark$ & $\checkmark$ & $\checkmark$ & $\checkmark$ & $\checkmark$ & $\checkmark$ \\
\hline Origin-by-Period FX & $\checkmark$ & $\checkmark$ & $\checkmark$ & $\checkmark$ & $\checkmark$ & $\checkmark$ & $\checkmark$ \\
\hline Observations & 17,165 & 17,165 & 14,294 & 12,535 & 11,052 & 9,874 & 8,603 \\
\hline Number of Orig-Dest Pairs & 1981 & 1981 & 1771 & 1710 & 1511 & 1474 & 1428 \\
\hline First Stage F-Stat & & 138.0 & 119.4 & 125.4 & 62.48 & 65.19 & 69.67 \\
\hline
\end{tabular}

Notes: See Appendix 4 for discussion. Standard errors are clustered at the level of origin-by-destination pairs. ${ }^{*} 10 \%, * * 5 \%$, *** $1 \%$ significance levels. 
Table A.23: The Gains from Tourism Across Alternative Parameter Combinations

\begin{tabular}{|c|c|c|c|c|c|c|c|c|c|c|c|c|c|c|}
\hline & $\begin{array}{l}\sigma=\rho \\
=1.5\end{array}$ & $\begin{array}{l}\sigma=\rho \\
=2.0\end{array}$ & $\begin{array}{l}\sigma=\rho \\
=2.5\end{array}$ & $\begin{array}{l}\sigma=\rho \\
=3.0\end{array}$ & $\begin{array}{l}\sigma=\rho \\
=3.5\end{array}$ & $\begin{array}{l}\sigma=\rho \\
=4.0\end{array}$ & $\begin{array}{l}\sigma=\rho \\
=4.5\end{array}$ & $\begin{array}{l}\sigma=\rho \\
=1.5\end{array}$ & $\begin{array}{l}\sigma=\rho \\
=2.0\end{array}$ & $\begin{array}{l}\sigma=\rho \\
=2.5\end{array}$ & $\begin{array}{l}\sigma=\rho \\
=3.0\end{array}$ & $\begin{array}{l}\sigma=\rho \\
=3.5\end{array}$ & $\begin{array}{l}\sigma=\rho \\
=4.0\end{array}$ & $\begin{array}{l}\sigma=\rho \\
=4.5\end{array}$ \\
\hline$\dddot{n} \gamma_{\mathrm{s}}=0$ & 4.60 & 3.19 & 2.77 & 2.61 & 2.56 & 2.56 & 2.60 & 1.22 & 1.00 & 0.91 & 0.84 & 0.78 & 0.71 & 0.64 \\
\hline$\| \quad \gamma_{S}=0.027$ & 5.36 & 3.93 & 3.50 & 3.32 & 3.26 & 3.26 & 3.29 & 1.79 & 1.53 & 1.39 & 1.29 & 1.18 & 1.06 & 0.94 \\
\hline$\stackrel{w}{\frac{\omega}{i}} \gamma_{S}=0.057$ & 6.14 & 4.67 & 4.22 & 4.03 & 3.96 & 3.94 & 3.96 & 2.29 & 1.97 & 1.79 & 1.64 & 1.48 & 1.32 & 1.16 \\
\hline$\unrhd \gamma_{S}=0.087$ & 6.81 & 5.32 & 4.82 & 4.61 & 4.51 & 4.47 & 4.46 & 2.49 & 2.07 & 1.84 & 1.65 & 1.48 & 1.31 & 1.13 \\
\hline$\cong \gamma_{\mathrm{s}}=0$ & 4.62 & 3.24 & 2.83 & 2.67 & 2.63 & 2.64 & 2.68 & 1.31 & 1.09 & 1.00 & 0.93 & 0.87 & 0.79 & 0.71 \\
\hline$\| \gamma_{S}=0.027$ & 5.40 & 4.00 & 3.58 & 3.42 & 3.37 & 3.38 & 3.41 & 1.93 & 1.68 & 1.55 & 1.44 & 1.32 & 1.20 & 1.06 \\
\hline$\stackrel{w}{\leftarrow} \gamma_{S}=0.057$ & 6.22 & 4.79 & 4.36 & 4.20 & 4.14 & 4.14 & 4.17 & 2.54 & 2.25 & 2.07 & 1.91 & 1.75 & 1.57 & 1.38 \\
\hline 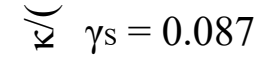 & 6.96 & 5.50 & 5.05 & 4.88 & 4.81 & 4.80 & 4.82 & 3.04 & 2.69 & 2.48 & 2.27 & 2.06 & 1.84 & 1.60 \\
\hline$\cong \gamma_{\mathrm{s}}=0$ & 4.68 & 3.32 & 2.92 & 2.78 & 2.74 & 2.75 & 2.80 & 1.43 & 1.23 & 1.13 & 1.06 & 0.99 & 0.90 & 0.81 \\
\hline$\stackrel{\sim}{\|} \gamma_{S}=0.027$ & 5.50 & 4.13 & 3.73 & 3.58 & 3.54 & 3.55 & 3.60 & 2.12 & 1.88 & 1.75 & 1.63 & 1.50 & 1.36 & 1.21 \\
\hline$\stackrel{\omega}{\underline{H}} \gamma_{S}=0.057$ & 6.39 & 5.00 & 4.60 & 4.45 & 4.41 & 4.42 & 4.46 & 2.85 & 2.57 & 2.39 & 2.22 & 2.04 & 1.83 & 1.61 \\
\hline$\stackrel{\underbrace{}}{\unrhd} \gamma_{S}=0.087$ & 7.25 & 5.84 & 5.43 & 5.28 & 5.23 & 5.24 & 5.28 & 3.54 & 3.22 & 2.99 & 2.77 & 2.52 & 2.26 & 1.97 \\
\hline
\end{tabular}

Notes: See Section 5.2 and Appendix 4 for discussion. The left panel reports the gains from tourism, and the right panel from international tourism. The highlighted cells indicate the model's best-fitting parameter calibration given the data. 
Table A.24: The Gains from Tourism Across Alternative Parameter Combinations

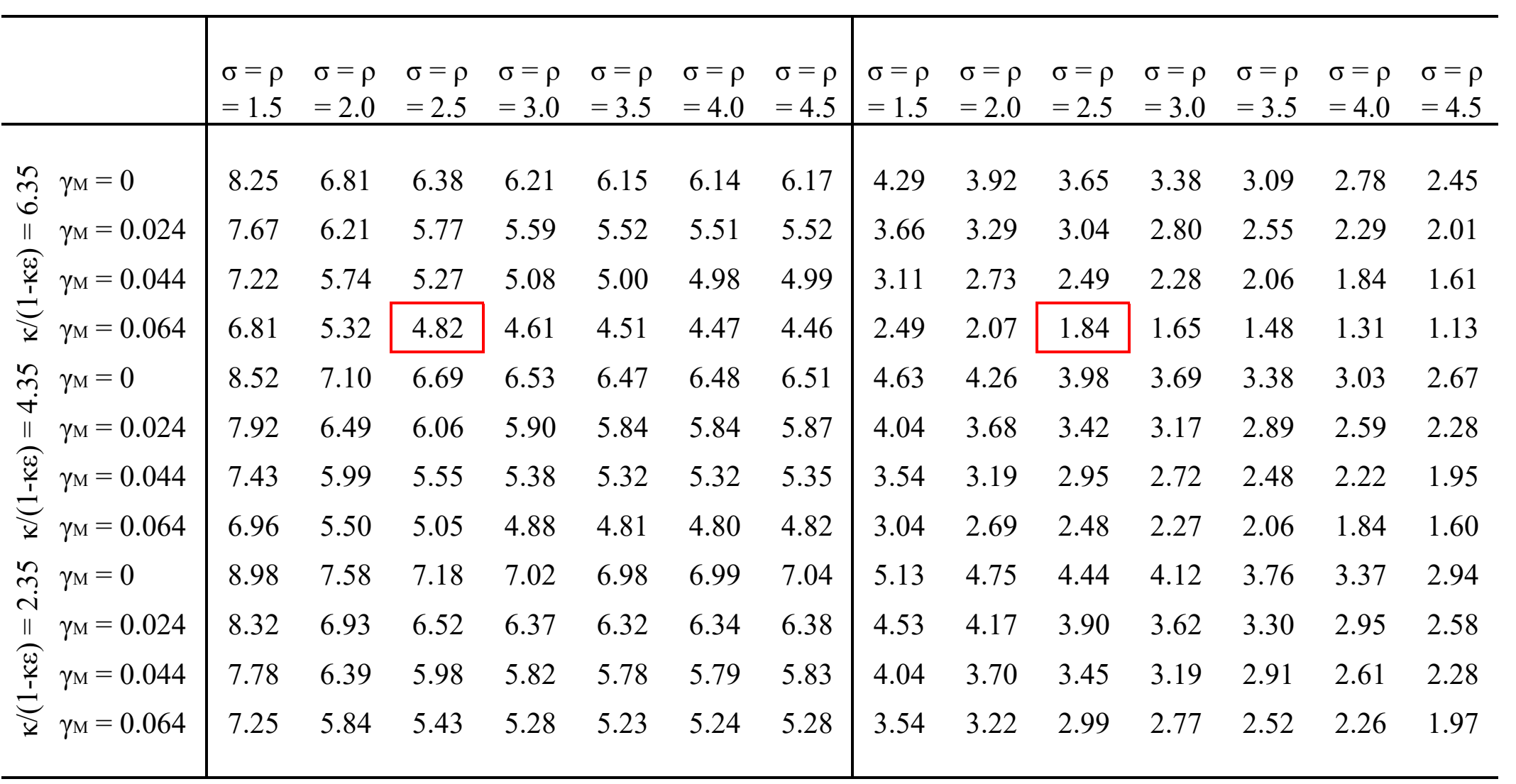

Notes: See Section 5.2 and Appendix 4 for discussion. The left panel reports the gains from tourism, and the right panel from international tourism. The highlighted cells indicate the model's best-fitting parameter calibration given the data. 
Table A.25: The Gains from Tourism Allowing for Non-Homotheticity

Baseline Counterfactual

Allowing for Increase in Tourism

Due to Higher Incomes

$\begin{array}{lll}\text { Gains from Tourism } & 4.82 \% & 4.74 \%\end{array}$

Notes: See Section 5.2 for discussion.

Table A.26: IV Point Estimates of Endogenous Reduction in Trade Costs

\begin{tabular}{lccc}
\hline & $\begin{array}{c}(1) \\
\text { Log Transport Time } \\
\text { Dependent Variables: }\end{array}$ & $\begin{array}{c}\text { Log Transport Time } \\
\text { (Simple Average) }\end{array}$ & $\begin{array}{c}\text { Log Transport Time } \\
\text { (GDP-Weighted Average) }\end{array}$ \\
\hline Log Hotel Sales & $-0.0276^{* * *}$ & $-0.0282^{* * *}$ & $-0.0360^{* * *}$ \\
& $(0.00586)$ & $(0.0104)$ & $(0.0138)$ \\
Year-By-Coast FX & & & $\checkmark$ \\
Full Set of Controls & $\checkmark$ & $\checkmark$ & $\checkmark$ \\
& & & 4,889 \\
Observations & 4,889 & 4,889 & 2455 \\
Number of Municipalities & 2455 & 2455 & 15.13 \\
First Stage F-Stat & 15.13 & 15.13 & \\
\hline
\end{tabular}

Notes: See Sections 3.3 and 5.2 for discussion. The table reports second-stage IV estimates using the island, beach and ruins instruments. "Transport Time" refers to the mean (or weighted mean as indicated) of municipality travel times to other municipalities and border crossings on the full terrestrial Mexican transport network. Standard errors are clustered at the level of municipalities. ${ }^{*} 10 \%, * * 5 \%, * * * 1 \%$ significance levels.

Table A.27: The Gains from Tourism Before and After Allowing for Endogenous Transport Cost Reductions

\begin{tabular}{lcccc}
\hline & Baseline Counterfactual & $\begin{array}{c}\text { Allowing for Highway } \\
\text { Connections to State } \\
\text { Capitals }\end{array}$ & $\begin{array}{c}\text { Allowing for 50 Percent } \\
\text { Reduction in Transport } \\
\text { Costs }\end{array}$ & $\begin{array}{c}\text { Allowing for Estimated } \\
\text { Reduction in Transport } \\
\text { Costs (Elasticity 0.036) }\end{array}$ \\
\hline Gains from Tourism & 4.82 & 4.74 & 4.64 & 5.23 \\
Gains from International Tourism & 1.84 & 1.63 & 1.28 & 0.08 \\
$\gamma_{\mathrm{S} \text { Estimate }}$ & 0.087 & 0.086 & 0.08 & 0.076 \\
$\gamma_{\mathrm{M}}$ Estimate & 0.064 & 0.070 & & 0.07 \\
\hline
\end{tabular}

Notes: See Section 5.2 for discussion. 
Table A.28: The Local Gains from Tourism Without Labor Mobility

\begin{tabular}{|c|c|c|}
\hline \multirow[t]{2}{*}{ Dependent variable: } & \multicolumn{2}{|c|}{ Counterfactual Change in Log Local Worker Utility } \\
\hline & (1) & (2) \\
\hline Counterfactual & All Tourism & International Tourism \\
\hline Parameters & $\mathrm{K}=0$ & $\mathrm{~K}=0$ \\
\hline & Three IVs & Three IVs \\
\hline \multirow[t]{2}{*}{ Counterfactual Change in Log Tourism GDP } & $0.237 * * *$ & $0.235 * * *$ \\
\hline & $(0.0719)$ & $(0.0715)$ \\
\hline Full Set of Controls & $\checkmark$ & $\checkmark$ \\
\hline Coast FX & $\checkmark$ & $\checkmark$ \\
\hline Observations & 300 & 300 \\
\hline Number of Clusters & 32 & 32 \\
\hline First Stage F-Stat & 3.532 & 3.514 \\
\hline OverID P-Value & 0.179 & 0.181 \\
\hline
\end{tabular}

Notes: See Appendix 4.6 for discussion. The point estimates are from an IV regression using the island, beach and ruins instruments. Standard errors are clustered at the level of Mexican states. ${ }^{*} 10 \%,{ }^{* *} 5 \%,{ }^{* * *} 1 \%$ significance levels.

Table A.29: The Gains from Tourism Accounting for Imperfect Competition and FDI

Fraction of Gains from Tourism if 35 Percent of Profits Are Repatriated (Relative to All Profits Remaining in Mexico)

Notes: See Appendix 4.6 for discussion.

Table A.30: The Gains from Tourism With Different Numbers of Regions

300 Mexican Regions $\quad 2455$ Mexican Regions

$\begin{array}{lcc}\text { Gains from All Tourism } & 4.82 \% & 4.94 \% \\ \text { Gains from International Tourism } & 1.84 \% & 1.80 \%\end{array}$

Notes: See Appendix 4.6 for discussion. 
Table A.31: The Regional Implications of Tourism With Different Numbers of Regions

\begin{tabular}{lcc}
\hline Dependent variable: & \multicolumn{2}{c}{ Counterfactual Change in Log Total GDP } \\
& $(1)$ & $(2)$ \\
& $0.409^{* * *}$ & $0.403^{* * *}$ \\
& $(0.0900)$ & $(0.0996)$ \\
Log Tourism GDP & $\checkmark$ & $\checkmark$ \\
& $\checkmark$ & $\checkmark$ \\
Coast FX & 300 & 2455 Mexican Regions \\
Full Set of Controls & $\mathbf{0 . 0 4 8 2}$ & $\mathbf{0 . 0 4 9 4}$ \\
Observations & 32 & 32 \\
Welfare Gains & & \\
Number of Clusters &
\end{tabular}

Notes: See Appendix 4.6 for discussion. The point estimates are from an IV regression using the island, beach and ruins instruments. Standard errors are clustered at the level of Mexican states. ${ }^{*} 10 \%,{ }^{* *} 5 \%, * * * 1 \%$ significance levels.

\section{Appendix 2: Data}

Hotel Revenues and Local Production Every five years the Mexican statistical institute INEGI undertakes a census of all economic establishments located in municipalities with more than 2500 inhabitants, and covers a representative sample of establishments in rural locations with less than 2500 inhabitants. In our analysis, we use the municipality-level data of the Censos Economicos 1999 and 2009, which contain information about economic activity in 1998 and 2008 respectively. The timing of these two datasets closely coincides with the two most recent national population censuses in Mexico in 2000 and 2010 that we describe below.

Our main explanatory variable of interest is municipality-level sales of hotels and other temporary accommodation (e.g. hostels). In our specifications, we label this variable as hotel sales. They are covered as part of the Censos Economicos Comerciales y de Servicios, from which we obtain two cross-sections of municipality hotel revenues for 1998 and 2008. We combine this information on hotel sales with data from the Censos Economicos for the same years on total municipality GDP, total municipality wage bill, and GDP broken up by sector of activity (e.g. manufacturing, mining, agriculture).

In the analysis, we interpret differences in log hotel sales across municipalities as effectively capturing proportional differences in total local tourism expenditures. The reason is that the available data for other tourist expenditures, such as restaurants, do not distinguish between sales to local residents vs visiting non-residents. The underlying assumption is that hotel sales are a constant share of tourist expenditure. As we discuss in Section 3, we also examine this assumption using available data over time and across destinations (see appendix Tables A.2 and A.10).

Finally, we obtain data on the number of foreign tourist arrivals in Mexico over time from the Mexican Secretariat for Tourism (Sectur), and data on the average airfares in constant US Dollars faced by US travelers from the US Transportation Statistics Database at the Bureau of Labor Statistics. As we discuss in Section 3, we use these data to corroborate the cross-sectional results with panel variation.

Population Census Data We use IPUMS microdata from the Mexican Population Census in 2000 and 2010 to construct municipality-level total population and employment, as well as individual- 
level wages including information on gender, education, age and ethnicity. The IPUMS microdata provide us with 10 percent random census samples in addition to population weights that are linked to each observation.

To construct municipality population, we sum up the number of people surveyed and weight the summation by population weights. To construct total municipality-level employment, we make use of the fact that the Mexican population censuses in 2000 and 2010 asked people in which municipality they work, and sum up the number of people (again weighted by population weights) that work in a given municipality. ${ }^{1}$

In order to construct wages, we first divide monthly incomes by hours worked in the census data. We then construct Mincerized wage residuals from a regression of log wages on dummies for gender and ethnicity in addition to the cubic polynomials of years of education and years of age as well as census year fixed effects. We weight these regressions by population weights. The final step is to take the population weighted average of the log wage residuals by year and municipality in the data.

In addition to the two most recent census rounds, we use historical Mexican population census data for the years 1921, 1930, 1940 and 1950 in order to estimate a set of placebo falsification tests. To that end, we use INEGI's database Archivo Historico de Localidades to construct spatial units for the year 2010 that we can trace back consistently to 1921. In particular, we extract the history of each census tract that existed in each of the 10 national population censuses conducted between 1921-2010. For example if municipality boundaries changed over time, or a census tract was split or merged, these instances are reported and traceable. ${ }^{2}$ The historical census database provides us with municipality populations, but not employment.

GIS and Satellite Data We use GIS and satellite data to build various measures of the attractiveness for beach tourism. As discussed in the next section, we use these measures to build a set of instrumental variables that influence local tourism demand. To this end, we use the earliest highresolution satellite data that we could obtain. ${ }^{3}$ The data source is the Global Land Survey (GLS) 1990 dataset that is based on the raw data from the LandSat 4-5 Thematic Mapper (TM). The GLS dataset provides a consolidation of the best quality LandSat imagery that were taken during the period of 1987-1997 over the coast of Mexico. We obtained these data at the original resolution of 30x30 meter pixels for six different wavelength bands. ${ }^{4}$ When restricted to a $2 \mathrm{~km}$ buffer around the Mexican shoreline, these satellite data provide us with six raster data layers that each have approximately 52 million 30x30 meter pixels. Figure 1 provides an illustration of the satellite data when illustrated with all six bands using the GLS data tiles that intersect with the Mexican coastline. The satellite data also provide us with detailed information on coastal elevation and relief at the same level of spatial resolution, that we use for a robustness test as discussed below.

\footnotetext{
${ }^{1}$ To verify that the 10 percent samples from IPUMS do not give rise to concerns about sparseness at the municipality level, we also report robustness checks using municipality-level population data that is computed from 100 percent samples at INEGI. While the 100 percent sample data are available for total population, we do not have access to the microdata, which we require to compute Mincerized wages as well as employment.

${ }^{2}$ Using this information, we construct population numbers over time for consistent municipality units that are as close as possible to the units we observe in 2010. Given the richness of the database at the census tract level, the only (rare) case when boundaries change relative to 2010 is when a census tract splits over time and some of the splitted units change municipality boundaries while others not.

${ }^{3}$ We are interested in historical satellite coverage to limit the potential concern that some municipalities invest more to maintain high quality beaches (e.g. efforts against coastal erosion). As we discuss in the empirical section, we also present a number of additional robustness checks against such concerns (e.g. reporting results before and after including controls, and verifying to what extent the island IV yields similar point estimates).

${ }^{4}$ Band 1 covers 0.45-0.52, Band 2 covers 0.52-0.60, Band 3 covers 0.63-0.69, Band 4 covers 0.76-0.90, Band 5 covers 1.55-1.75, and Band 6 covers 2.08-2.35. We do not make use of a seventh band covering thermal infrared (10.40-12.50) that was only recorded at a resolution of 120 instead of $30 \mathrm{~m}$ pixels.
} 
We combine these satellite data with a number of GIS data layers that we obtain from the Mexican statistical institute INEGI. These geo-coded data layers include the administrative shape file of municipality boundaries for the 2010 population census, the position of the Mexican coastline, the Mexican transport network for the year 2009 (airports, seaports, paved roads and railways), and the coordinates for each island feature within the Mexican maritime territory from the Mexican census of maritime land territory. The second panel in Figure 1 depicts the position of islands within $5 \mathrm{~km}$ of the Mexican coast. Finally, the geo-statistics division at INEGI provided us with the location of pre-Hispanic archaeological sites in Mexico that we also depict in Figure 1.

We also obtain GIS data from additional sources. The first is a measure of monthly temperature and precipitation at the level of 30 arc seconds (roughly $1 \mathrm{~km}$ ) for the period 1950-2000 from the WorldClim database. We take annual means of precipitation and temperature from the monthly data and collapse the grid cells to the municipality-level mean values of these two variables. The second is a measure of primary ocean productivity at the level of 0.1 degree cells from the Nasa Earth Observation (NEO) program. Primary productivity indicates the amount of biomass created from photosynthesis (measured by chlorophyll concentrations), which is an important determinant of the density of fish populations that can be sustained. We use these data to measure the mean primary ocean productivity within $50 \mathrm{~km}$ of the coastline among coastal municipalities for the year 2005.

Municipality-Level Information on Public Investment in Tourism We obtain information on public investments in local tourism development at the municipality level from INEGI's department for public finances (Estadística de Finanzas Públicas Estatales y Municipales (EFIPEM)). This database is the most detailed available account of public finances for both federal, state-level and local spending at the municipality-level covering the period 1989-2010. For earlier years, we complement this database with records that we obtain from Mexico's Fondo Nacional de Fomento al Turismo (FONATUR) that provide us with information on public investments in tourism going back to the beginning of the 1960s.

Public investments in tourism mainly take one of two forms. The first are investments in public capital and local infrastructure that are specific to the development of the tourism sector, such as building museums, tourist information centers, developing the marina, restoring historical buildings and monuments as well as investing in tourism promotion and advertising campaigns for local tourism. The second are investments in transport infrastructure, such as roads and airports, that historically have been mainly targeted at the seven government-planned tourism centers (until 2010) and implemented through federal funding by FONATUR and its predecessors.

To construct a measure of the stock of public capital invested in tourism development across municipalities for 1998 and 2008, we need two additional pieces of information. First, we convert all listed investments over time, that are reported in current Mexican Pesos at the time, into constant 1998 or 2008 Mexican Pesos (adjusted for inflation), using data on annual inflation rates over time from INEGI. Second, past investments in tourism-related capital depreciate over time, so that more recent investments should receive a higher weight relative to investments over past decades. To adjust for this in computing today's capital stock, we use an estimate of capital depreciation from the Bureau of Economic Analysis (BEA, 2010), that report capital deprecation rates separately for different types of public and private capital investments. We use the upper range of the reported estimates of capital depreciation for non-defense government investments at 12 percent per year. This is conservative in our setting as some of largest past investments by FONATUR are reported in the current market valuation of these investments, rather than values in the past. As a result, using a higher rate of depreciation implies a larger level of annualized public investment in the model calibration compared to using a lower estimate of capital depreciation (see Appendix 
4.1). ${ }^{5}$ Using this approach we estimate a value of the stock of public government investment in tourism development at 26.48 billion USD as of 2008. Appendix 4.1 provides further details on the model calibration.

Bilateral Tourism Exports 1990-2011 To estimate the tourism trade elasticity, we use data on bilateral tourism exports from the World Bank WITS database on trade in services. We link these data to information from the IMF on PPP rates for final consumption goods across countries in order to empirically capture the relative price of local consumption for origin-destination country pairs over time. The database spans the years 1990-2011 and includes 115 origin and destination countries.

\section{Appendix 3: Model}

\section{Solving for Counterfactual Changes}

As discussed in section 4.3, we consider counterfactual changes where (i) public investment changes, and/or (ii) travel frictions to tourism change. Variables in the counterfactual equilibrium are noted with a prime, and changes compared to the current equilibrium are noted: $\hat{x}=\frac{x^{\prime}}{x}$.

Given the expression for the prices indexes (10) and (8), the expression for trade and tourism shares, (9) and (7), and the expression of manufacturing productivity (11) and tourism unit costs (6), changes in trade shares and prices between two equilibria are simple functions of changes in wages, public investment, and local populations working in the services or the manufacturing sector:

$$
\begin{aligned}
& \widehat{\pi_{n i}}=\frac{{\widehat{c_{M, i}}}^{-\theta} \widehat{M}_{i}^{\theta}}{\widehat{P_{M, n}}-\theta} \\
& {\widehat{P_{M, n}}}^{-\theta}=\sum_{j} \pi_{n j}{\widehat{c_{M, j}}}^{-\theta} \widehat{M}_{j}^{\theta} \\
& \widehat{c_{M, i}}=\left(\widehat{w}_{n}\right)^{v_{M}^{L}} \prod_{s \in M, N} \widehat{P}_{s, n}^{v_{M}^{s}} \\
& \widehat{M}_{i}={\widehat{L_{M}, i}}^{\gamma_{M}} \widehat{L}_{S T, i} \gamma_{S} \\
& \widehat{\lambda_{n i}}=\frac{\widehat{c_{T, i}}-\beta \widehat{t_{n i}}-\beta}{\widehat{P_{T, n}}-\beta} \\
& {\widehat{P_{T, n}}}^{-\beta}=\sum_{j} \lambda_{n j}{\widehat{t_{n j}}}^{-\beta}{\widehat{C_{T, j}}}^{-\beta} \\
& \widehat{c_{T, i}}=\widehat{G}_{i}^{-\alpha_{F}}\left(\widehat{w}_{n}\right)^{v_{T}^{L}} \prod_{s \in M, N} \widehat{P}_{s, n}^{v_{T}^{s}} \\
& \widehat{\chi_{n}}=\frac{{\widehat{P_{M, n}}}^{1-\rho}}{{\widehat{P_{M T, n}}}^{1-\rho}} \\
& {\widehat{P_{M T, n}}}^{1-\rho}=\left(\left(1-\chi_{n}\right){\widehat{P_{T, n}}}^{1-\rho}+\chi_{n}{\widehat{P_{M, n}}}^{1-\rho}\right),
\end{aligned}
$$

We assume that public investment remains in constant proportion to what is observed in the current equilibrium, but varies in level in response to the level of tax such that the government

\footnotetext{
${ }^{5}$ We confirm this conjecture by alternatively using a rate of depreciation at 2.5 percent, which yields estimates of the gains from tourism of 5.2 percent instead of the 4.8 percent we report in our baseline approach.
} 
budget constraint holds, i.e.:

$$
\begin{aligned}
\frac{G_{n}}{\sum_{\mathcal{M}} G_{n}} & =\frac{G_{n}^{\prime}}{\sum_{\mathcal{M}} G_{n}^{\prime}} \\
\sum_{\mathcal{M}} G_{n}^{\prime} & =\sum_{\mathcal{M}} \iota^{\prime} L_{n}^{\prime} w_{n}^{\prime}
\end{aligned}
$$

Changes in local population levels within Mexico are determined by the location choice equation (12) together with the maintained assumption that total population is unchanged in the counterfactual equilibrium, i.e. $\sum_{n \in \mathcal{M}} L_{n}^{\prime}=L_{\mathcal{M}}$ :

$$
\widehat{L_{n}}=\frac{\left(\widehat{w}_{n}^{\alpha_{M T}}\left(\widehat{P}_{M T, n}\right)^{-\alpha_{M T}}\right)^{\tilde{\kappa}}}{\sum \frac{L_{i}}{L_{\mathcal{M}}}\left(\widehat{w}_{i}^{\alpha_{M T}}\left(\widehat{P}_{M T, i}\right)^{-\alpha_{M T}}\right)^{\tilde{\kappa}}} \forall n \in \mathcal{M} .
$$

Finally, the system is closed by the market clearing conditions in each sector, that is, equations (13)-(15) expressed in the counterfactual equilibrium, together with:

$$
\begin{aligned}
L_{i}^{\prime} & =L_{M, i}^{\prime}+L_{T, i}^{\prime}+L_{S, i}^{\prime} \\
L_{S T, i}^{\prime} & =L_{T, i}^{\prime}+L_{S, i}^{\prime}
\end{aligned}
$$

Finally, welfare change $\widehat{U_{\mathcal{M}}}$ is equalized across all regions between two equilibria:

$$
\widehat{U_{\mathcal{M}}}=\left(\frac{1-\iota^{\prime}}{1-\iota}\right)\left(\frac{\widehat{w_{n}}}{\hat{P}_{M T, n}}\right)^{\alpha_{M T}}{\widehat{L_{n}}}^{-\frac{1}{\tilde{\kappa}}}, \text { for all } n \in \mathcal{M}
$$

\section{Appendix 4: Calibration and Quantification}

\section{A.4.1 Data and Calibration}

Calibration of Rest of the World We calibrate the wage in RoW as the trade-weighted average wage of Mexico's trading partners (measured as GDP per capita), and adjust population of RoW so that the ratio of GDP of Mexico to the GDP of RoW in the quantified model matches the one in the data. The shares of workers in the manufacturing and tourism industries for RoW are calibrated to the share of world GDP in each sector.

Share of Workers in Non-Traded Services We first estimate the relative size of tourism in the traded sector in each region: $\xi_{n} \equiv L_{T, n} /\left(L_{T, n}+L_{M, n}\right)$ using local manufacturing GDP and local hotel sales data that we scale up by a constant scale factor so that aggregate values match the data. The share of workers in the non-traded services sector is then estimated, accounting for the fact that local non traded services are used both for final consumption, as well as for the production of tourism and manufacturing (see input-output coefficients in Appendix 4.2 below). The share of workers in the non-traded services sector is then derived from the local market clearing condition in the non-traded services sector, which leads to:

$$
\frac{L_{S, n}}{L_{n}}=\frac{\alpha_{S}(1-\iota)+\xi_{n} \frac{v_{T}^{S}}{v_{T}^{L}}+\frac{v_{M}^{S}}{v_{M}^{L}}\left(1-\xi_{n}\right)}{1+\xi_{n} \frac{v_{T}^{S}}{v_{T}^{L}}+\frac{v_{M}^{S}}{v_{M}^{L}}\left(1-\xi_{n}\right)} .
$$

Stock of Public Investment in Tourism Development We use the Mexican database on public investments described in the Appendix 2 to construct the stock of public investments in tourism 
development across municipalities $K_{n}$. To convert this into the local investment in tourism infrastructure $G_{n}$ in a unit consistent with the model, we compute an annualized flow based on $K_{n}$. We do this using the depreciation rate discussed above, assuming that our model corresponds to one period in the steady-state. That is, to maintain a capital stock $K_{n}$, yearly investments have to be $G_{n}$ where $K_{n}=\sum_{t=0}^{\infty} G_{n}(1-d)^{t}$ and $d$ is the depreciation rate of investment. We express this measure of yearly investment relative to Mexico's GDP, and use this measure in the calibration. As discussed in Section 5.1 of the paper, we calibrate the share $\alpha_{G}$ from equation (5) using the ratio of government investment over total tourism GDP, which leads to $\alpha_{G}=0.057$. This is close to related elasticities estimated in e.g. Fajgelbaum et al. (2015).

\section{A.4.2 Elasticity Estimates}

Input Shares We calibrate the input-output shares of the model using total requirement coefficients for services and manufacturing inputs of the 2003 Mexican input-output table. The remaining value added is attributed to a single factor labor. The corresponding input shares are:

$\begin{array}{ccc} & \text { Tourism } & \text { Manufacturing } \\ v_{j}^{L} & 0.63 & 0.40 \\ v_{j}^{M} & 0.20 & 0.45 \\ v_{j}^{S} & 0.17 & 0.15\end{array}$

Parameter $\alpha_{G}$ The parameter $\alpha_{G}$ controls the impact of government investment on tourism productivity. Recall that the production function for tourism services is:

$$
q_{T, n}=Z_{T, n}^{01-\alpha_{G}} G_{n}^{\alpha_{G}} \prod_{j \in L, M, S} m_{j, n}^{T} v_{T}^{j} .
$$

To calibrate $\alpha_{G}$, we compare government investment to tourism GDP. If the government is investing in tourism infrastructure in an optimal way, then its spending in tourism infrastructure should be equal to a constant fraction $\frac{\alpha_{G}}{\alpha_{G}+v_{T}^{L}}$ of tourism GDP. We assume that this holds, which leads to a calibrated value of $\alpha_{G}=0.057$. To benchmark this value, we compare it to results in Fajgelbaum et al. (2015). They calibrate a related parameter that governs how much productivity increases with government spending using US tax data. Their preferred estimate is 0.05 , which is in the same order of magnitude of what we find here.

Consumption Shares We calibrate $\alpha_{S}$ using the following accounting equality, which comes from the market clearing condition for the local non traded services sector in each region (equation 15) aggregated at the national level:

$$
\alpha_{S}=\left[\left(1+\frac{v_{M}^{S}}{v_{M}^{L}}\right) \frac{G D P_{S}}{G D P}-\left(\frac{v_{T}^{S}}{v_{T}^{L}}-\frac{v_{M}^{S}}{v_{M}^{L}}\right) \frac{G D P_{T}}{G D P}-\frac{v_{M}^{S}}{v_{M}^{L}}\right] \frac{1}{(1-\iota)^{\prime}},
$$

where $\frac{G D P_{S}}{G D P}$ and $\frac{G D P_{T}}{G D P}$ measure the relative size of tourism and services in aggregate GDP. This equation relates aggregate value added shares to both consumption shares and input shares. In turn, $\alpha_{M T}=1-\alpha_{S}$.

Tourism Trade Elasticity To estimate the elasticity $\beta$, we use the panel data on country-level bilateral tourism exports. Equation (7) leads to the following estimation equation:

$$
\log E_{n k t}=\delta_{n t}+\zeta_{n k}-\beta \log w_{k t}+\xi_{n k t},
$$

where $E_{n k t}$ is the spending of country $n$ on tourism in country $k$ at period $t, \delta_{n t}$ is an origin-by-time fixed effect (e.g. capturing productivity shocks), $\zeta_{n k}$ is an origin-by-destination fixed effect (e.g. 
capturing distances or cultural proximity), $\ln w_{k t}$ is the relative consumption price of tourism services across destinations, and $\xi_{n k t}$ is a mean zero error term. To empirically measure $\log w_{k t}$, we use country-level PPP rates for final consumption goods that the International Price Comparison (ICP) program computes for all 115 countries over the period 1990-2011 in our database. The ICP constructs this measure, $P P P_{k t}$ as the number of units of a country $k^{\prime}$ s currency required to buy the same basket of goods and services in $k^{\prime}$ s domestic market as one US Dollar would buy in the United States. To measure $\log w_{k t}$, we take the $\log$ of $\left(1 / P P P_{k t}\right)$. Given the inclusion of origin-byperiod and origin-by-destination fixed effects, this measure effectively captures (with some error) relative consumption price changes across different destination countries from the point of view of a given origin-by-time cell.

The main concern for the identification of $\beta$ is that changes in consumption prices across destinations are correlated with other factors that may increase or decrease bilateral tourism flows in the error term. For example, if prices in a destination increase at the same time that travelers at the origin become more likely to travel to the destination for other reasons (e.g. due to business travel or attractiveness), this would lead to an upward biased estimate of $-\beta$ (towards zero).

The first step we take to address this concern is to condition on a basic control for time changing economic conditions in the destination countries, by including the log of country GDP as a control. Second, to address remaining concerns, in addition to the very likely concern of measurement error in our measure of $\log w_{k t}$, we use nominal exchange rate changes across destination countries with respect to the US Dollar, $\log e_{k t}$, as an instrumental variable for $\log \left(1 / P P P_{k t}\right)$. The exchange rates are used as part of the PPP rate construction by the ICP, so that we can expect a strong first stage. The exclusion restriction is that differential exchange rate changes across different destination markets to not affect bilateral tourism expenditure except through relative price changes of tourism services, conditional on the included fixed effects and destination-specific changes in log GDP.

To further assess the validity of this assumption, we also estimate specification (A.15) after restricting attention to what we label touristic destinations: i.e. destinations for which more than 80 percent of total travel inflows are due to leisure rather than business travel. Finally, to allow for tourist flows to respond to relative price information across destination markets with some time lag, we also estimate specifications in which we lag the independent variable by 1-5 years.

Appendix table A.22 presents the estimation results. We find a negative and statistically significant tourism trade elasticity that reaches $\beta=.7$ when we lag the relative destination price changes by 3-4 year (1.5 with lesser lags). These results are confirmed with a slightly lower point estimate of .6 once we restrict attention to destinations with more than 80 of travel inflows driven by leisure rather than business purposes. These results indicate that the tourism trade elasticity appears to be significantly lower than common estimates of the trade elasticity for flows of goods. To be conservative in our quantification of the gains from tourism, we compute the upper end of the $95 \%$ confidence intervals supported by the point estimates in Table A.22 as $\beta+1=2.5$. In a similar vein, we choose the value of $\rho=\beta+1=2.5$. As discussed above, we also report results of the counterfactual analysis across a range of different parameterizations in Section 5.2.

\section{A.4.3 Indirect Inference Procedure}

The procedure relies on solving for a counterfactual equilibrium with no tourism, for a range of possible values for $\left(\gamma_{M}, \gamma_{S}\right)$. To do so, we model a shut down of all public investment to tourism infrastructure. This brings the tourism shifter $\widetilde{A_{i}}$ down to 0 in every location in Mexico, corresponding to a counterfactual equilibrium with no tourism. For any candidate value of the agglomeration parameters $\left(\gamma_{M}, \gamma_{S}\right)$, we use the system of equations (A.1)-(A.14) to compute numerically the corresponding vector of exogenous manufacturing productivities, $M_{n}^{o}\left(\gamma_{M}, \gamma_{S}\right)$, as 
well as the counterfactual distribution of population under no tourism, $L_{n}^{o}\left(\gamma_{M}, \gamma_{S}\right)$, while holding all other exogenous parameters constant. ${ }^{6}$ We then compute the correlation of these vectors with our set of instrumental variables, conditional on the full set of controls used in Section 3. Specifically, we estimate the following regressions within the model across alternative parameter combinations of $\left(\gamma_{M}, \gamma_{S}\right)$ :

$$
\log \left(y_{n c}\right)=\alpha_{c}^{(j)}+\beta_{y}^{(j)} z_{n c}^{(j)}+\alpha^{(j)^{\prime}} X_{n c}+u_{n c}^{(j)}
$$

for each of the instruments $j \in 1 \ldots 3$, and for $y=L_{n}^{o}\left(\gamma_{M}, \gamma_{S}\right)$ and $y=M_{n}^{o}\left(\gamma_{M}, \gamma_{S}\right)$ respectively. The vector $X_{n c}$ is the full vector of pre-determined controls described in (1). The indirect inference procedure finds the combination of spillover parameters such that:

$$
\left(\widehat{\gamma_{M}}, \widehat{\gamma_{S}}\right)=\operatorname{argmin} \boldsymbol{\beta}\left(\gamma_{M}, \gamma_{S}\right)^{\prime} \boldsymbol{W} \boldsymbol{\beta}\left(\gamma_{M}, \gamma_{S}\right) \text {, }
$$

where $\boldsymbol{\beta}\left(\gamma_{M}, \gamma_{S}\right)$ is the vector of $\beta_{y}^{(j)}\left(\gamma_{M}, \gamma_{S}\right)$ for $\mathrm{j}=1 \ldots 3$ and $y=\left\{L_{n}^{o}, M_{n}^{o}\right\}$, and $\mathbf{W}$ is a weighting matrix for which we use the inverse of the variance of the point estimates of each $\beta_{y}^{(j)}$ in equation (A.16).

The results of this procedure are reported graphically in Figure 2, where the loss function is given by $\mathcal{L}=\boldsymbol{\beta}\left(\gamma_{M}, \gamma_{S}\right)^{\prime} \boldsymbol{W} \boldsymbol{\beta}\left(\gamma_{M}, \gamma_{S}\right)$. To minimize computing power requirements, we look for the parameter combination that delivers the best fit over a grid of possible values for $\gamma_{M}$ and $\gamma_{S}$ ranging from 0 to .2 in both parameters. After inspection of Figure 2, it is clear that the best-fitting parameter combination is insensitive to extending the grid space to larger (less realistic) values. To get the standard errors we bootstrap the procedure accounting for sampling error as discussed in Appendix 4.4. In line with the estimated standard errors, the function is flatter in the direction of $\gamma_{M}$ than it is in the direction of $\gamma_{S}$ : the cross-sectoral spillover parameter is more precisely identified by the procedure, whereas the within-sector parameter has somewhat wider confidence intervals.

\section{A.4.4 Confidence Intervals / Bootstrap}

To obtain confidence intervals, we bootstrap the quantification exercise 200 times. In each bootstrap, we draw the parameters for both the trade and tourism trade elasticities $\theta$ and $\beta$ from a normal distribution with a mean equal to the point estimate and a standard deviation equal to the standard error of the estimate. And as discussed above, for each draw of $\beta$, we also adjust $\rho=\beta+1$. The standard error associated to the point estimate 6.1 of the trade-in-goods elasticity is 1.046 as reported in Table 1 of Adao et al. (2015). The standard error for the point estimate of the tourism trade elasticity is reported in appendix Table A.22.

In addition, we also allow for the possibility that the regional data we feed into the model's calibration as part of Section 5.1 in the text are reported with measurement error. In particular, we treat each of the raw data moments (regional employment, wages, manufacturing and tourism GDP) as if each region's reported number was not a data point, but instead a point estimate subject to a signal-to-noise ratio of 80-20. The implied standard error for each of the regional data points are consistent with a point estimate that has a t-statistic (ratio of reported regional number over standard error) equal to 5, reflecting the 80-20 assumption. This implies that we are drawing each

\footnotetext{
${ }^{6}$ As discussed above, there is the potential for multiple equilibria in the model in the presence of spillovers. We implement the following equilibrium selection rule. We solve for the closest counterfactual equilibrium compared to the baseline. That is, we use the values of the endogenous variables from the current equilibrium as a starting point for the counterfactual equilibrium. The procedure then updates the candidate value of endogenous variables in the counterfactual equilibrium based on a weighted average of this initial guess and the new values that come out of solving the model. The procedure is iterated until new values and initial values converge.
} 
regional moments from a distribution whose mean is the reported number with a $95 \%$ confidence interval of $+/-40 \%$ of the reported regional value.

This procedure follows a parametric bootstrap (e.g. Horowitz, 2001) that implicitly assumes errors are uncorrelated across datasets. Finally, the bootstrap confidence intervals do not take into account 9 cases of degenerate equilibria where in excess of half of Mexico's total population concentrates in just one region in the no-tourism equilibrium. For reference, the largest regional share of population in today's observed equilibrium with 300 regions is less than 5 percent.

\section{A.4.5 Counterfactuals With Less Aggregated Interior Regions}

In this appendix we provide additional results to investigate the sensitivity of the welfare quantifications with respect to more or less regional aggregation for the interior regions of Mexico. As we discuss in Section 5.1, the 2455 regions case pushes the limits of the computational requirements when it comes to our indirect inference approach (involving a grid of parameter combinations) as well as for the bootstrapping of the computation of counterfactual equilibria several hundreds of times.

To this end, we document the welfare gains from tourism as well as the regional effects of tourism across regions when running counterfactuals based on the disaggregated 2455 regions case compared to the baseline 300 regions case that we work with in the main text. In particular, we use the same model parameter values as in our preferred counterfactuals, but solve the model for counterfactual no-tourism equilibria in both the more and less aggregated scenarios.

Appendix tables A.30 and A.31 report the quantification results back-to-back. Reassuringly, we find very similar estimates of the welfare gains from tourism and international-only tourism, and we also find that the regional implications of tourism are remarkably similar across the two levels of regional aggregation. As discussed in the main text, these results are as expected, because the key source of variation that we use to inform the calibration of the model and its parameters stems from coastal municipalities. The aggregation of interior municipalities into larger regions that are centered around the 150 largest economic centers -while keeping the coastal geography as in the regression analysis- is thus greatly convenient for computational power, but largely inconsequential for the estimated results.

\section{A.4.6 Model Extensions and Robustness}

\section{Alternative Parameter Values}

Appendix table A.23 reports the estimated gains from tourism as well as from internationalonly tourism across different parameter combinations for the trade elasticity of tourism $(\beta)$, the spatial labor supply elasticity $(\widetilde{\mathcal{K}})$ and the cross-sector co-agglomeration force $\gamma_{S}$. All other parameters are held constant at their values of our baseline calibration discussed above.

First, the tourism trade elasticity $(\beta)$ directly affects the magnitude of the estimated neoclassical gains from lower frictions to tourism trade. In particular, a larger tourism trade elasticity implies a lower gain from trade in tourism for a given set of empirical moments. This is analogous to the role of the trade-in-goods elasticity in the recent quantitative literature on the gains from trade (Arkolakis et al., 2012). Intuitively, moving from the observed level of tourism consumption to tourism autarky implies a larger loss in welfare if the demand elasticity of tourism consumption is lower (less elastic). As reported in Table A.23, the gains from tourism are about 8 percent lower (4.46 vs 4.82 ) if the tourism trade elasticity were to increase to 4.5 relative to the upper bound of the point estimate of 2.5 that we estimate in the data. ${ }^{7}$

\footnotetext{
${ }^{7}$ Note that a very similar logic applies to the elasticity of substitution between tourism and manufacturing consumption $(\rho)$. A lower value magnifies the gains from tourism because the less substitutable tourism becomes relative to other consumption, the more will an increase in the frictions to tourism trade deprive consumers from the
} 
Second, we explore the sensitivity of the gains from tourism with respect to different assumptions about the spatial labor supply elasticity. As noted in Section 5.1 above, our preferred estimate of $\widetilde{\kappa}=6.35$ is significantly larger than many of the estimates in the existing literature that have exploited shorter-term variation over time, rather than cross-sectional estimates. Table A.23 thus reports the gains from tourism across three alternative parameterizations for $\widetilde{\kappa}=6.35, \widetilde{\kappa}=4.35$ and $\widetilde{\kappa}=2.35$, with the first one equal to our empirical estimate from the data. Interestingly, our welfare quantification appears to be quite robust to different assumptions about the spatial labor supply elasticity. Holding all other parameters constant, the gains from tourism range between 4.82 and 5.43 percent across the different rows, and the gains from international-only tourism range between 1.84 and 2.99 percent.

Finally, we explore to what extent lower values of the estimated cross-sector spillover parameter affect the welfare results. As we have discussed in the previous section, the servicesto-manufacturing externality matters directly for the extent of net gains or losses in traded goods production in the aggregate due to the development of tourism. This is also apparent in Table A.23: holding other parameter values at their baseline, the estimated gains from tourism range between 4.82 and 2.77 percent as we move from the baseline calibration of $\gamma_{S}=0.087$ to 0.057 , 0.027 and finally 0 . In turn, the gains from international tourism range between 1.84 percent in the baseline calibration to 0.91 percent in the absence of co-agglomeration forces.

For completeness, the table also reports the full cross of these parameter ranges. In particular, moving towards the lower left of each panel tends to increase the estimated gains from tourism (reducing $\beta$ and $\widetilde{\kappa}$, and increasing $\gamma_{S}$ ). Conversely, moving toward the upper right of each panel tends to lower the estimated gains from tourism (increasing $\beta$ and $\widetilde{\kappa}$, and reducing $\gamma_{S}$ ).

Finally, appendix Table A.24 also reports the identical exercises depicted in Table A.23, but instead of varying the parameter of the cross-sector agglomeration force, we instead vary the value of the within-manufacturing spillover, $\gamma_{M}$, in the same way, while holding $\gamma_{S}$ constant. In line with the discussion of the role of the spillover parameters at the end of Section 4 , we find that, for every given parameter combination of $\beta$ and $\widetilde{\kappa}$, the estimated gains from both domestic and international tourism increase as we reduce the strength of the within-manufacturing agglomeration externality.

\section{Local Gains from Tourism Without Migration}

What would the local welfare effect of tourism be in absence of a long-term spatial equilibrium with labor mobility. To address this question, we first solve for the counterfactual spatial equilibrium with prohibitive frictions to both domestic and international tourism in Mexico. Starting from this initial equilibrium, we then simulate the new equilibrium that arises when lowering the tourism travel frictions to today's level for either both domestic and international or internationalonly tourism, but now under the assumption that labor is immobile across regions within Mexico. We thus effectively shut down the economic geography dimension of the model, and evaluate the local welfare implications of tourism in a world with trade in goods and tourism-related services. All other forces in the model, such as input-output linkages and agglomeration economies, are held constant at their baseline parameters, but the model no longer allows workers to choose their region of residence, so that expected real incomes are no longer equalized across regions.

Appendix table A.28 reports the counterfactual effect of regional variation in tourism activity on local worker welfare. In particular, the table replaces the left-hand side in specification (21) by the log change in worker utility when moving from the no-tourism equilibrium to the current level of tourism trade frictions. We regress this variable on the counterfactual change in local tourism GDP (which in specification (21) was equal to today's level of tourism GDP, but this is no longer

$\overline{\text { benefits of tourism consumption. In the limit of }} \rho=1$ (Cobb-Douglas) this leads to infinite gains from tourism. 
the case in absence of mobility) in addition to the full set of controls. As in the previous subsection, we instrument for the change in local tourism activity with our island and beach IVs.

We find that a 10 percent increase in local tourism activity causes a 2.37 percent increase in local worker welfare in the absence of immigration. When focusing on international-only tourism, we find almost the same point estimate (0.235 with standard error of 0.0715$)$. In principle, there are several factors that could lead to differences in the local welfare elasticity with respect to international and domestic tourism activity. As we have discussed above, international and domestic tourism are concentrated in different regions of Mexico. For example, the initial sectoral composition of the local economies could differ when hit by the tourism shock, and this could lead to heterogeneous local welfare effects due to the presence of both within and cross-sector agglomeration forces. In practice, however, the local welfare effects of the two counterfactuals turn out to be very similar in terms of proportional changes.

In summary, we estimate large and significant local welfare gains of tourism that would have occurred in the absence of regional migration. These local welfare gains are the model-based counterpart of the strong migration responses to local variation in tourism that we have documented in the regression analysis in Section 1.

\section{Profits in the Tourism Sector}

Model We describe here an extension where the tourism sector is imperfectly competitive. All other dimensions of the model are unchanged. Demand for tourism services is nested CES, with the upper-nest driving demand for different regions to which we add a lower nest for demand for various tourism services (henceforth, "hotels") provided in a given region:

$$
Q_{T, n}=\left[\sum_{i \neq n} A_{i}^{\frac{1}{\beta+1}} q_{T, i}^{\frac{\beta}{\beta+1}}\right]^{\frac{\beta+1}{\beta}} ; \quad q_{T, i}=\left[\int_{\omega \in H(i)} q(\omega)^{\frac{\sigma_{H-1}}{\sigma_{H}}} d \omega\right]^{\frac{\sigma_{H}}{\sigma_{H}-1}}
$$

There is a continuum of hotels $\omega \in H(i)$ in each region. The mass of hotels in each region $\mathrm{NH}_{i}$ is taken as exogenous. Hotels produce tourism services combining labor and manufacturing input according to $q(\omega)=\ell(\omega)^{v_{T}} m(\omega)^{1-v_{T}}$. Hotels are small and take the price index of tourism in their region as given. They compete according to monopolistic competition. Therefore, a hotel $\omega$, located in region $n$, prices at a constant markup over its marginal cost: $p(\omega)=\frac{\sigma_{H}}{\sigma_{H}-1} c_{T, n}$. As in the main text, $c_{T, n}=\Psi_{T} w_{n}^{v_{T}} P_{M, n}^{1-v_{T}}$. It follows that the price index of tourism services sold in region $n$ is:

$$
P_{T, n}=\frac{\sigma_{H}}{\sigma_{H}-1}\left(\sum_{i \neq n} \widetilde{A_{i}}\left(c_{T, n} t_{n i}\right)^{-\beta}\right)^{-\frac{1}{\beta}},
$$

where we have defined $\widetilde{A_{i}} \equiv A_{i} N H_{i}^{\frac{-\beta}{1-\sigma_{M}}}$. The taste shifter for region $i, A_{i}$, is not separably identified from the variety effect of the range of tourism services and hotels offered in this region, governed by $\mathrm{NH}_{i}$. Expenditures shares in tourism take the same form as in the baseline model, that is, the share spent by region non tourism services in region $i$ is:

$$
\lambda_{n i}=\frac{\widetilde{A}_{i}\left(t_{n i} c_{T, i}\right)^{-\beta}}{\sum_{k \neq n} \widetilde{A}_{k}\left(t_{n k} c_{T, k}\right)^{-\beta}} .
$$

Finally, to close the model, write $I_{n}$ the income of workers in region $n$. The market clearing condi- 
tion are:

$$
\begin{aligned}
\frac{w_{i} L_{i, M}}{v_{M}} & =\sum_{n=1}^{N} \pi_{n i}\left(\alpha_{T} \chi_{n} I_{n}+\frac{1-v_{T}}{v_{T}} w_{n} L_{n, T}+\frac{1-v_{M}}{v_{M}} w_{n} L_{n, M}\right), \quad \text { for } n \in(1 . . N) . \\
\frac{w_{i} L_{i, T}}{v_{T}} & =\frac{\sigma_{H}-1}{\sigma_{H}}\left[\sum_{n=1}^{N} \lambda_{n i}\left(\alpha_{T}\left(1-\chi_{n}\right) I_{n}\right)\right], \quad \text { for } n \in(1 . . N) . \\
w_{i} L_{i, S} & =\alpha_{S} I_{i}, \quad \text { for } i \in(1 . . N) .
\end{aligned}
$$

Income of workers in region $n$ is their labor income plus a share $\tilde{\Pi}_{i}$ of the profits made in the tourism industry, that is,

$$
I_{n}=w_{n} L_{n}+\tilde{\Pi}_{n}
$$

The parameter $\Gamma$ governs the ownership structure of firms in the tourism sector in Mexico: a share $\Gamma$ in local, and (1- $\Gamma$ ) is foreign-owned (FDI). We assume that there is no Mexican FDI abroad, i.e. that firms operating in RoW are all owned by RoW. Within Mexico, we assume that profits are allocated proportionally to local GDP. The share of profits distributed in region $n \in \mathcal{M}$ is therefore:

$$
\tilde{\Pi}_{n}=\Gamma \frac{w_{n} L_{n}}{G D P_{\mathcal{M}}} \Pi_{\mathcal{M}}
$$

where $\Pi_{\mathcal{M}}$ is the profit of the tourism industry in Mexico, which can be expressed as a function of the wage bill in the Mexican tourism sector: $\Pi_{\mathcal{M}}=\frac{1}{\sigma_{H}-1} \frac{1}{\nu_{T}} \sum_{n=1}^{M} w_{n} L_{n, T}$. Profits distributed to RoW are $\tilde{\Pi}_{N}=\Pi_{\mathcal{M}}(1-\Gamma)+\Pi_{N}$, where $\Pi_{N}$ are profits realized by the tourism industry in RoW. Equations (A.17)-(A.22), together with the ones that govern the manufacturing sector, the nontradable services sector and labor mobility, unchanged from the main text, define an equilibrium of this economy.

Calibration We calibrate the new parameters of the model $\Gamma$ and $\sigma_{H}$ so as to match the share of profits over revenues and the share of FDI over total investments made in the Mexican hotel sector (37.5 and 35 percent respectively, source: FONATUR (2011)). We then redo step 1 of the calibration presented in the main text, with this extended version of the model. The new calibration of $A_{n}, M_{n}, t_{\text {border }}$ and $\tau_{\text {border }}$ ensures that equations (A.17)-(A.22) hold. All other elasticities remain unchanged.

Table A.29 reports the results of the welfare quantification in the extended model. We find that the welfare gains from tourism are 22 percent lower when 35 percent of tourism profits are captured by foreigners compared to the case where all profits made in Mexico stay within Mexico. Note, however, that the levels of the gains from tourism become higher in the calibrated model with profits (with or without repatriation) compared to our baseline estimate under perfect competition. The reason is that the models with and without profits are calibrated to the same data -in particular the same trade and tourism shares. Compared to a case where the tourism sector prices at its cost, the case where the tourism sector prices at a markup corresponds to a calibration with higher productivity/demand shifters for tourism relative to manufacturing. These ensure that the same consumption patterns can be rationalized despite a higher price of tourism. Therefore, touristic regions are revealed in the calibration with profits to have an even stronger comparative advantage in tourism than in the baseline calibration. This stronger comparative advantage mechanically leads to higher gains from tourism integration (gains of 8 percent in Mexico under 35 percent repatriation of profits relative to our baseline estimate of 4.82 percent). 